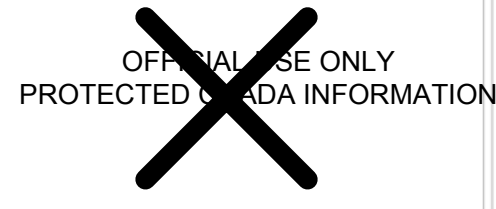

ORNL/TM-51757

CRADA/NFE-11-3310

\title{
Simulation and Controls for Heavy Duty Dual Mode Hybrid Powertrain
}

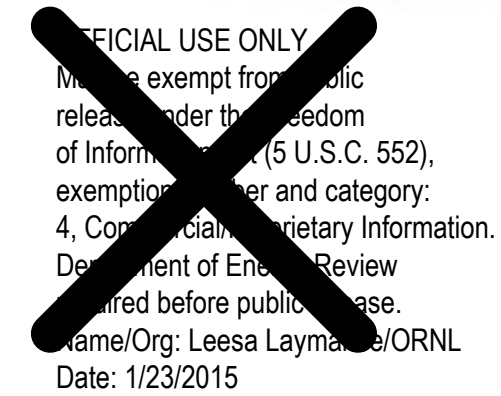

Date: $1 / 23 / 2015$

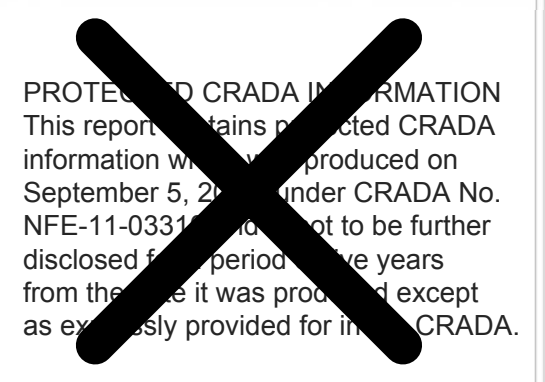

David Smith

Paul Chambon

Dean Deter

\section{September 2014}

This document has been reviewed and is determined to be APPROVED FOR PUBLIC RELEASE.

\section{OAK RIDGE NATIONAL LABORATORY} MANAGED BY UT-BATTELLE FOR THE US DEPARTMENT OF ENERGY
Name/Title: Leesa Laymance/ORNL TIO Date: $\underline{6 / 30 / 2020}$ 


\section{DOCUMENT AVAILABILITY}

Reports produced after January 1, 1996, are generally available free via US Department of Energy (DOE) SciTech Connect.

Website http://www.osti.gov/scitech/

Reports produced before January 1, 1996, may be purchased by members of the public from the following source:

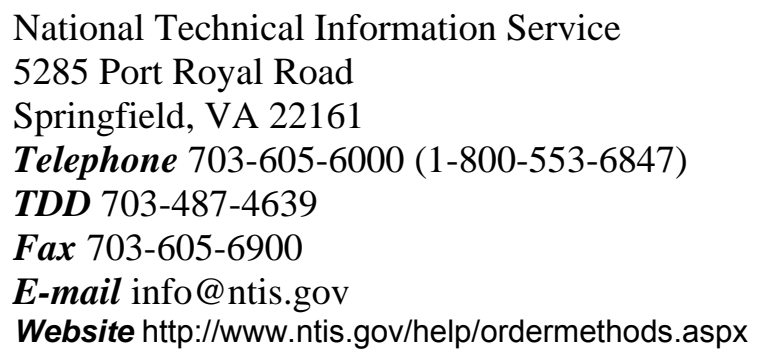

National Technical Information Service

5285 Port Royal Road

Springfield, VA 22161

Telephone 703-605-6000 (1-800-553-6847)

TDD 703-487-4639

Fax 703-605-6900

E-mail info@ntis.gov

Website http://www.ntis.gov/help/ordermethods.aspx

Reports are available to DOE employees, DOE contractors, Energy Technology Data Exchange representatives, and International Nuclear Information System representatives from the following source:

Office of Scientific and Technical Information

PO Box 62

Oak Ridge, TN 37831

Telephone 865-576-8401

Fax 865-576-5728

E-mail reports@osti.gov

Website http://www.osti.gov/contact.html

This report was prepared as an account of work sponsored by an agency of the United States Government. Neither the United States Government nor any agency thereof, nor any of their employees, makes any warranty, express or implied, or assumes any legal liability or responsibility for the accuracy, completeness, or usefulness of any information, apparatus, product, or process disclosed, or represents that its use would not infringe privately owned rights. Reference herein to any specific commercial product, process, or service by trade name, trademark, manufacturer, or otherwise, does not necessarily constitute or imply its endorsement, recommendation, or favoring by the United States Government or any agency thereof. The views and opinions of authors expressed herein do not necessarily state or reflect those of the United States Government or any agency thereof. 
ORNL/TM-51757

CRADA/NFE-11-03310

Energy \& Transportation Science Division

\title{
SIMULATION and CONTROLS for MEDIUM and HEAVY DUTY DUAL MODE HYBRID POWERTRAIN
}

\author{
David Smith \\ Paul Chambon \\ Dean Deter
}

Date Published: September 2014

\author{
Prepared by \\ OAK RIDGE NATIONAL LABORATORY \\ Oak Ridge, Tennessee 37831-6283 \\ managed by \\ UT-BATTELLE, LLC \\ for the \\ US DEPARTMENT OF ENERGY \\ under contract DE-AC05-00OR22725
}

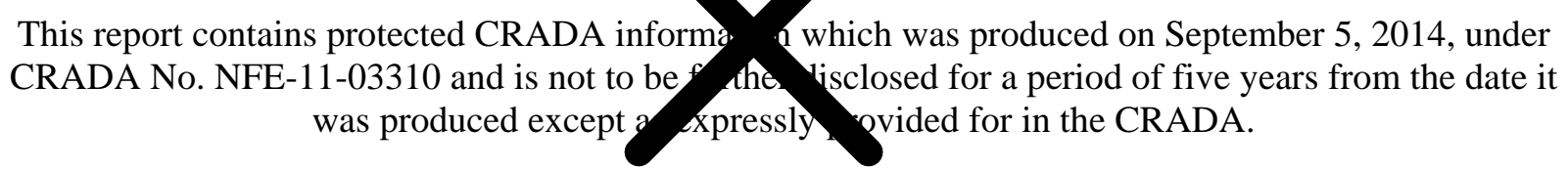




\section{CONTENTS}

Page

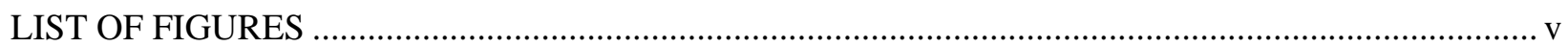

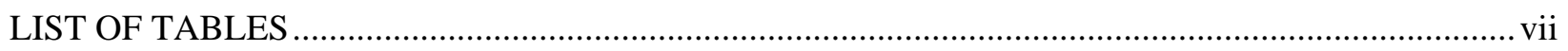

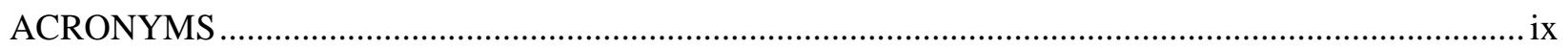

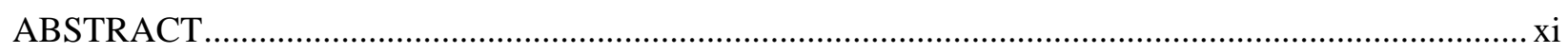

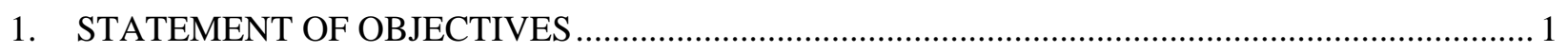

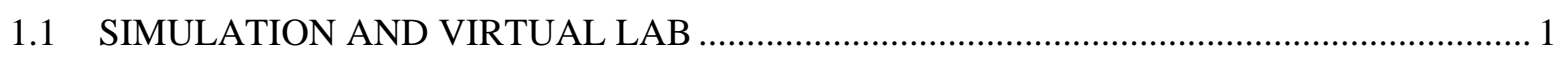

1.1.1 Simulation Model and Control Algorithm Development ............................................ 1

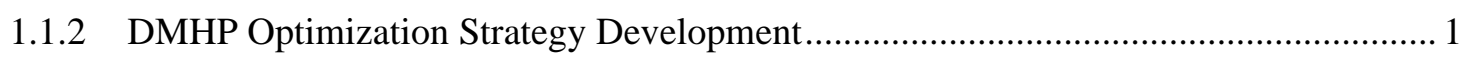

1.1.3 DMHP System Optimization Studies ..................................................................... 2

1.1.4 Alternative Technology Evaluation ........................................................................ 2

1.2 HARDWARE AND EXPERIMENTAL TESTING …..................................................... 2

1.2.1 DMHP System Development and Baseline ............................................................ 2

1.2.2 Engine Acquisition, Installation, and Mapping ….................................................. 3

1.2.3 DMHP Simulated and Full System Dynamometer Testing .......................................... 3

1.2.4 DMHP On-Road Testing in a HD Class 8 Truck ….................................................... 3

2. BENEFITS TO THE DOE VEHICLE TECHNOLGIES OFFICE MISSION.................................. 5

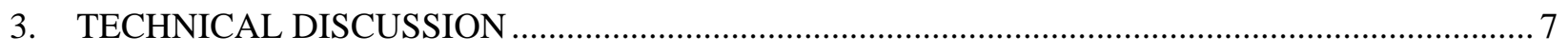

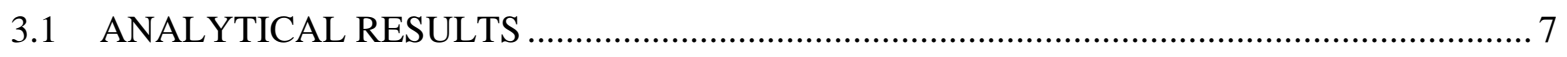

3.1.1 Simulation Model and Control Algorithm Development ........................................... 7

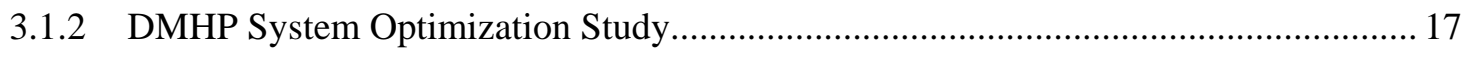

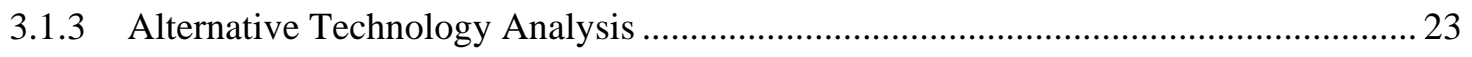

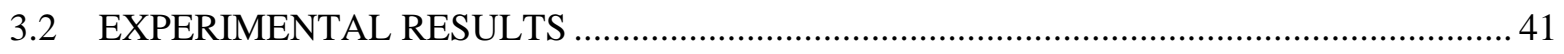

3.2.1 Test facility: ORNL Vehicle Systems Integration (VSI) Laboratory ........................... 41

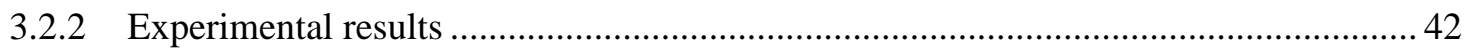

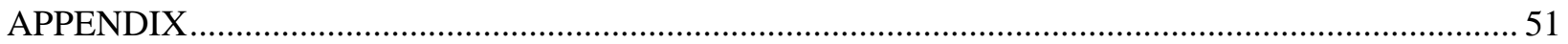




\section{LIST OF FIGURES}

Figure

Figure 1 Functional diagram of DMHP powertrain (courtesy Meritor, Inc.) ............................................ 7

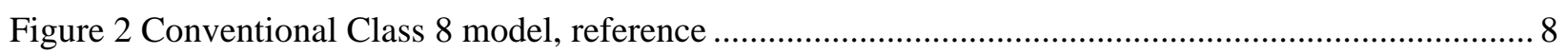

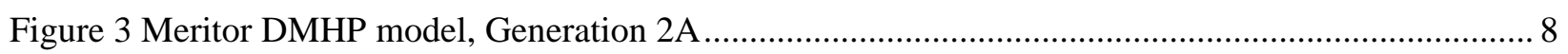

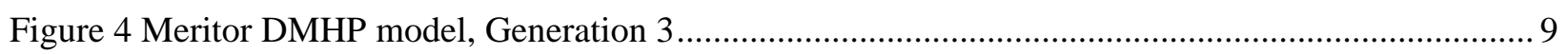

Figure 5 DMHP power flow for series HEV operation (courtesy Meritor, Inc.) ....................................... 10

Figure 6 DMHP power flow for parallel HEV operation (courtesy Meritor, Inc.) ..................................... 10

Figure 7 Supervisory control architecture for the DMHP model............................................................ 11

Figure 8 Example DMHP performance operating map ....................................................................... 12

Figure 9 Determination of battery SOC maintenance power for BMCP ................................................ 13

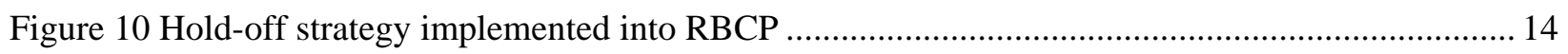

Figure 11 Basic flowchart for EMCP power distribution during HEV operation .................................... 16

Figure 12 Engine power with respect to the state of charge of the battery............................................. 18

Figure 13 Both the Autonomie model with the original controller and the one with the optimal controller were followed precisely the CSHVR driving cycle.............................................. 19

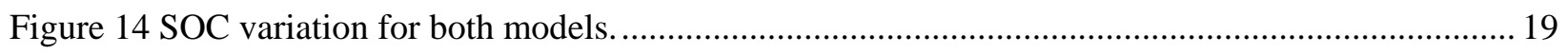

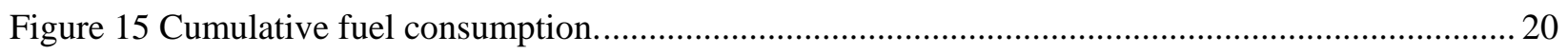

Figure 16 Both the Autonomie model with the original controller and the one with the optimal controller were followed precisely the HDDDT65 driving cycle. .......................................... 21

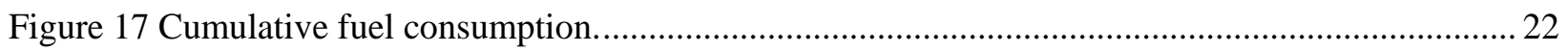

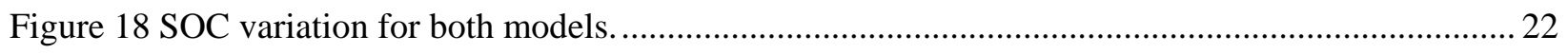

Figure 19 “Mild/moderate” parallel pre-transmission hybrid model ......................................................... 23

Figure 20 "Full” parallel pre-transmission hybrid model ........................................................................ 23

Figure 21 “Mild/moderate” parallel post-transmission hybrid model ....................................................... 24

Figure 22 "Full” parallel post-transmission hybrid model...................................................................... 24

Figure 23 Simulated fuel economy comparison, Mild and Medium hybrids........................................... 29

Figure 24 Simulated fuel economy improvement (ref. conventional baseline) for Mild and Medium

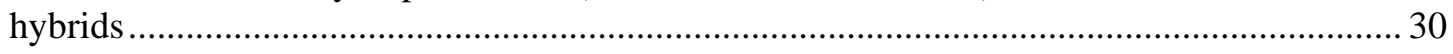

Figure 25 Parametric study results for eAxle final drive ratios ............................................................. 30

Figure 26 Fuel economy comparison, Full hybrids with larger battery ................................................... 31

Figure 27 Fuel economy improvement, “full” hybrids baseline (with larger battery) ............................... 31

Figure 28 Comparison of drive cycle performance for full hybrids with large battery ............................. 32

Figure 29 Engine operation comparison for full pre-transmissions parallel hybrid versus DMHP............ 33 
Figure 30 Simulated fuel economy improvement (ref. conventional baseline), Full hybrids with small battery (700V).

Figure 31 DMHP battery size simulated fuel economy improvement comparison ................................... 34

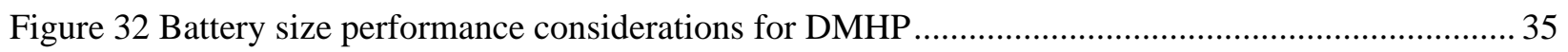

Figure 33 Fuel economy improvement comparison for pre-transmission hybrids based on battery

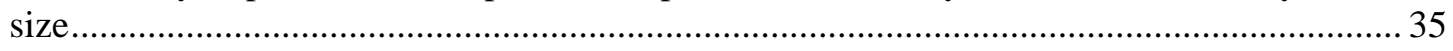

Figure 34 Effect of motor torque/speed limitations on pre-transmission hybrids..................................... 36

Figure 35 Fuel economy improvement considering electrical accessories and anti-idle impacts............... 37

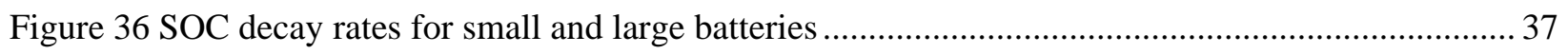

Figure 37 Pre-transmission versus post-transmission motor efficiency .................................................. 38

Figure 38 Pre-transmission hybrid versus DMHP engine performance considerations (speed)................. 38

Figure 39 Pre-transmission hybrid versus DMHP engine performance considerations (torque

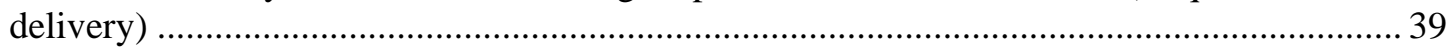

Figure 40 Pre-transmission hybrid versus DMHP vehicle performance considerations............................ 39

Figure 41 Pre-transmission hybrid versus DMHP regenerative braking performance considerations ....... 40

Figure 42 Hardware-in-the-loop representation of the ORNL VSI laboratory ......................................... 42

Figure 43 Engine-in-the-loop installation in the ORNL VSI Laboratory ................................................. 43

Figure 44 Engine-in-the-loop experimental fuel economy improvement test results ................................ 44

Figure 45 Engine-in-the-loop fuel use comparison for the conventional and Meritor DMHP

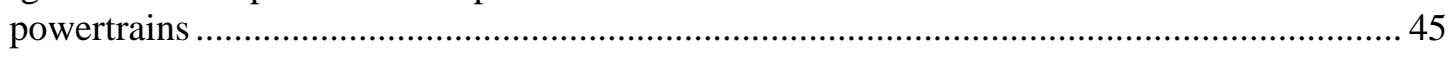

Figure 46 First 400 seconds of the HHDDT65 drive cycle for engine-in-the-loop testing......................... 45

Figure 47 Last 400 seconds of the HHDDT65 drive cycle for engine-in-the-loop testing ......................... 46

Figure 48 Prototype Meritor Hybrid Drive Unit installed in the ORNL VSI laboratory............................ 46

Figure 49 Full installation of the Meritor HDU with test engine in ORNL VSI Laboratory...................... 47

Figure 50 Powertrain-in-the-loop fuel economy improvement experimental results summary ................. 48

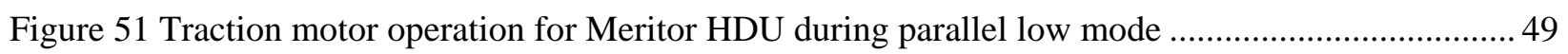

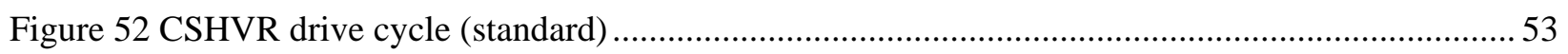

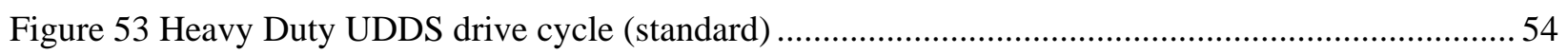

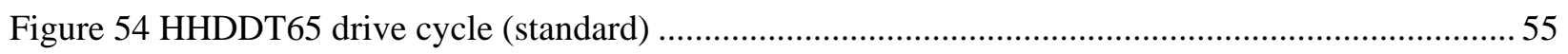

Figure 55 Nashville, TN to Knoxville, TN via I-40 drive cycle (ORNL HTDC)................................... 56

Figure 56 Clarksville, TN to Danville, IN duty cycle (ORNL HTDC) …............................................. 57 


\section{LIST OF TABLES}

\section{Table}

Page

Table 1 Meritor DMHP sequential transmission control requirements .................................................. 17

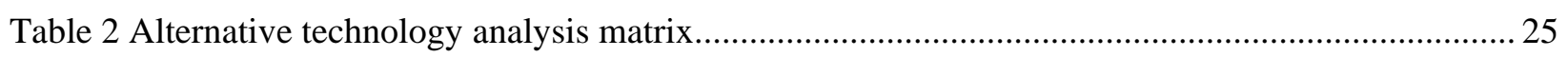

Table 3 Drive cycles and mass considerations for alternative technology analysis................................. 27

Table 4 Matrix of battery pack configurations and sizes ................................................................... 27

Table 5 Fuel economy improvement summary (ref. conventional baseline) ........................................... 28 


\section{ACRONYMS}

$\mathrm{AC}$

BCM

BSFC

BMCP

$\mathrm{CO}$

$\mathrm{CO}_{2}$

CRADA

CSHVR

DC

DMHP

DOE

EMCP

ESS

FE

FEERC

GHG

$\mathrm{HC}$

HD

HHDDT65

HTDC

HDU

HEV

HD-UDDS

HIL

HP

HTDC

HV

IC

$\mathrm{kW}$

MD

MPH

MTDC

$\mathrm{NO}_{\mathrm{X}}$

$\mathrm{NVH}$

ORNL

OTR

PEEM

PEEMRC

PID

R\&D

RBCP

RC

RPM

SIL

SOC

TCU

TMCP

VMCP
Alternating Current

Battery Control Module

Brake Specific Fuel Consumption

Battery Management Control Process

Carbon Monoxide

Carbon Dioxide

Cooperative Research and Development Agreement

City/Suburban Heavy Vehicle Route

Direct Current

Dual Mode Hybrid Powertrain

U.S. Department of Energy

Energy Management Control Processor

Energy Storage System

Fuel Economy

Fuels, Engines and Emissions Research Center

Greenhouse Gas

Hydrocarbon

Heavy Duty

Heavy Heavy Duty Diesel Truck, $5^{\text {th }}$ Mode

Heavy Truck Duty Cycle

Hybrid Drive Unit

Hybrid Electric Vehicle

Heavy Duty Urban Dynamometer Driving Schedule

Hardware-in-the-Loop

Horsepower

Heavy Truck Duty Cycle

High Voltage

Internal Combustion

Kilowatt

Medium Duty

Miles per Hour

Medium Truck Duty Cycle

Nitrogen Oxide

Noise, Vibration, Harshness

Oak Ridge National Laboratory

Over the Road

Power Electronics and Electric Machines Laboratory

Power Electronics and Electric Machinery Research Center

Proportional Integral Derivative

Research and Development

Regenerative Braking Control Process

Resistor/Capacitor

Revolutions per minute

Software-in-the-Loop

State of Charge

Transmission Control Unit

Transmission Mode Control Process

Vehicle Mode Control Process 
VSCM

VSI

VTO

ZEV
Vehicle Supervisory Control Module

Vehicle Systems Integration

Vehicle Technologies Office

Zero Emission Vehicle 


\begin{abstract}
Hybrid powertrains are of considerable interest because of potential reductions in fuel consumption, criteria pollutants and green house gas (GHG) emissions. Parallel hybrids have been applied to light and medium duty trucks, where urban driving cycles are prevalent, while series hybrids have been successfully used for other applications like transit and school buses. Unfortunately, hybridization of the Class 8, heavy-duty (HD) powertrain is inherently challenging due the expected long-haul driving requirements and limited opportunities for regenerative braking. The Participant has conceived and demonstrated a transformational Dual Mode Hybrid Powertrain (DMHP) technology developed specifically for the needs and function of Class 8 line haul trucks. The DMHP system enables a new paradigm in powertrain operational efficiency in the Class 8 truck segment. It decouples the connection between the engine operating point and the truck road load demands over a broad operating range through an innovative hybrid design. The DMHP operation choices include running in full series, full parallel and engine-off modes. The DMHP offers the opportunity for an engine to operate in a narrow range, thus providing a strategy for maximized fuel economy and minimized emissions. Further, it is expected that transient torque and power wheel demands are handled in whole or part by the electric system, thus reducing the frequency and intensity of engine transients and further improving the fuel economy and emissions. Fuel consumption and emissions have been further reduced through the elimination of overnight hoteling and idling at stops. Finally, based on the unique operating profile of an engine integrated into our hybrid powertrain, a transformational HD truck engine design concept next can emerge.
\end{abstract}

Recent research activities by Oak Ridge National Laboratory (ORNL) have yielded significant data in real-life speed and load profiles of Class 8 , long haul trucks. In addition, preliminary simulations of the DMHP carried out by ORNL reveal significant optimization opportunities of the DMHP by applying systematic simulation and controls approaches. An improved understanding of the complex interactions offered by the on-board engine, energy storing system, and electric machines is necessary for the development of control methodologies and practical implementation. We will continue to further this understanding through detailed experimentation and modeling, drawing on and expanding ORNL's core competency in basic engine research and development (R\&D) and advanced controls. This knowledge will be used to develop, implement, and evaluate control strategies on an actual DMHP using Meritor's components and subsystems. Our initial focus will be on optimization of DMHP utilizing a "stock" diesel engine that is commercially available in the market place. A new DMHP-specific engine design concept will be pursued at a later phase of this Cooperative Research and Development Agreement (CRADA).

Meritor will develop the experimental setup, conduct sub-system experiments at their facility, and implement and evaluate potential control strategies resulting from this CRADA partnership. Oak Ridge National Laboratory (ORNL) will develop a real-time simulation model for use in real-time control of the DMHP. The model and potential algorithms will be evaluated on a HD, hybrid powertrain dynamometer facility that will also be developed at the ORNL Vehicle Systems Integration facility. 


\section{STATEMENT OF OBJECTIVES}

The successful implementation of the Dual Mode Hybrid Powertrain (DMHP) will require a thorough technical understanding of the complex interactions between various energy sources and energy consumption components, for various operating modes of medium-duty (MD) and heavy-duty (HD) trucks. Further, the Oak Ridge National Laboratory (ORNL) has been developing and applying methods for the analysis, interpretation, and control of dynamic engine phenomena in single- and multi-cylinder engines for over fifteen years. Meritor has extensive knowledge and experience in DMHP components and subsystems. A partnership involving these knowledge bases is the main key to overcoming the critical barriers associated with the realistic implementation of DMHP and enabling a measurable progress in applying hybrid powertrain in the next generation of HD truck transportation systems. ORNL and Meritor have collaborated on a preliminary investigation that warrants much deeper research and development (R\&D) efforts.

\subsection{SIMULATION AND VIRTUAL LAB}

\subsubsection{Simulation Model and Control Algorithm Development}

ORNL in partnership with Meritor will develop a comprehensive DMHP simulation strategy using the previously conducted analyses as a springboard. A detailed engine model shall be employed evaluating potential control strategies before implementation on an actual DMHP. Synergistic engine strategies will be explored via a low-order, predictive simulation model for integration into the DMHP controller.

- Construct an engine model using GT-Power or equivalent. A more detailed model will be developed for integration with the DMHP for understanding the engine interactions within the hybrid powertrain. This model will be the basis for a more computationally efficient model to be used in real-time control of the DMHP.

- Update and further develop a robust DMHP vehicle simulation model for the study and discovery of potential operating scenarios of the total system, major components such as the engine and battery pack, and synergistic interactions under simulated load cycles.

Note: All models will be refined for steady-state and transient operation as experimental data becomes available during the course of this activity.

\subsubsection{DMHP Optimization Strategy Development}

ORNL in partnership with Meritor will develop an optimization strategy, identify optimization parameters, and define the optimization constraints.

- For prescribed duty cycles, various optimization criteria will be developed based on fuel efficiency, freight efficiency, emissions or other relevant influential factors.

- Optimization parameters will be identified for the system, including for the supervisory control strategy. Capacities of engine, E-machines, and energy storage will be studied. Mechanical parameters such as gear ratios, number of transmission gears, and shift points will be included.

- Optimization constraints will include vehicle driveability \& performance requirements such as startability, gradeability, and acceleration. Additional constraints such as minimum fuel consumption and emissions will be explored. 


\subsubsection{DMHP System Optimization Studies}

ORNL will collaborate with Meritor to carry out a comprehensive optimization analysis of the DMHP system, using rigorous optimization methods. System variants, optimization criteria, optimization parameters, and constraints shall be considered.

- $\quad$ System variants will include engine types that are of interest.

- The DMHP “5-position sequential shifter” will be analyzed.

- Full independence between various states of the DMHP sub-systems will be studied. This includes configuration (Series vs. Parallel), transmission gear ratio (Lo vs. high), traction motor clutch (engaged vs. disengaged), and possibly a more complex energy storage system (for both energy and burst power.)

ORNL will conduct a sensitivity parametric analysis to identify future opportunities to improve overall system efficiency. Parametric studies will explore the contribution of the following:

- Component efficiencies and sizing (E-machines, battery, gearboxes - including axle).

- $\quad$ System Voltages (350, 700, 900).

- Cooling systems scenarios and capacities.

- Accessory electrification.

- Other integrated system influential parameters.

\subsubsection{Alternative Technology Evaluation}

A comprehensive comparison of alternative technologies shall be conducted to assess current and proposed DMHP concepts as well as other relevant Class 8 line haul hybrid powertrain systems. The alternative technologies considered shall possibly include different energy sources (engines, etc.) Competitive and/or promising technologies may be examined.

\subsection{HARDWARE AND EXPERIMENTAL TESTING}

ORNL will utilize expert engine dynamometer testing, the ORNL Vehicle Systems Integration (VSI) laboratory facility and/or mule trucks to validate the virtual (simulation) tasks, provide experimental data for future simulation and provide suggestions on methodologies and control strategies for DMHP operation. Meritor shall utilize simulation data for developing modifications to Meritor's current generation controls software and for future hybrid design considerations. The development of controls software or any computer software by ORNL is specifically excluded from the scope of work. Testing of SIL, HIL and Rapid Prototyping of engine systems have been a well-recognized expertise of ORNL. This will be applied and further extended to advanced hybrid powertrains.

\subsubsection{DMHP System Development and Baseline}

Meritor in partnership with ORNL will construct and baseline a DMHP in support of this activity. The DMHP setup will be located at Meritor's facility. 
- Determine appropriate DMHP hardware including motor, generator, battery pack, clutches, sensors, harnesses, etc.

- Build DMHP management system and power electronics.

- Implement latest software set in the controller of the DMHP.

- $\quad$ Build a DMHP for the Contractor's experimental setup.

\subsubsection{Engine Acquisition, Installation, and Mapping}

ORNL in coordination with Meritor will acquire a representative HD engine and dynamometer compatible controller and wiring harness. In addition, necessary hardware and software will be identified and developed as necessary to support installation of the engine for dynamometer testing. After installation, a baseline will be performed on the engine to develop a performance/emissions map to support modeling efforts.

\subsubsection{DMHP Simulated and Full System Dynamometer Testing}

ORNL in coordination with Meritor will develop and test a simulated DMHP on the HD engine acquired in the previous task. This will include the use of a hardware-in-the-loop and advanced control methodologies. The next step will include Meritor delivering a complete DMHP unit and associated components to ORNL. The DMHP system will be installed on the new hybrid HD dynamometer test stand for full system hardware testing.

\subsubsection{DMHP On-Road Testing in a HD Class 8 Truck}

Meritor will deliver a prototype, Class 8 truck equipped with DMHP. ORNL will develop a test plan and install the necessary data acquisition and instrumentation on the test vehicle. The vehicle will be placed into service with a representative fleet in order to observe normal fleet operation over the road in realistic conditions. Information, such as vehicle loading, duty cycle, component physical conditions, etc. will be obtained through this study that can be transferred back to both the vehicle simulation model and the experimental full system test facility. 


\section{BENEFITS TO THE DOE VEHICLE TECHNOLGIES OFFICE MISSION}

The Department of Energy (DOE) Vehicle Technologies Office (VTO) develops and deploys efficient and environmentally friendly highway transportation technologies that will enable America to use less petroleum. These technologies will provide Americans with greater freedom of mobility and energy security, while lowering costs and reducing impacts on the environment.

Hybrid powertrains are of considerable interest because of potential reductions in fuel consumption, criteria pollutants and greenhouse gas emissions. Parallel hybrids have been applied to light and medium duty trucks, where urban driving cycles are prevalent, while series hybrids have been successfully used for other applications like transit and school buses. Unfortunately, hybridization of the Class 8, HD powertrain is inherently challenging due the expected long-haul driving requirements and limited opportunities for regenerative braking. The Participant has conceived and demonstrated a transformational DMHP technology developed specifically for the needs and function of Class 8 line haul trucks. The DMHP system enables a new paradigm in powertrain operational efficiency in the Class 8 truck segment. It decouples the connection between the engine operating point and the truck road load demands over a broad operating range through an innovative hybrid design. The DMHP operation choices include running in full series, full parallel and engine-off modes. The DMHP offers the opportunity for an engine to operate in a narrow range, thus providing a strategy for maximized fuel economy and minimized emissions. Further, it is expected that transient torque and power wheel demands are handled in whole or part by the electric system, thus reducing the frequency and intensity of engine transients and further improving the fuel economy and emissions. Fuel consumption and emissions have been further reduced through the elimination of overnight hoteling and idling at stops. Finally, based on the unique operating profile of an engine integrated into our hybrid powertrain, a transformational HD truck engine design concept next can emerge.

The success of this project would further the potential for fuel consumption reduction technology development in medium and heavy-duty vehicles, supporting the DOE VTO mission of petroleum reduction and energy security. 


\section{TECHNICAL DISCUSSION}

\subsection{ANALYTICAL RESULTS}

In order to assess the viability of the Meritor DMHP and provide insight into supervisory controls optimization, a detailed vehicle system level model will be created. A target Class 8 heavy duty vehicle will be identified for the purposes of conventional powertrain comparisons to the DMHP, as well detailed vehicle performance criteria necessary for advanced powertrain component sizing and supervisory control strategy development. The full vehicle model will be exercised utilizing duty cycle information mined from the ORNL Heavy Truck Duty Cycle (HTDC) database. Duty cycles will be developed based on real world test data collected from Class 8 line haul trucks that includes vehicle speed, grade information, and varying payloads. For reference purposes, a functional diagram of the DMHP architecture is shown in Figure 1.

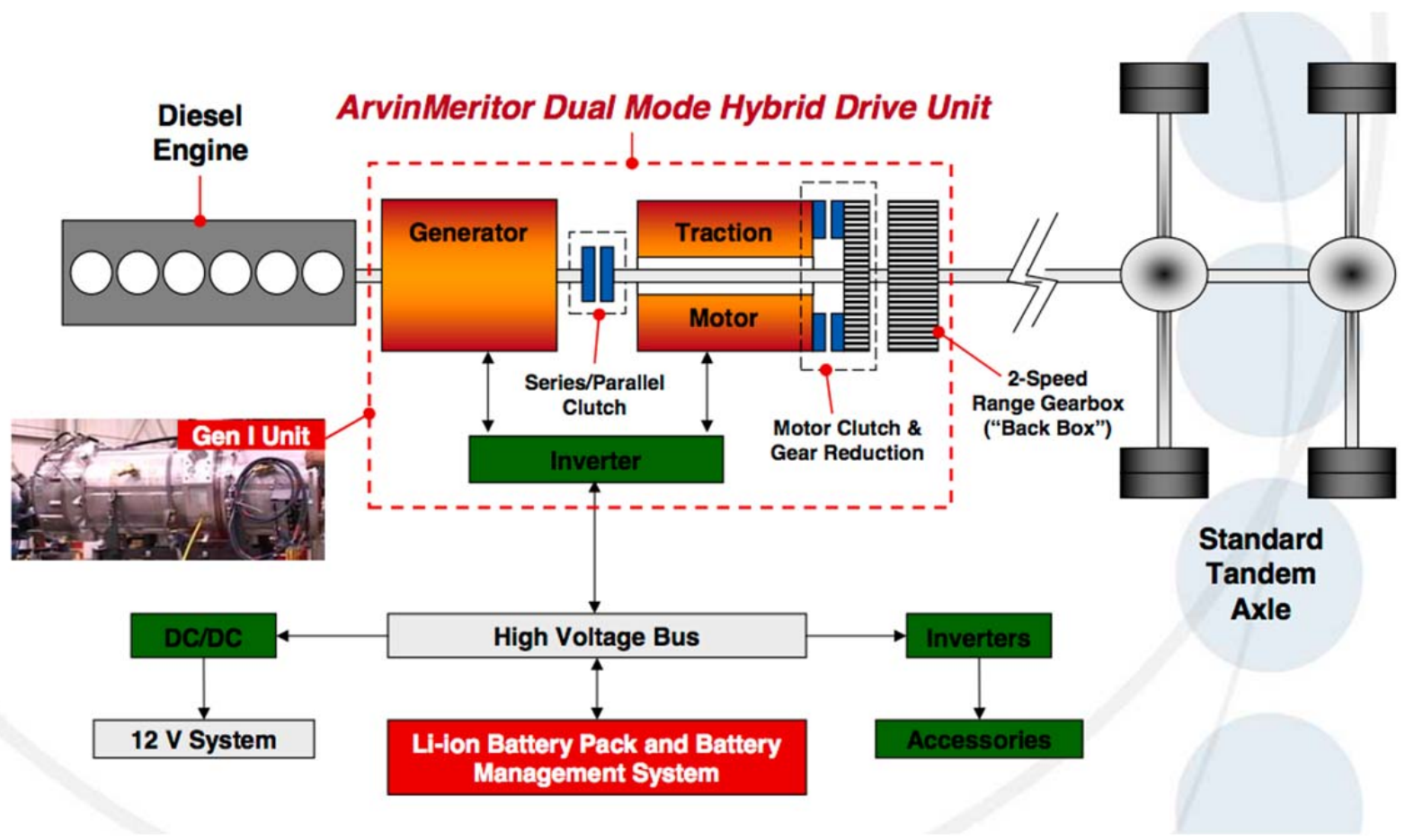

Figure 1 Functional diagram of DMHP powertrain (courtesy Meritor, Inc.)

\subsubsection{Simulation Model and Control Algorithm Development}

\subsubsection{Autonomie Vehicle and Powertrain Model}

For reference purposes, a baseline vehicle model was created based on a conventional Class-8 heavy duty vehicle. Figure 2 shows a graphical representation of the conventional powertrain in Autonomie, with component and vehicle assumptions labeled accordingly. This model was based on a "representative" truck for the purposes of this project. It should be noted that all efficiencies and accessory loads for all models developed for this study are assumed constant for the duration of each drive cycle. While this is not as accurate as having more detailed models for friction losses, accessory loads, etc., it represents average loads across each cycle. Therefore, the results obtained from these models should be taken as qualitative rather than quantitative. 


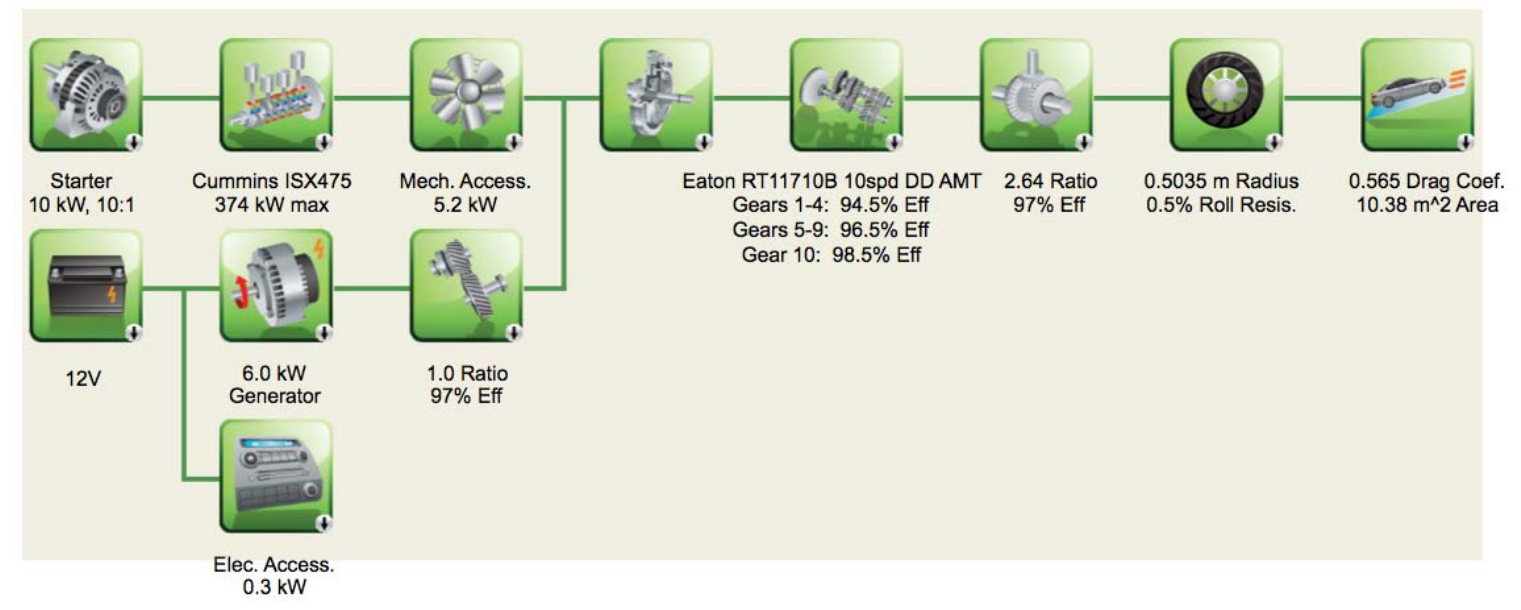

Figure 2 Conventional Class 8 model, reference

Figure 3 illustrates the powertrain model representative of the Meritor DMHP, for the revision referred to as Generation 2A. The final drive ratio of 2.64:1 for this model matches that of the baseline vehicle, which yields the same ratio as the reference vehicle in top gear. Meritor supplied the data for the pertinent high voltage traction drive system (traction motor, generator, and energy storage system). The electric machines are modeled assuming full symmetry in all four quadrants of operation. This powertrain architecture was configured such that a variety of DMHP combinations and gear ratios could be assessed. Figure 4 illustrates a proposed Generation 3 version of the Meritor DMHP that effectively changes the gearing of the traction motor and the engine. A shift position table is shown in the figures that provides the status of the respective clutches in the system (one for the traction motor, and one for parallel operation). It is important to note that the shift sequence is sequential in nature, and no positions can be "skipped."

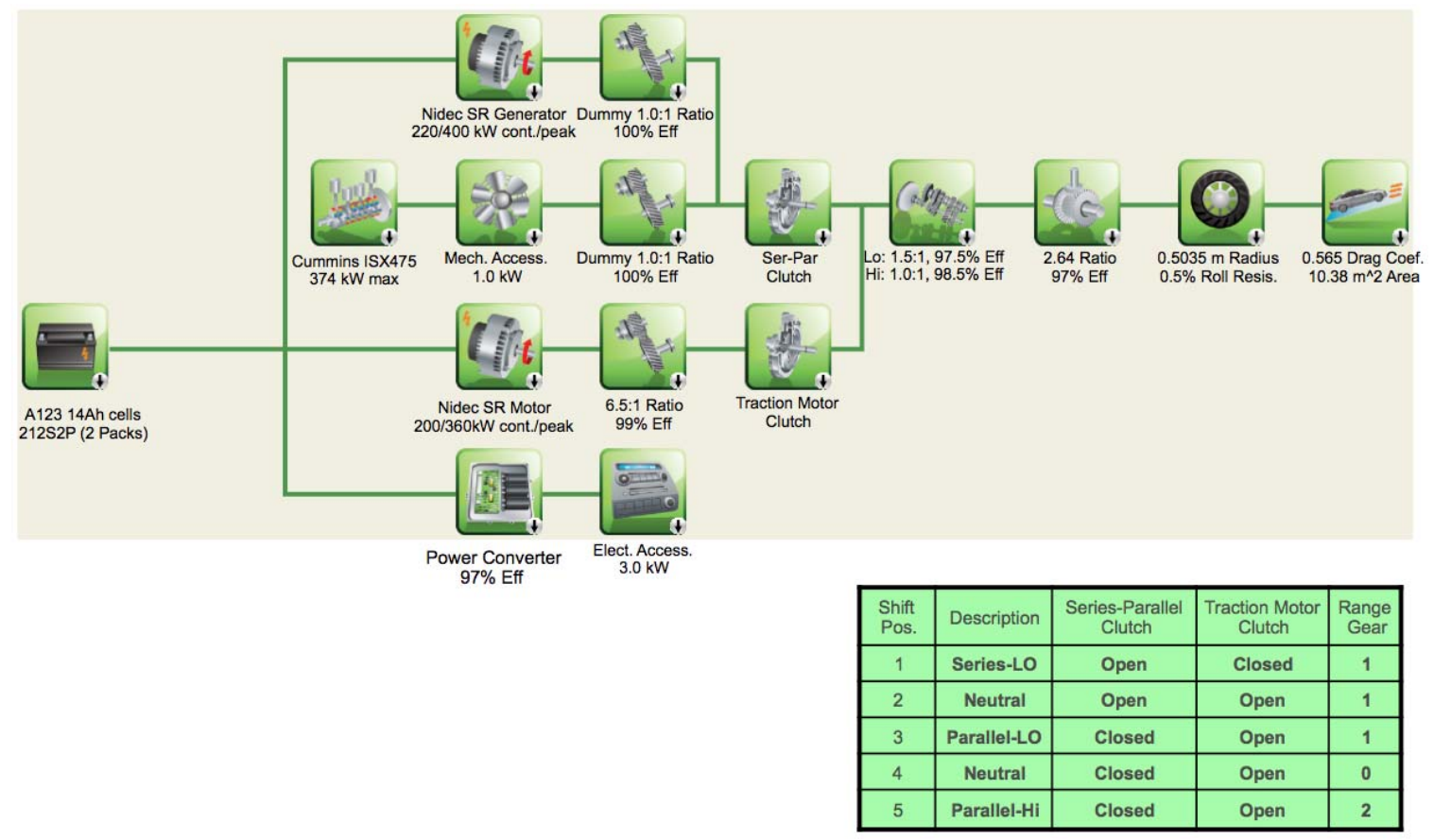

Figure 3 Meritor DMHP model, Generation 2A 


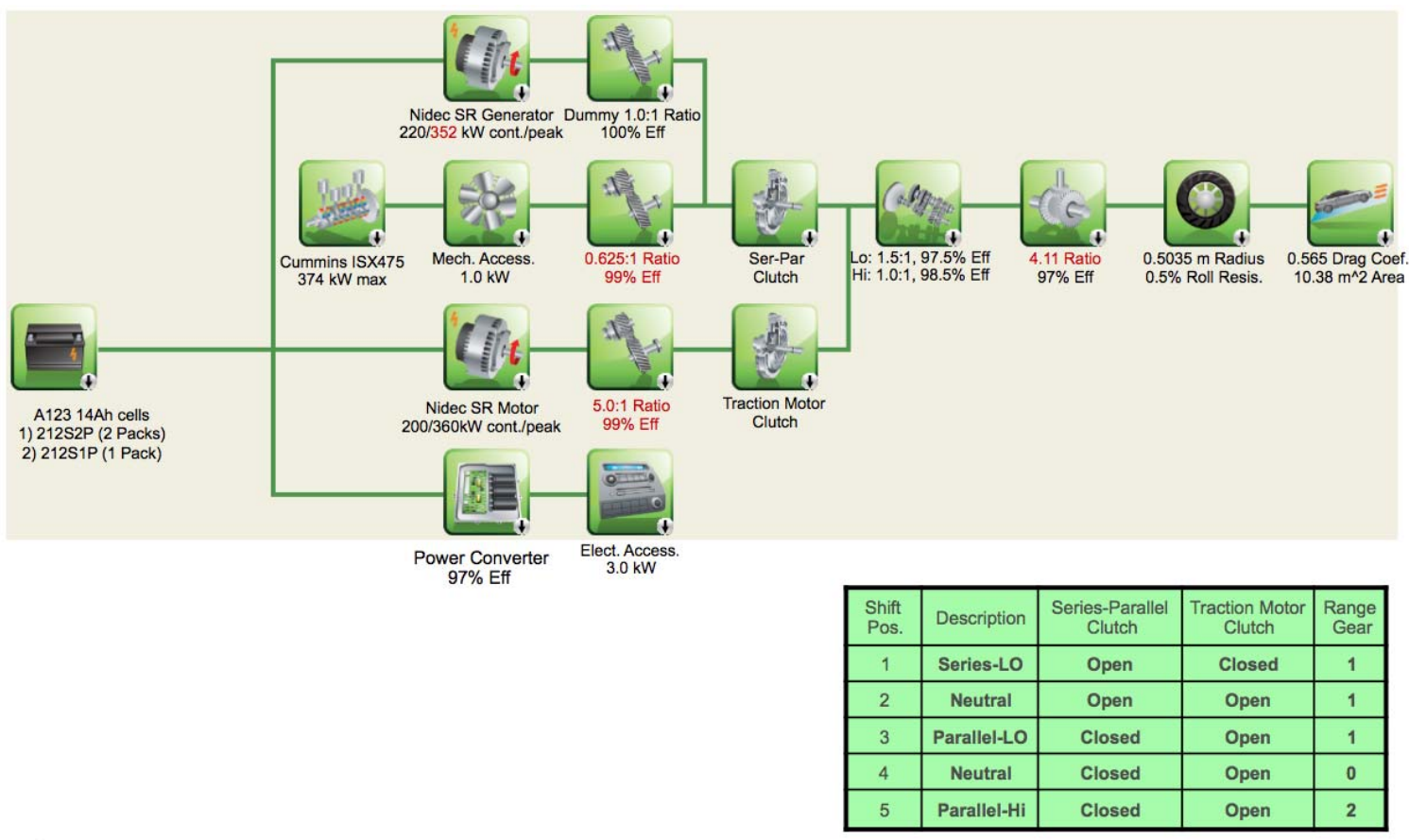

Figure 4 Meritor DMHP model, Generation 3

\subsubsection{Basic Dual Mode Hybrid Powertrain Operation}

In order to develop a suitable supervisory control model, the basic operation of the DMHP must be understood. There are two (2) basic operating modes for this powertrain, which are series hybrid electric vehicle (HEV) and parallel HEV. It can be argued that electric mode could be considered a third mode; it will be treated as a sub-state of series HEV mode for the purpose of this research.

Figure 5 graphically depicts the flow of power for the DMHP during series HEV operation. The engine and generator are not physically connected to the drive wheels. The traction motor alone provides tractive effort during series HEV operation. Having the engine decoupled from the drive wheels allows the engine to be operated at its optimal speed for a given power demand. Idle charging is also permitted with this configuration allowing for the potential to use the vehicle as a mobile power source and for hoteling operation. The traction motor only, in this mode, handles regenerative braking duties. As mentioned previously, a sub-state of this mode of operation is all-electric, or engine off. 


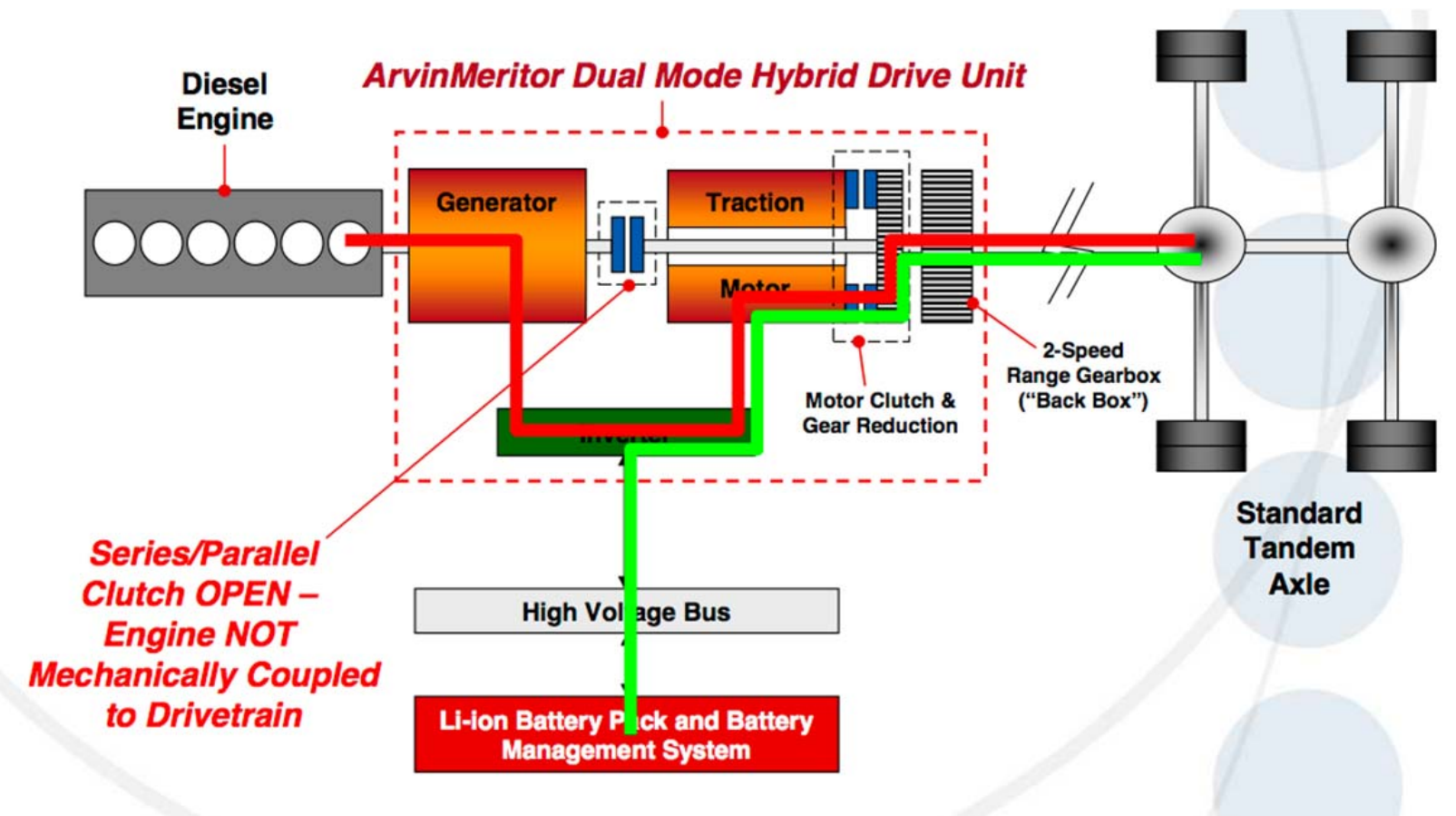

Figure 5 DMHP power flow for series HEV operation (courtesy Meritor, Inc.)

Figure 6 graphically depicts the flow of power for the DMHP during parallel HEV operation. The engine and generator are now physically connected to the drive wheels through closing of the parallel clutch. Tractive effort can be provided from any combination of the engine, generator, and traction motor for moderate vehicle speeds. At highway speeds, the traction motor must be decoupled from the powertrain to over-speeding. For moderate vehicle speeds, the traction motor can be utilized for regenerative braking, while the generator must be used at highway speeds.

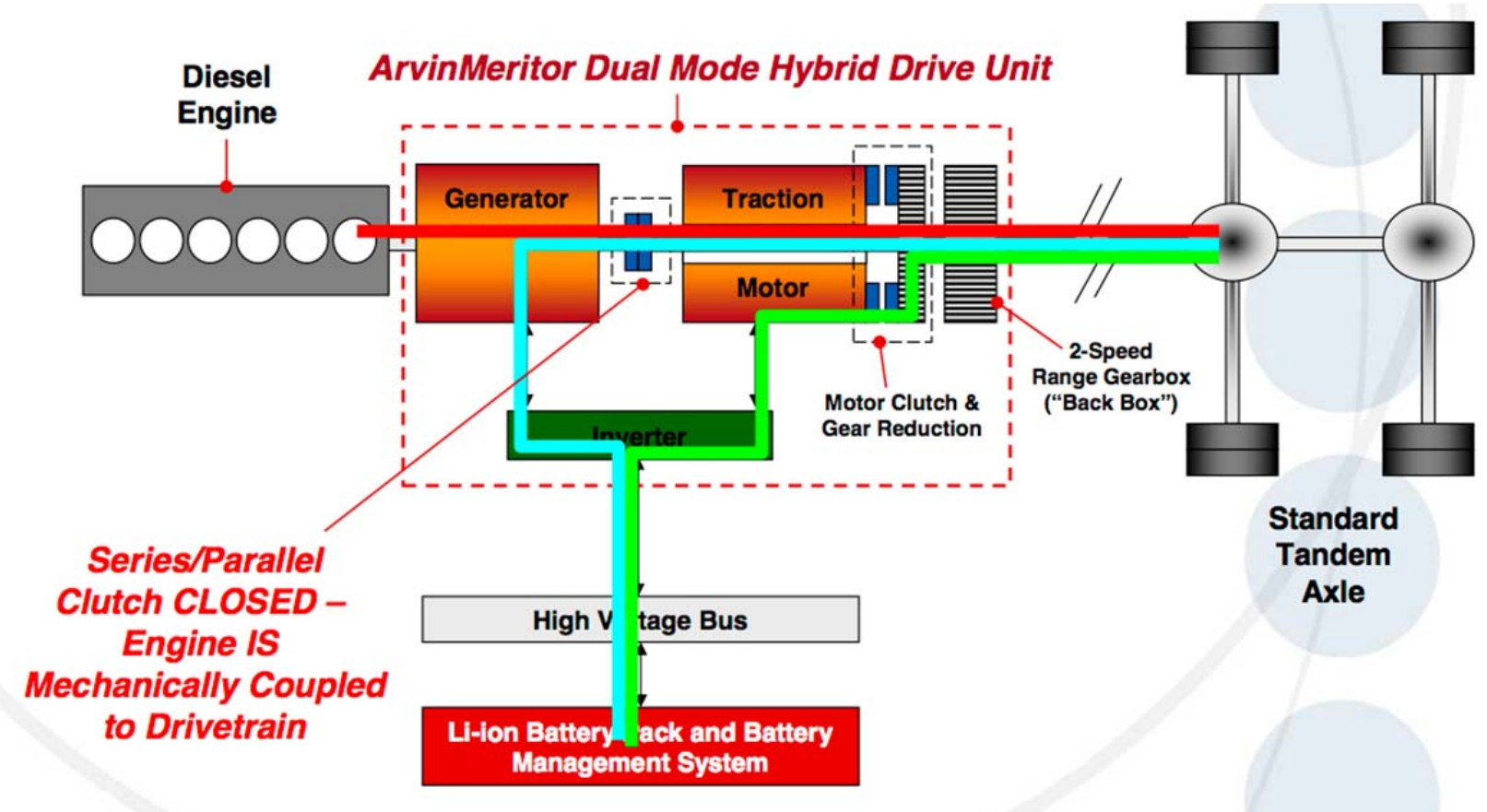

Figure 6 DMHP power flow for parallel HEV operation (courtesy Meritor, Inc.) 


\subsubsection{Overall control strategy approach and implementation}

The basic control strategy imposed for the DMHP during both series and parallel operation is a load following approach. For series operation, the power output of the engine/generator is commanded to closely follow the demand of the operator. The engine/generator is commanded to deliver this power request at its most efficient speed/torque point. For parallel operation, the engine is commanded to deliver the same power, but there is no flexibility for running at an arbitrary speed since the engine is now physically connected to the road. However, with correct sizing of the final drive ratio, the engine runs very efficiently at highway speeds just as a conventional vehicle currently operates. The total demanded engine power is a function of wheel demand and state of charge (SOC) maintenance.

The focus area for development of the DMHP powertrain model was creating a structured, logical supervisory control architecture and baseline control strategy. The approach taken for the supervisory control architecture was to break down the functionality of the system into various control processes. These control processes are modeled independently within the overall supervisory framework, thus being modular in nature. However, all of the control processes do communicate information with each other to accomplish the goals of the system. Figure 7 illustrates the supervisory control architecture and brief description of each control process. The following sections provide a more detailed summary of the roles of each of the control processes, and how they are implemented into the overall control architecture.

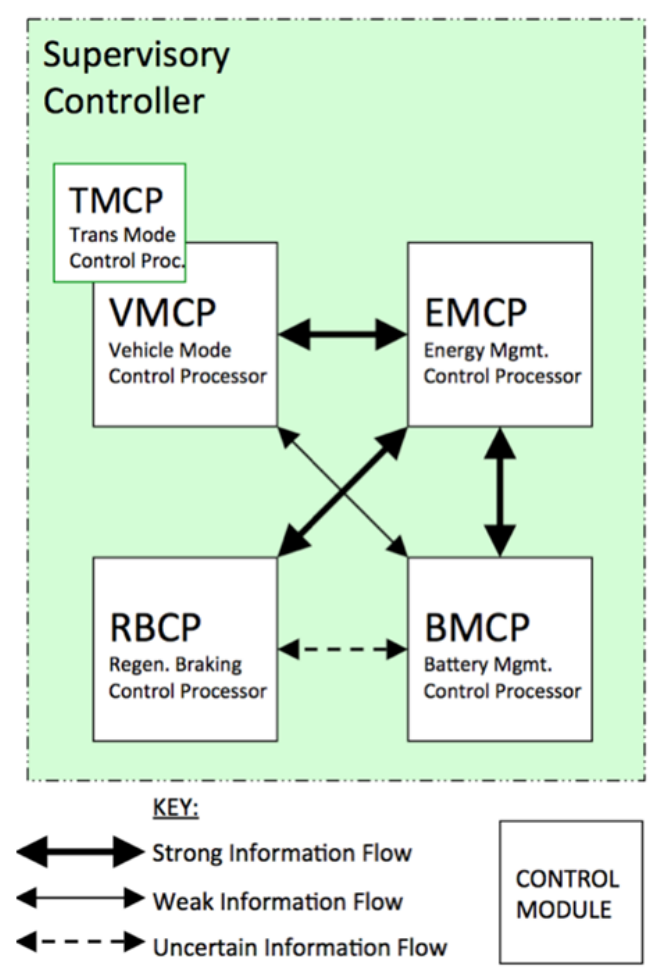

\begin{tabular}{|l|l|l|}
\hline $\begin{array}{l}\text { Control } \\
\text { Module }\end{array}$ & \multicolumn{1}{|c|}{ Function(s) } & \multicolumn{1}{|c|}{ Example States } \\
\hline VMCP & $\begin{array}{l}\text { Controls vehicle operating } \\
\text { modes such as key on/off } \\
\text { sequence, engine on/off/ } \\
\text { starting sequence, etc. }\end{array}$ & $\begin{array}{l}\text { Key On/Off } \\
\text { Engine On/Off/Starting } \\
\text { Series/Parallel } \\
\text { Hybrid Mode (strategy) }\end{array}$ \\
\hline EMCP & $\begin{array}{l}\text { Controls propelling power } \\
\text { distribution to engine \& e- } \\
\text { machines. Enforces system } \\
\text { limitations. }\end{array}$ & $\begin{array}{l}\text { Series \{thermostatic, load } \\
\text { following\} } \\
\text { Parallel \{load following\} }\end{array}$ \\
\hline RBCP & $\begin{array}{l}\text { Controls regenerative braking } \\
\text { and brake blending. } \\
\text { Include engine and electric } \\
\text { retarding. }\end{array}$ & $\begin{array}{l}\text { Regen On/Off } \\
\text { Blended Regen } \\
\text { Retarding Mode }\end{array}$ \\
\hline BMCP & $\begin{array}{l}\text { Controls battery calibration and } \\
\text { maintenance, and reports } \\
\text { battery status. }\end{array}$ & $\begin{array}{l}\text { Soc } \\
\text { Temperature } \\
\text { Calibration }\end{array}$ \\
\hline TMCP & Controls transmission shifting. & $\begin{array}{l}\text { Shift Position \{1-5\} } \\
\text { Shift Status \{static, } \\
\text { upshifting, downshifting\} }\end{array}$ \\
\hline
\end{tabular}

Figure 7 Supervisory control architecture for the DMHP model

\subsubsection{Vehicle mode control process (VMCP)}

Overall vehicle mode/status. The VMCP is responsible for determining what state, or mode, the vehicle should be operating in. The most basic functionality of the VMCP is to monitor key-on and key-off events. While not considered for the purpose of the mode development, in an actual vehicle implementation the VMCP would perform subsystem initialization and handshaking to prepare the vehicle for normal operation. The VMCP would also handle proper shut-down sequences. 
The main function of the VMCP is to identify the correct state that the vehicle should be operating in based upon physical information from the powertrain. Figure 8 provides an example performance map for the DMHP to illustrate the various operating states of the vehicle. At low vehicle speeds, the vehicle must be operating in series mode (including all electric). As the vehicle speed increases, the powertrain is allowed to engage the engine and generator to the powertrain. At higher vehicle speeds, the traction motor must be decoupled from the powertrain, and finally a range shift must occur at highway speeds such that the engine does not overspeed. All of this basic functionality, sequential by design, is directed by the VMCP.

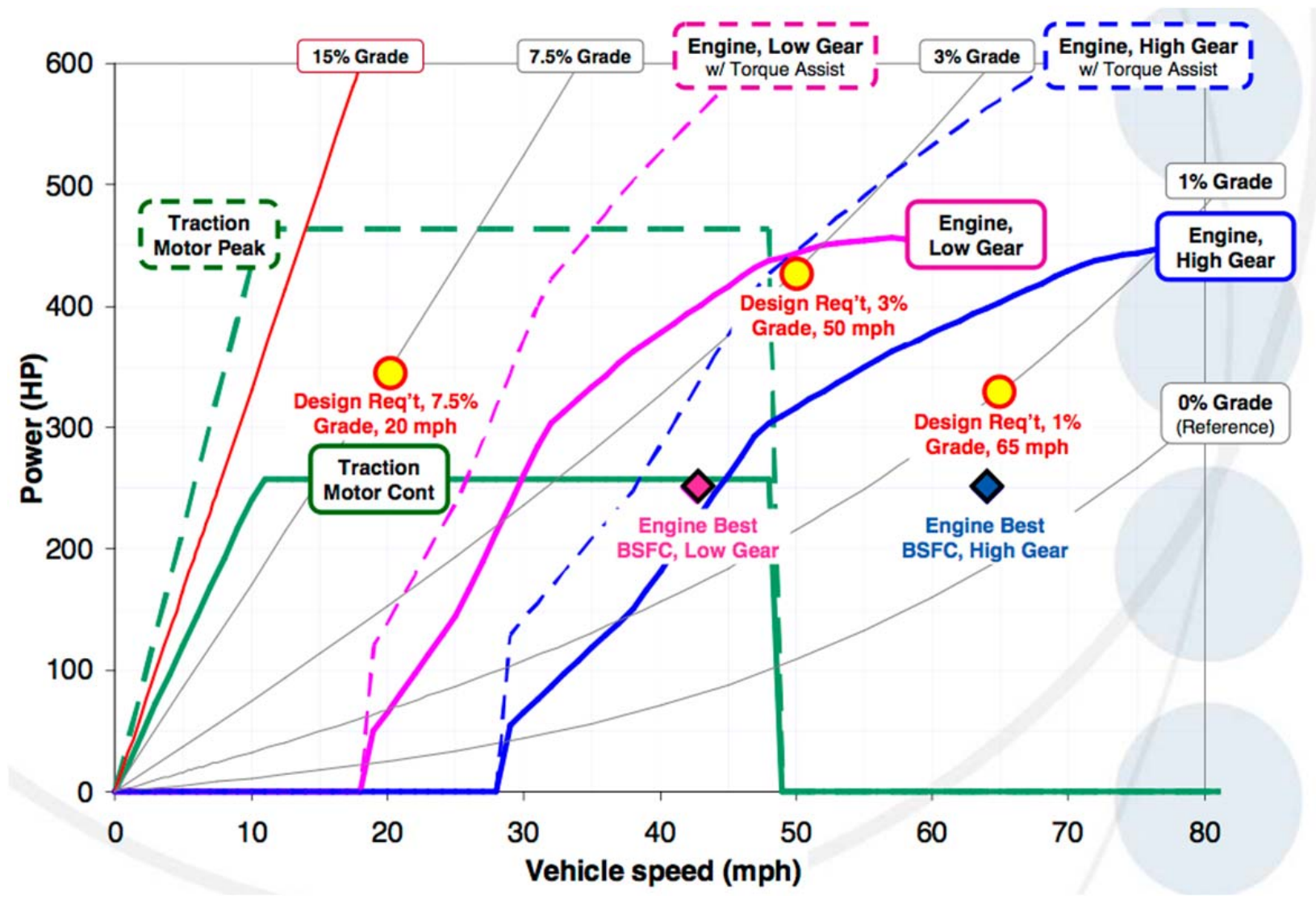

Figure 8 Example DMHP performance operating map

Transient engine operation demonstration. The VMCP also dictates when the engine should be turned "ON" or "OFF." This transient means of operation of the heat engine directly impacts the achieved fuel economy of the vehicle. The basic restraints for the operation of the engine are linked to the power demanded by the driver and the state of the high voltage battery pack. The basic strategy for the engine "ON" and "OFF" operation is summarized below.

- Engine ON Logic. The engine will turn back “ON” if the sum of the demanded power exceeds a higher power threshold (on/off hysteresis). The engine remains on for a minimum given amount of time. Note that the engine "ON" logic does not use a lower SOC limit in the current version. It does, indirectly, when the SOC gets very low such that the corresponding battery SOC maintenance power demand gets high enough to trip the threshold.

- Engine OFF Logic. The Engine will turn "OFF" if the sum of the demanded power drops below a given power threshold for a certain length of time. While the engine is "OFF," the battery supplies all the propulsion energy to the vehicle. Note that as the SOC is depleted, the 
battery SOC maintenance power demand increases until the engine is forced "ON" for charging considerations.

\subsubsection{Battery mode control process (BMCP)}

The Battery Mode Control Process (BMCP) has the responsibility for reporting the appropriate and corrected HV battery power limits to the Energy Management Control Process (EMCP) for further analysis and calculation. The strategy makes use of a calibrateable table to determine the additional power required of the engine to maintain the SOC of the $\mathrm{HV}$ battery pack. This power, termed $P_{S O C}$, is a one-dimensional function of battery SOC. An example of this is illustrated in Figure 9. Here, a negative value for $P_{S O C}$ indicates that the battery needs to be charged towards to the SOC target. Conversely, a positive value means that the HV battery has a surplus of energy and should be discharged to utilize this stored energy in the pack. It should be noted that the power necessary to maintain the SOC can be calculated in a variety of methods. The method presented in Figure 9 is merely a simple, basic approach. An optimization involving the efficiencies of the battery pack, traction motor, generator, and heat engine should be employed in such a way as to determine the optimal value for $P_{S O C}$ for a given set of physical conditions.

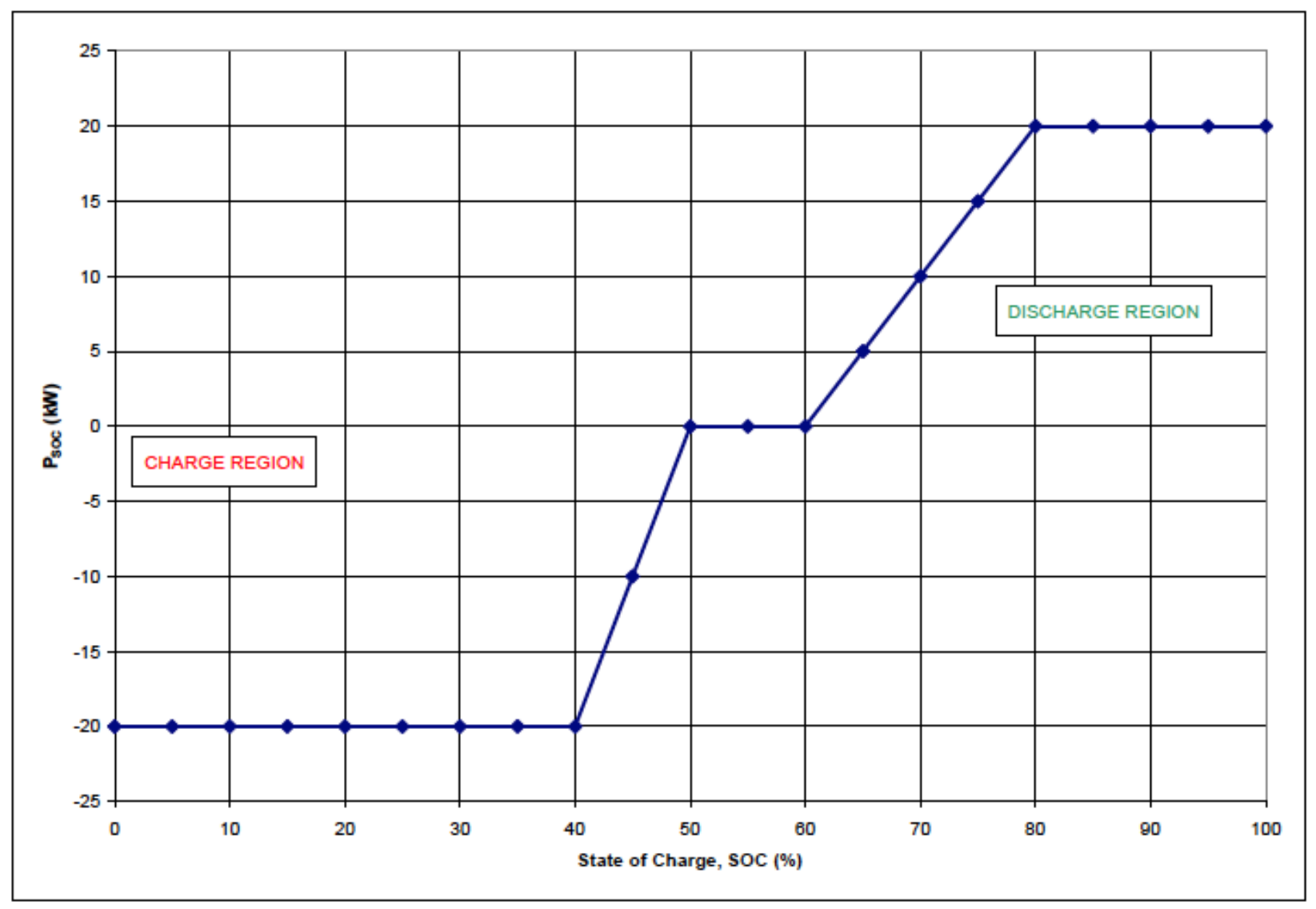

Figure 9 Determination of battery SOC maintenance power for BMCP

The BMCP is also responsible for modifying the battery power limits that are calculated inside the BCM. The BMCP corrects these limitations for such conditions as high SOC, low SOC, high battery module temperature, low battery module temperature, etc. as deemed appropriate. 


\subsubsection{Regenerative braking control process (RBCP)}

The Regenerative Braking Control Process (RBCP) is responsible for translating the braking intent of the driver. The RBCP receives a brake pedal demand and converts this signal into a percentage demand (normalized based upon the maximum braking force available). The demand is modified based upon several factors. The RBCP implements a hold-off and foundation brake blending strategy, as depicted in Figure 10. In addition, the RBCP reduces regenerative braking commands to the EMCP at low vehicle speeds. This is due to NVH and drivability concerns at these low speeds. The RBCP also features flags to effectively turn off all regenerative braking commands to the EMCP in order to perform assessments of the effectiveness of regenerative braking on overall vehicle efficiency.

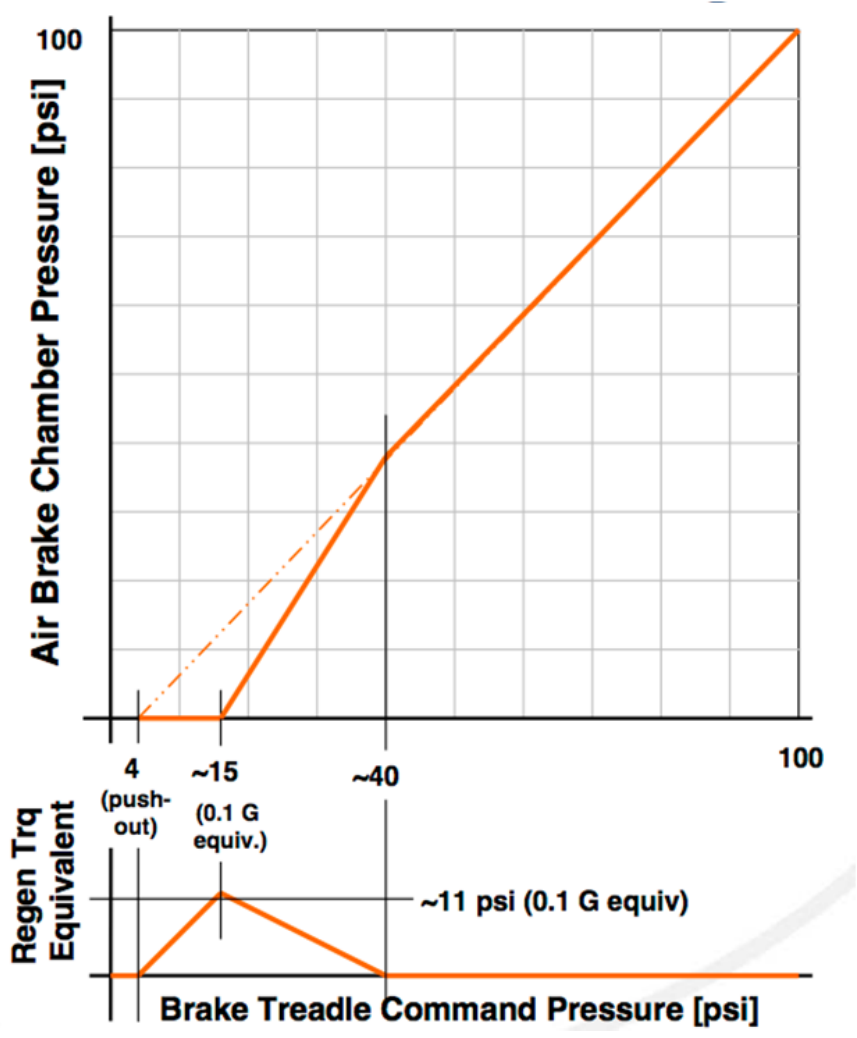

Figure 10 Hold-off strategy implemented into RBCP

\subsubsection{Energy management control process (EMCP)}

The Energy Management Control Process (EMCP) is the most critical process within the Vehicle Supervisory Control Module (VSCM). The EMCP is responsible for coordinating the interaction of the heat engine, generator, battery, and the traction motor. The EMCP must ensure that the driver demanded power is satisfied while at the same time maintaining the SOC of the HV battery pack. The EMCP must deliver these items while also enforcing overall system limitations for sub-system protection.

The EMCP joins the output from the BMCP and the VMCP to determine what is required of the heat engine, generator, and the traction motor. The EMCP calculates the driver demanded power, $P_{d r v}$. The prime output of the BMCP is the power necessary to maintain the SOC of the HV battery pack, referred to as $P_{\text {SOC. }}$. The variables together for the total power required of the engine in HEV mode. It is worth noting that PSOC is ignored in a zero emissions vehicle (ZEV) mode. The total engine power desired, $P_{\text {Tот, }}$, thus becomes

$$
P_{\text {tot }}=P_{d r v}-P_{S O C}
$$


where,

$$
\begin{gathered}
P_{S O C}<0 \text { indicates power to CHARGE the battery } \\
P_{S O C}>0 \text { indicates power to DISCHARGE the battery. }
\end{gathered}
$$

The primary function of the EMCP is to deliver the appropriate torque commands to the engine, generator, and traction motor that (a) satisfy the driver demand and SOC maintenance demand and b) apply overall system limitations and constraints. Figure 11 is a flow diagram that outlines how the respective system limitations are applied in a hybrid mode of operation. The flow diagram starts with $P_{d r v}$, since meeting the driver demand is the most important characteristic of the VSCM as a whole.

For a ZEV mode of operation, the flow diagram is modified to remove references to the engine. Basically, the bottom half of the diagram is used. The general outputs from this flow diagram are a modified engine power desired and traction motor power desired (filtered through the system limits). These values are divided by each respective speed to give a torque command to the engine and traction motor. However, certain further adjustments to these values must be made in order to compensate for electrical system power losses (conversion of electrical energy to mechanical energy). This is also accomplished in the EMCP. 


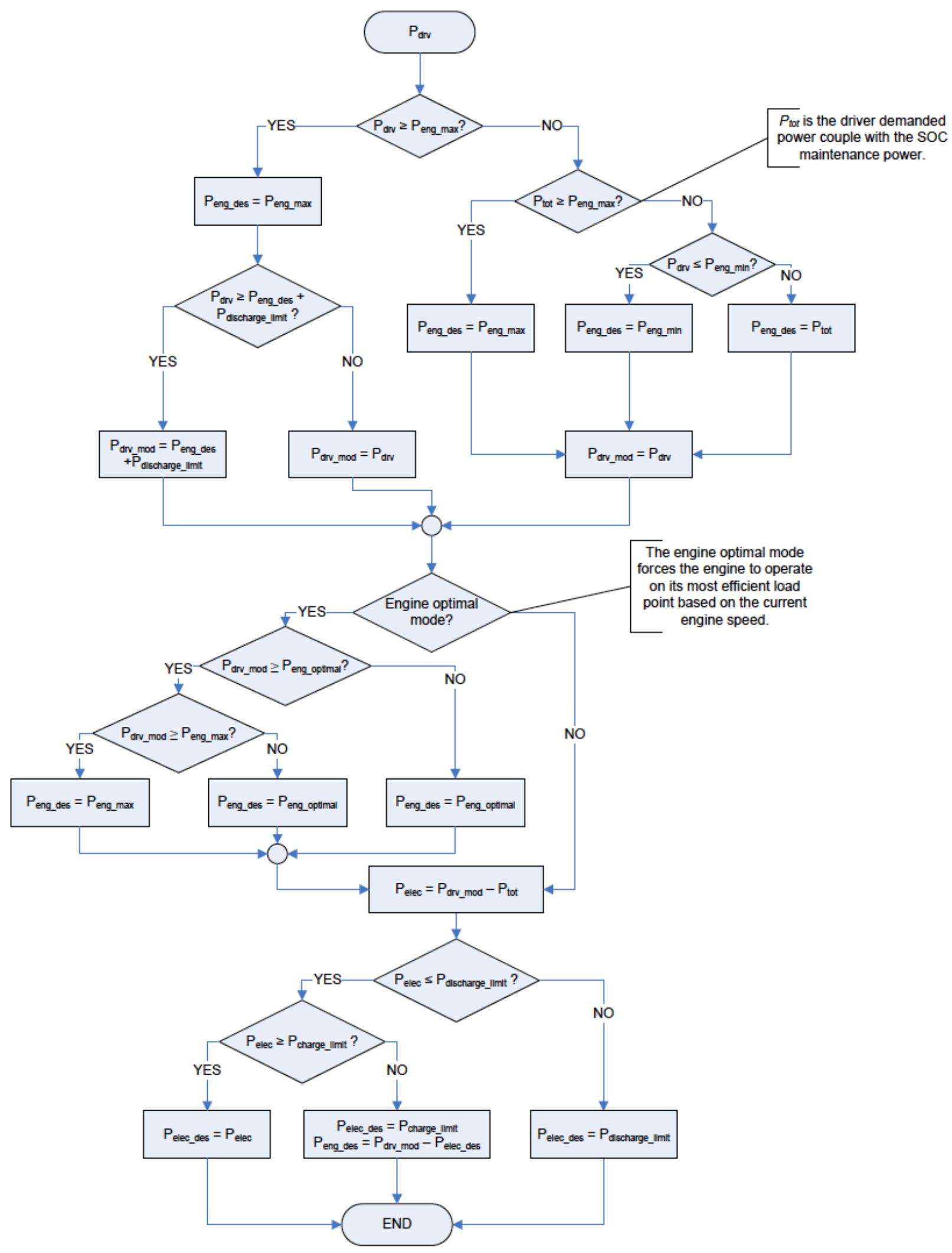

Figure 11 Basic flowchart for EMCP power distribution during HEV operation 


\subsubsection{Transmission mode control process (TMCP)}

An important aspect of this effort was to incorporate the logic of the transmission shifting control system in the supervisor, as well as restructure the low-level control systems within the powertrain model into the supervisor. The Meritor DMHP transmission has a sequential shift pattern that must be followed. The TMCP also handles transitions to each respective shift position, including component speed matching during appropriate shifts. Table 1 below represents the distinct states of the transmission that were incorporated into the supervisory control model.

Table 1 Meritor DMHP sequential transmission control requirements

\begin{tabular}{|l|c|c|c|c|}
\hline \multicolumn{1}{|c|}{ Description } & Position & Series/Parallel Clutch & Traction Motor Clutch & Range Gear Number \\
\hline Series - Low & 1 & Disengaged & Engaged & 1 \\
\hline Parallel - Low 1 & 2 & Engaged & Engaged & 1 \\
\hline Parallel - Low 2 & 3 & Engaged & Disengaged & 1 \\
\hline Neutral & 4 & Disengaged & Disengaged & 0 \\
\hline Parallel - High & 5 & Engaged & Disengaged & 2 \\
\hline
\end{tabular}

\subsubsection{DMHP System Optimization Study}

\subsubsection{Series Hybrid Mode}

In the approach adapted here, a power management control algorithm is developed that can make series HEVs to continuously operate at their optimal efficiency with respect to fuel economy. The HEV is considered as cooperative multi-agent systems in which the subsystems (i.e., internal combustion (IC) engine, motor, generator, and battery) will be treated as autonomous intelligent agents. The agents will attempt through their interaction to jointly maximize overall HEV operation. The problem is formulated as sequential decision-making under uncertainly where the supervisory controller is faced with the task to select those control actions in several time steps to achieve long-term goals efficiently. Sequential decision models are mathematical abstractions representing situations in which decisions must be made in several stages while incurring a certain cost at each stage.

In the series HEV mode of the DMHP, the motor provides all the power demanded by the driver. Thus we can operate the engine at any desired combination of engine torque and speed. The objective of the centralized controller is to maintain the SOC of the battery within a given range while operating the engine efficiently. So the optimal control policy of the controller is a sequence of the optimal engine power at each instant of time corresponding to the engine's current speed. To operate the engine under the condition designated by the centralized controller, a PID controller regulates the engine torque through the generator. The sequence of the engine's optimal power is converted to electrical power through the generator and goes to the battery.

In our problem formulation, engine operation was modeled as a controlled Markov chain with a state space $S$, and a control space $U$ from which control actions are chosen. The state space $S$ is the entire range of the engine speed and the control space $U$ is the engine power range. Thus the Markov chain is the evolution of the engine speed and the uncertainty is related to the power demanded by the driver through the battery SOC. The evolution of the engine occurs at each of a sequence of stages $t=0,1, \ldots$, and it is portrayed by the sequence of the random variables Xt and Ut corresponding to the system's state (engine speed) and control action (engine power). At each stage, the controller observes the system's state, and executes an action, from the feasible set of actions at that state. At the next stage t, the system transits to 
the state $\mathrm{Xt}+1=\mathrm{j} \in \mathrm{S}$ imposed by the conditional probability $\mathrm{P}(\mathrm{Xt}+1=\mathrm{j} \mid \mathrm{Xt}=\mathrm{i}, \mathrm{Ut})$, and $\mathrm{a} \operatorname{cost} \mathrm{k}(\mathrm{Xt}=$ $\mathrm{i}, \mathrm{Ut})=\mathrm{k}(\mathrm{i}, \mathrm{Ut})$ is incurred corresponding to fuel consumption. After the transition to the next state has occurred, a new action is selected and the process is repeated. The completed period of time over which the system is observed is called the decision-making horizon and is denoted by $\mathrm{T}$. We are concerned with deriving a stationary optimal control policy (sequence of engine power) to minimize the long-run average cost (average fuel consumption) per unit time.

The first step in designing the centralized controller is to identify the column vector of the cost function that is minimum for each state (engine speed). This can be derived by plotting the minimum brake specific fuel consumption (BSFC) of the engine for each engine speed. From this plot, we can choose the set of admissible state/action pairs. The optimal control policy can be achieved by the centralized controller, if the engine is operated at the speed range ensuring higher probability to the engine speed with lower BSFC values and lower probability to the engine speed with higher BSFC values. However, the centralized controller needs to maintain the battery's SOC close to the target value ( $70 \%$ in this case). To achieve both objectives, we establish a one-on-one correlation between SOC and the optimal engine power range. In particular, the controller is set up to command the engine to provide the power corresponding the minimum allowable value whenever SOC is equal to 70\% (target SOC) and gradually increase as SOC drops below $70 \%$ all the way down to the minimum allowable value (60\% in this case), as illustrated in Figure 12.

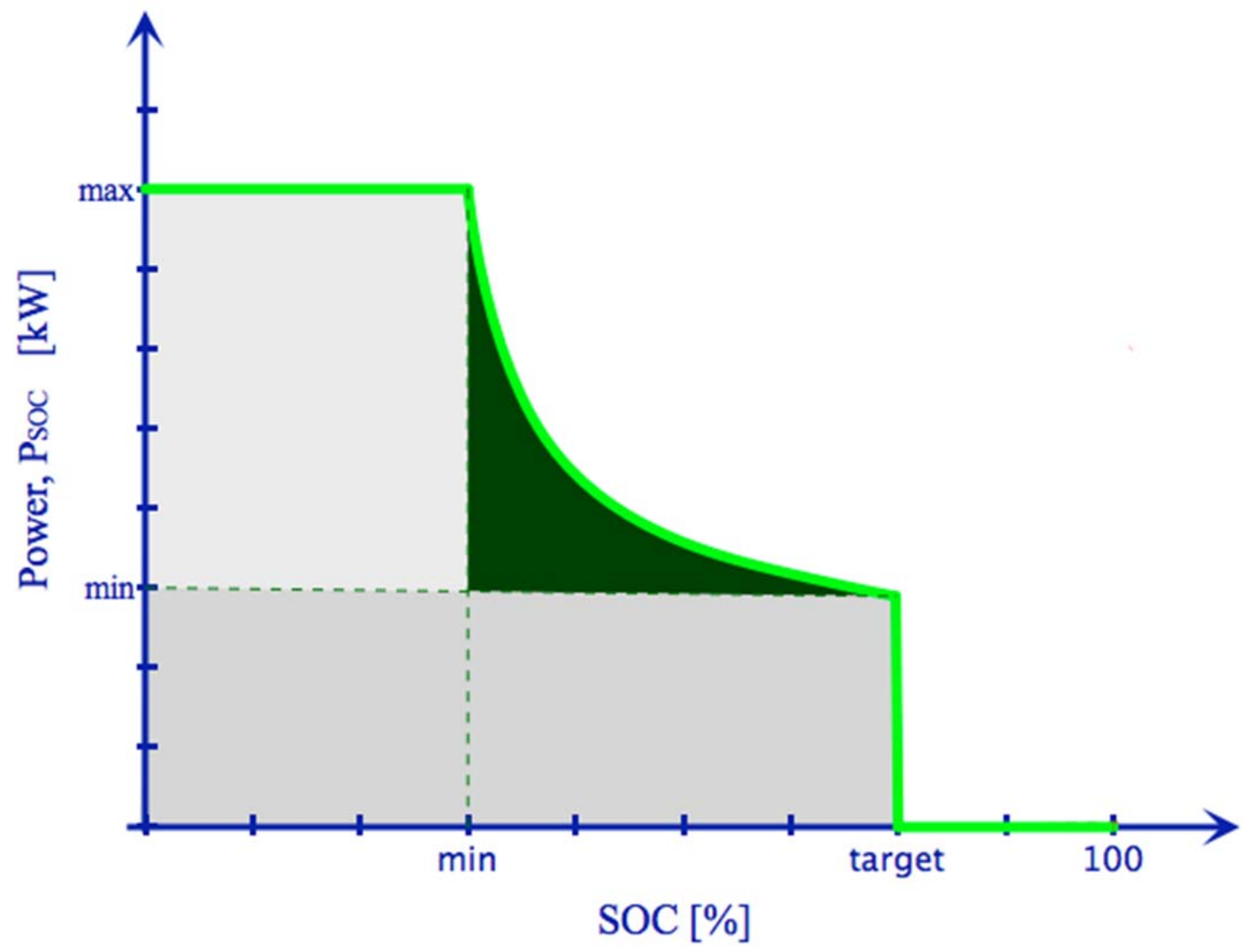

Figure 12 Engine power with respect to the state of charge of the battery.

To validate the effectiveness of the equilibrium control policy, we compared it to the baseline controller. Both HEV models, the one having the baseline controller and the one with the optimal controller, were run over the same driving cycle illustrated in Figure 13. The inherent algorithm in Autonomie called 
dichotomy was used to compare the simulation results. The algorithm runs the HEV model over the same driving cycle for multiple times and then provides results corresponding to the same initial and final SOC, as illustrated in Figure 14. The optimal control algorithm in the series mode of operation yields a 4.8\% fuel consumption improvement as shown in Figure 15.

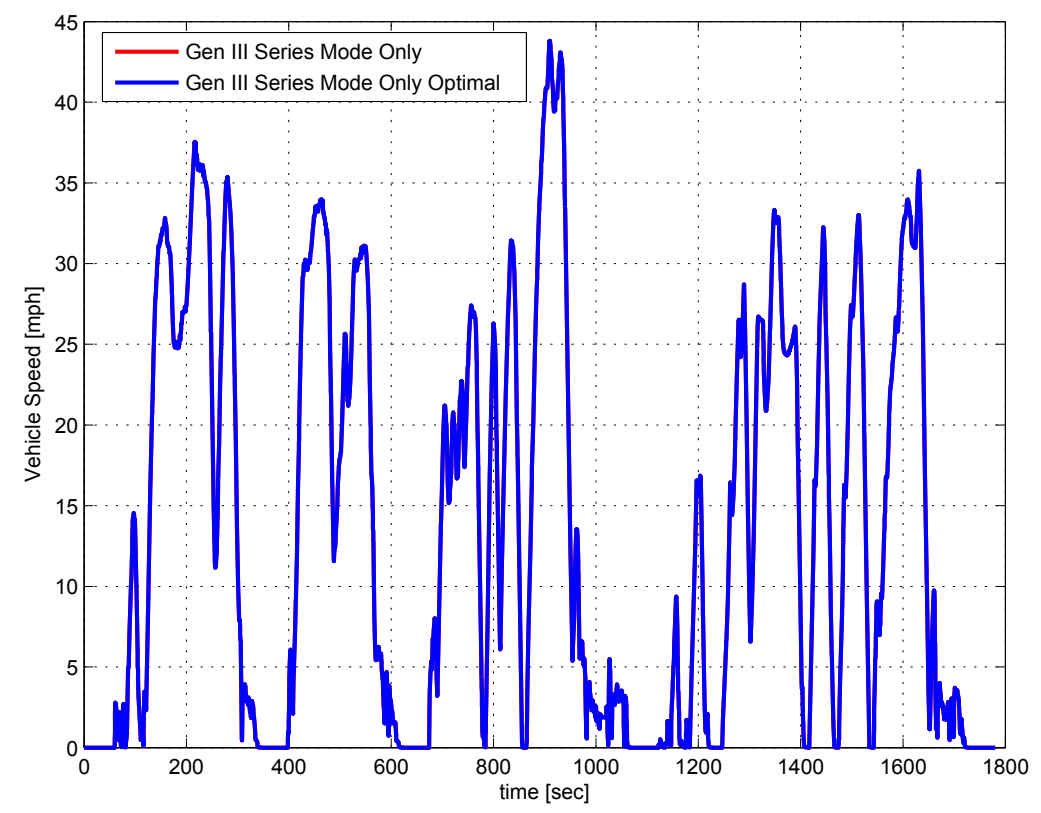

Figure 13 Both the Autonomie model with the original controller and the one with the optimal controller were followed precisely the CSHVR driving cycle.

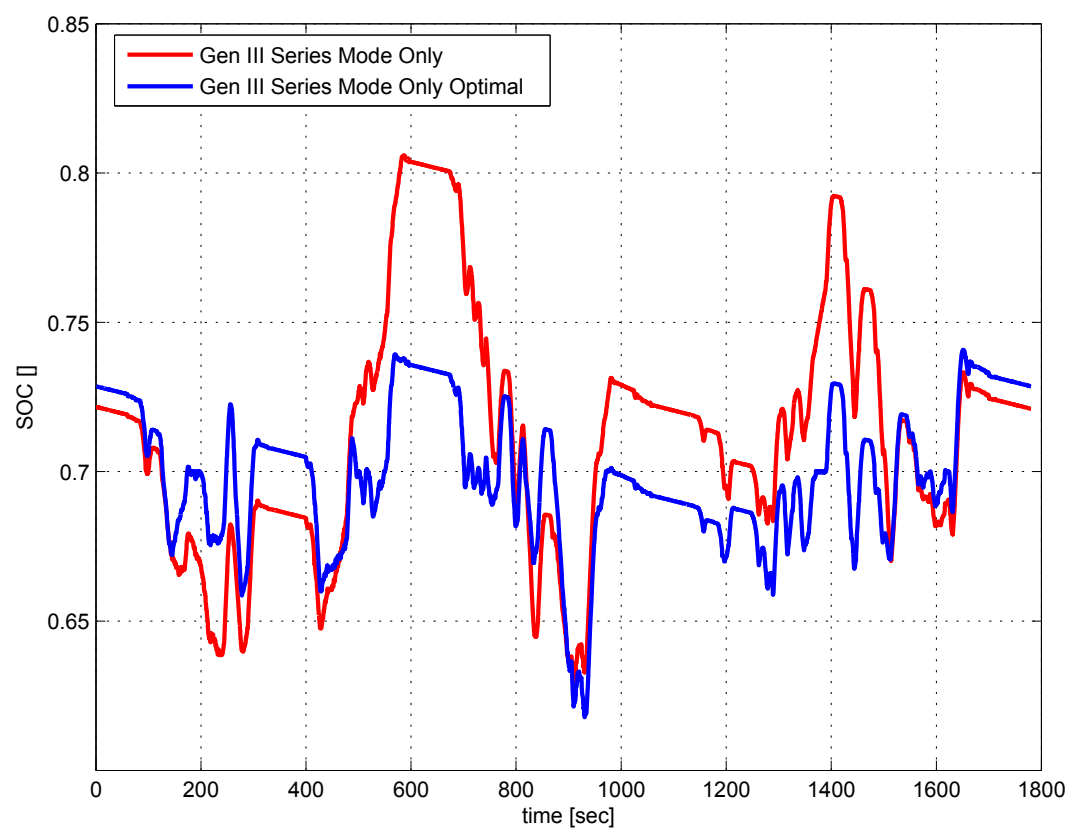

Figure 14 SOC variation for both models. 


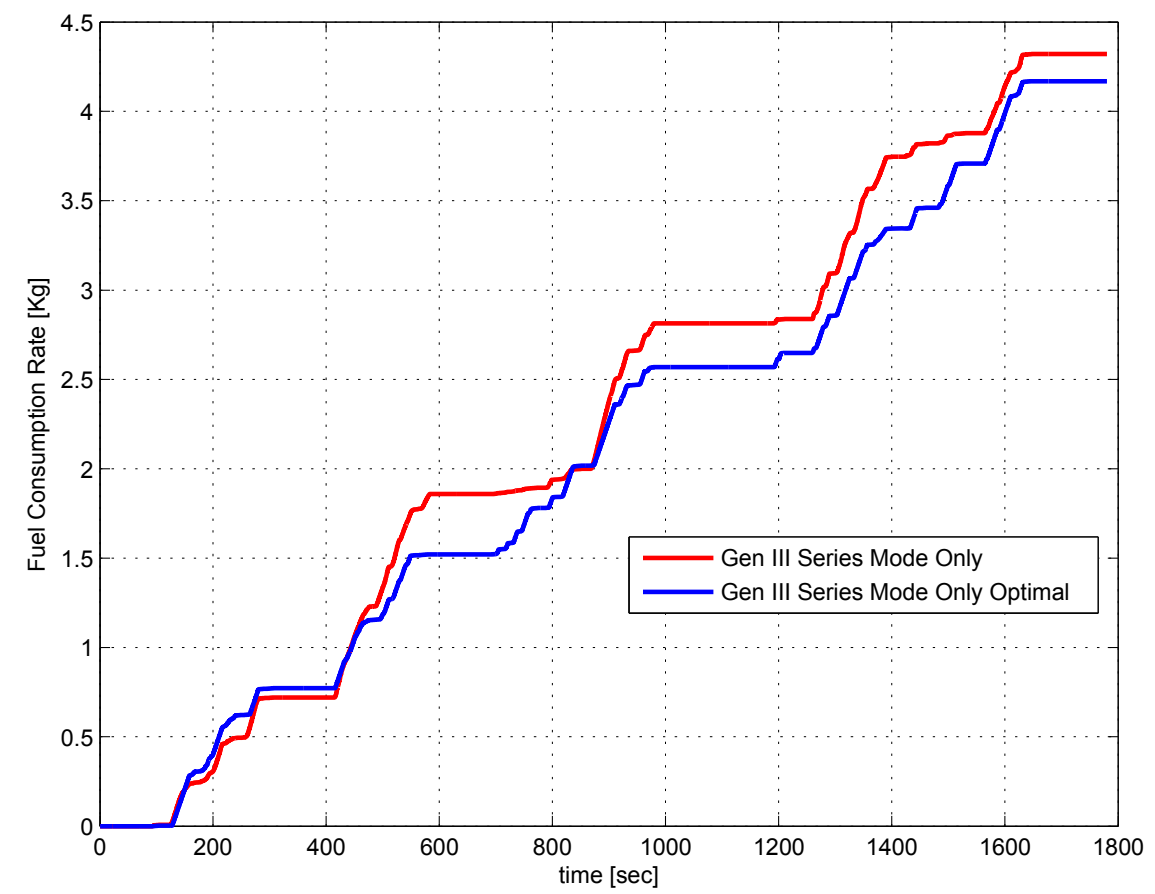

Figure 15 Cumulative fuel consumption.

\subsubsection{DMHP - Parallel Mode}

The power management control problem of the parallel configuration is addressed in a centralized fashion. The objective of the centralized controller is to guarantee the self-sustainability of the electrical path and distribute the power demanded by the driver optimally between the engine and the motor to minimize fuel consumption. The controller observes SOC of the battery as well as the engine and motor speed, and then computes the optimal engine and motor torque, and based on the power demanded by the driver.

In previous research reported in the literature, the SOC of the battery has been used as a component of the state. However, this may lead to a significant large state space with implications to increasing the computational burden associated with solving the problem. In our approach, the SOC is treated as an additional uncertainty by having it correlated to an additional power demand by means of a one- on-one mapping illustrated in Figure 12. Namely, depending on the SOC value there is a corresponding amount of power $P_{\text {SOC }}$ that needs to be provided to the battery in order to stay at the target SOC. This additional amount is added to the driver's power demanded. The one-on-one mapping aims to provide an increasing power request, $P_{\text {SOC }}$, as the $S O C$ drops up to a certain maximum value. If the $S O C$ is above the target value, then $P_{\mathrm{SOC}}$ is zero.

We seek the theoretical framework and control algorithm that will aim to yield the optimal control policy on-line while the driver drives the vehicle. In our proposed approach, HEVs are considered as cooperative multi agent systems in which the subsystems, i.e., engine, motor, and battery, are treated as autonomous agents. To simplify the problem, the focus in this study is on establishing the equilibrium between the engine and the motor only. However, future research should also consider the battery as an agent and investigate the implications associated with this. To compute the equilibrium operating point we formulate a multi-objective decision making problem consisting of the engine's BSFC, and the motor's 
efficiency. The objective is to find the optimal torque for the engine and the motor that minimizes HEV fuel consumption for a given speed and torque request.

To validate the effectiveness of the centralized controller using the optimal control policy we employed Autonomie. The DMHP Autonomie model was simulated under the optimal controller and compared with the baseline DMHP controller over the HDDDT65 driving cycle, shown in Figure 16. The optimal control algorithm in the parallel mode of operation yields a $1 \%$ fuel consumption improvement, illustrated in Figure 17. Higher fuel consumption improvements are expected in non-highway driving cycles. The SOC of the battery for the both cases is shown in Figure 18.

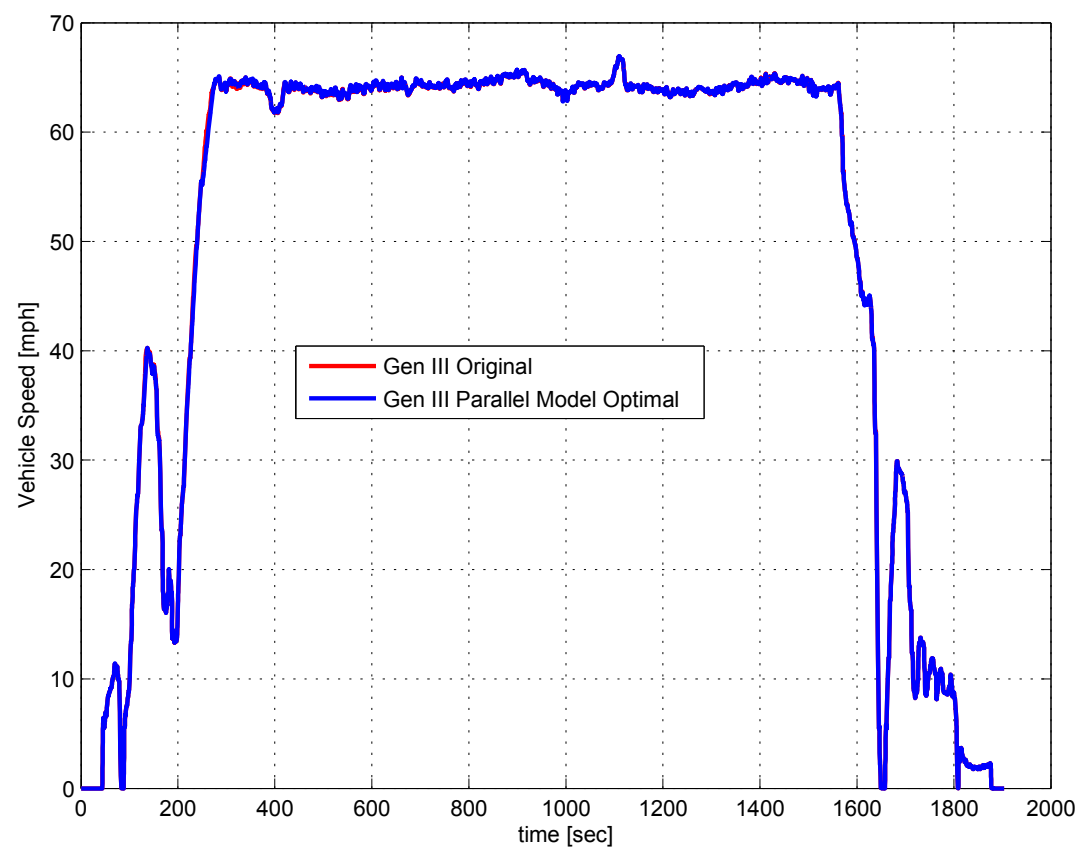

Figure 16 Both the Autonomie model with the original controller and the one with the optimal controller were followed precisely the HDDDT65 driving cycle. 


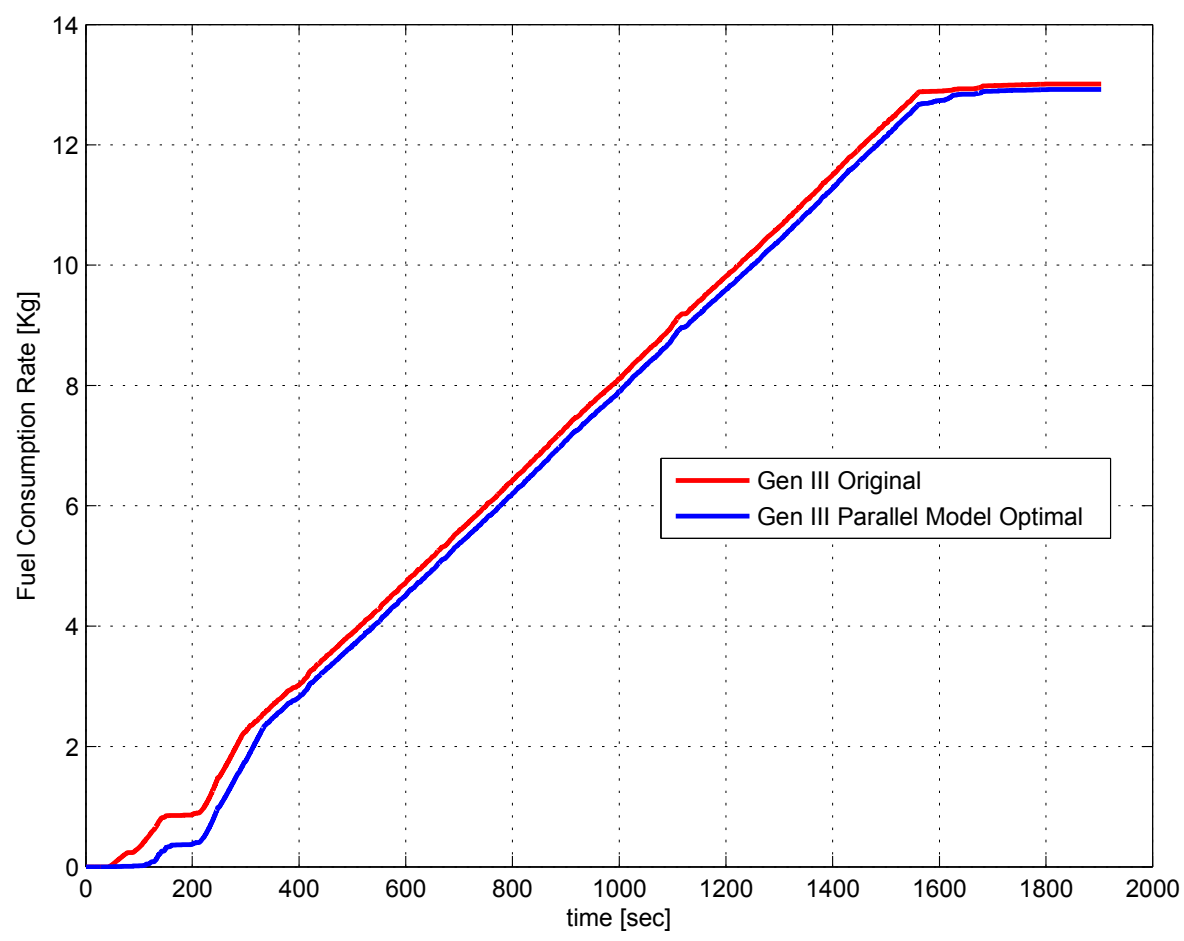

Figure 17 Cumulative fuel consumption.

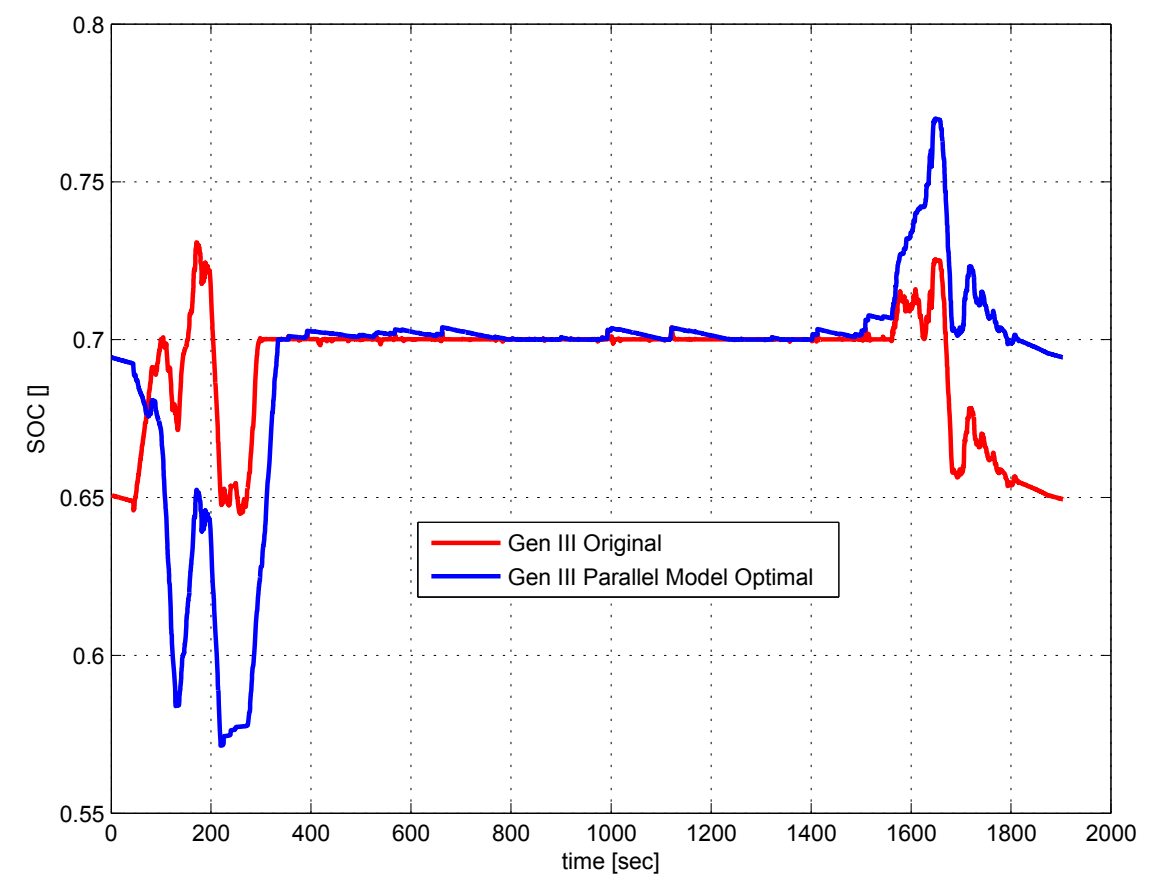

Figure 18 SOC variation for both models. 


\subsubsection{Alternative Technology Analysis}

In order to understand the merits of the Meritor DMHP, an alternative technology analysis was conducted. The purpose of this study was to compare various state-of-the-art powertrain technologies and hybrid approaches to that of the DMHP. This study provided vital information into the competitiveness of the DMHP system, forma performance and fuel economy perspective.

\subsubsection{Alternative technology powertrain architectures}

In addition to the Meritor powertrain (of which two variants were considered), this portion of the study focused on two (2) distinct powertrain architectures, with variations in component sizes for each. The first powertrain architecture that was considered is a pre-transmission parallel hybrid electric. This configuration is similar to existing medium and heavy-duty hybrids that are available today. Figure 19 represents a block diagram representation of the "mild/moderate" variant of this powertrain. "mild/moderate" refers to the traction motor sizing for this powertrain, or roughly its degree of hybridization. In these two cases, the vehicle has limited all electric capabilities. Note that for all powertrains considered, the heat engine remained constant, as well as all other vehicle parameters in order to keep the comparison as reasonable as possible and to only determine effects of the powertrain. Figure 20 is the third pre-transmission variant that has full electric drive capability (which includes larger battery packs by necessity).

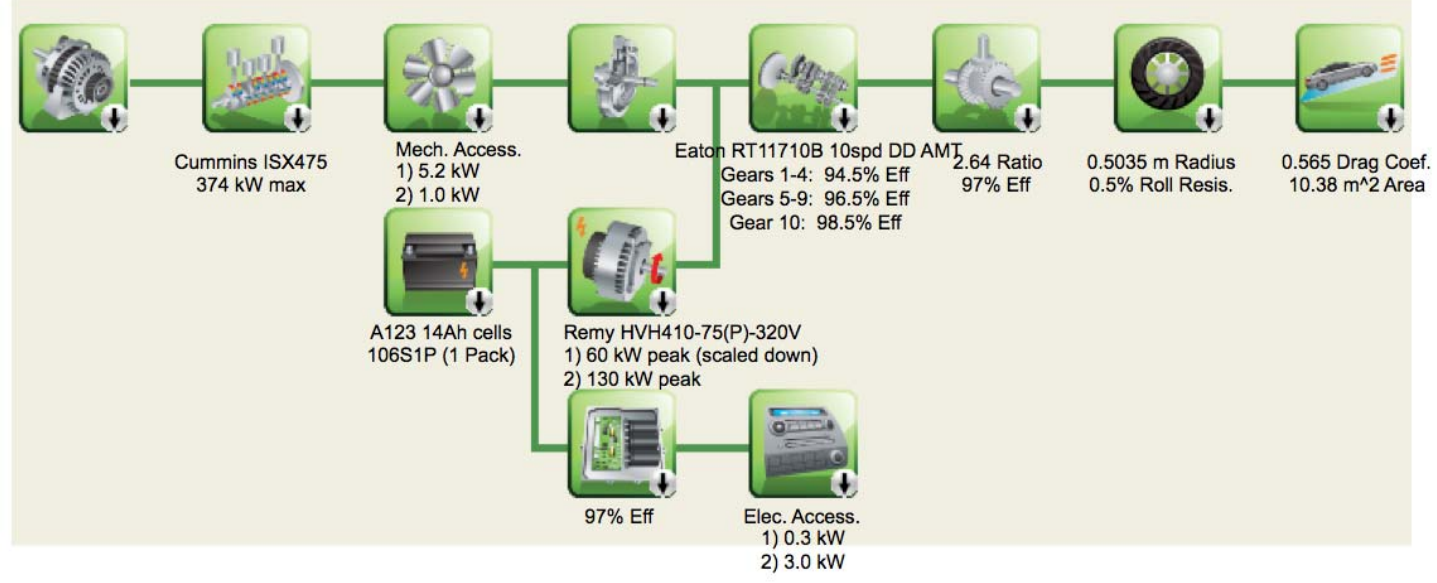

Figure 19 “Mild/moderate” parallel pre-transmission hybrid model

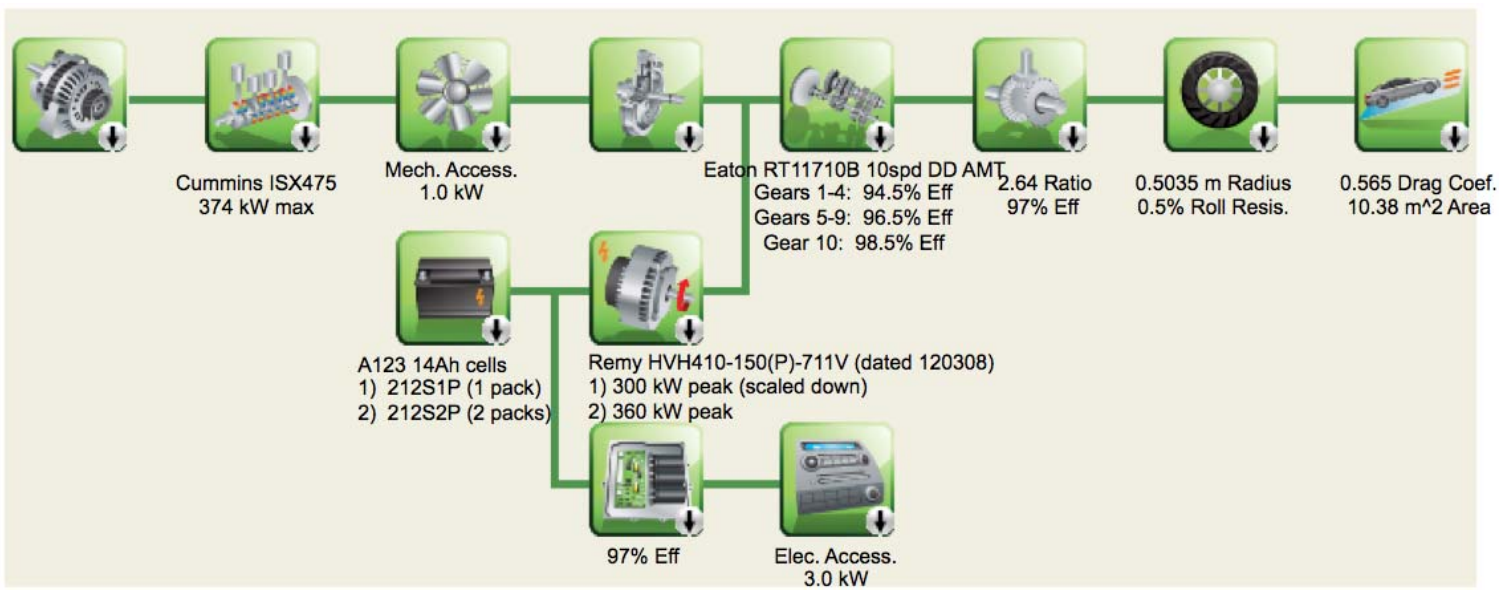

Figure 20 “Full” parallel pre-transmission hybrid model 
The second powertrain configuration considered for the study was based upon a post-transmission parallel hybrid. Just as for the pre-transmission cases, "mild/moderate" and "full" variants were studied. Figure 21 illustrates the powertrain configuration for the "mild/moderate" cases. Note that the motor sizing is identical to that of the pre-transmission counterparts. Figure 22 presents the "full” powertrain block diagram, with increased traction drive capability and larger battery pack (by necessity). The focus of the post-transmission powertrain architecture was to determine the maximum effects of regenerative braking on the powertrain, due this instance being more efficient than the pre-transmission version.

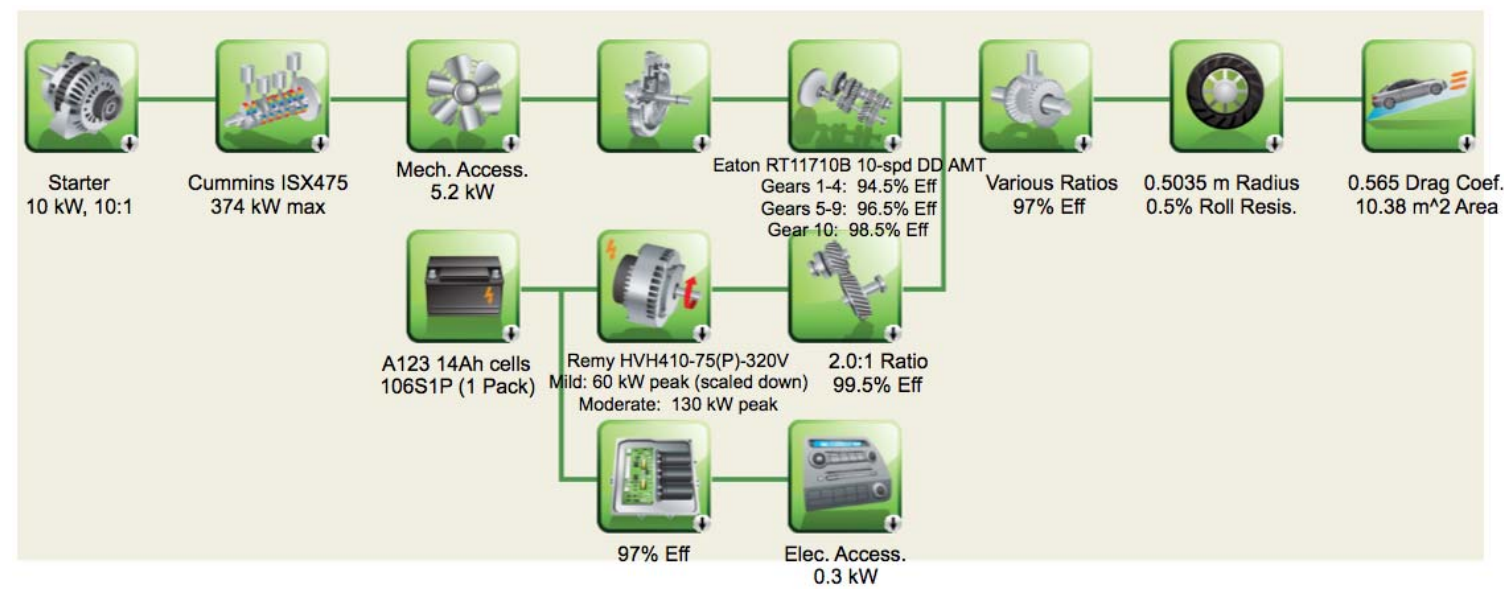

Figure 21 “Mild/moderate” parallel post-transmission hybrid model

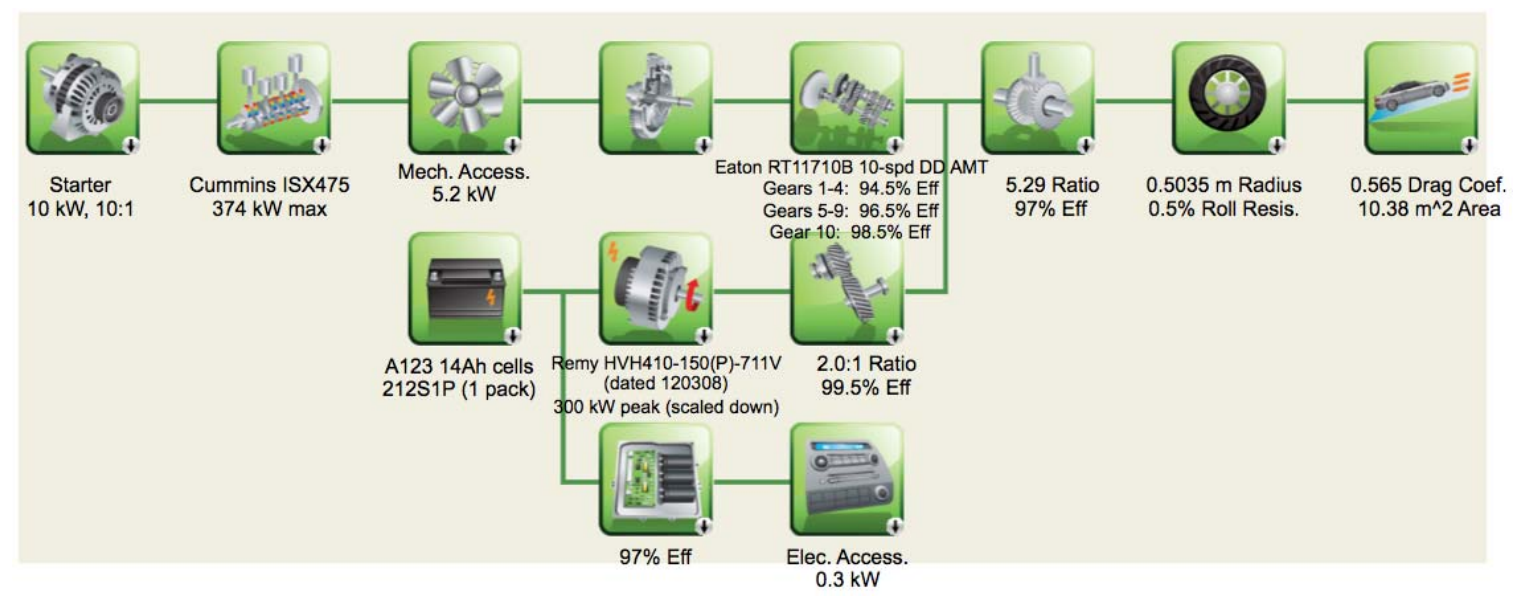

Figure 22 "Full” parallel post-transmission hybrid model

A full matrix of all the powertrain configurations and component sizing is shown in Table 2. As mentioned earlier, the primary components considered were the traction motor size and battery size. The battery was sized according to power requirements of the traction motor, at a minimum, with larger sizes considered to accommodate hoteling loads for anti-idling. For the post0-trnamission powertrain configuration, a host of various final drive ratios were modeled to understand the impact of traction motor speed on performance and overall vehicle efficiency. "Mild/moderate" cases were assumed to have no electrified accessories such the engine must remain "ON" during idle periods, while the "full” variants assumed electrified accessories and engine shut down during idle periods. 
Table 2 Alternative technology analysis matrix

\begin{tabular}{|c|c|c|c|c|c|c|c|c|c|}
\hline \multirow{2}{*}{ : } & \multirow{2}{*}{ Concept } & \multicolumn{4}{|c|}{ Ess } & \multicolumn{2}{|c|}{ Motor } & \multirow{2}{*}{ Accessories \& Operation } & \multirow{2}{*}{ Other } \\
\hline & & Call Contig & $\begin{array}{l}\text { Nominal } \\
\text { Whatage }\end{array}$ & Aspros. Capacty & Ratienath & san & Rationale & & \\
\hline 1" & \multirow{2}{*}{$\begin{array}{l}\text { Mas Pastel Pre: } \\
\text { Trassmibsion teV }\end{array}$} & \multirow{4}{*}{ 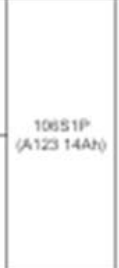 } & \multirow{4}{*}{$350 \mathrm{~V}$} & \multirow{4}{*}{$\begin{array}{l}5 \times 1 h \\
150 \mathrm{KW}\end{array}$} & \multirow{4}{*}{ 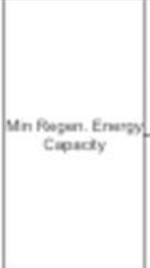 } & \multirow{2}{*}{ (scond thentsto-76) } & \multirow{2}{*}{ 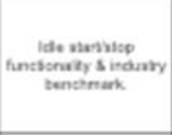 } & 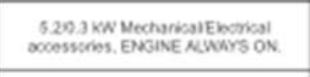 & \\
\hline ib & & & & & & & & 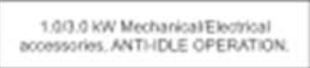 & \\
\hline $2 n$ & \multirow{2}{*}{ 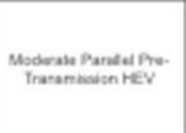 } & & & & & \multirow{2}{*}{$\begin{array}{l}130 \mathrm{~kW} \\
(\mathrm{~m} / \mathrm{N}+10-75)\end{array}$} & \multirow{2}{*}{ 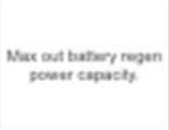 } & 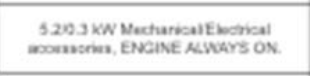 & \\
\hline $2 b$ & & & & & & & & 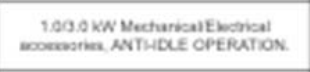 & \\
\hline 30 & \multirow{2}{*}{ 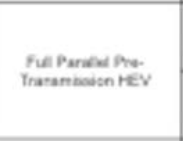 } & 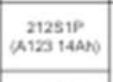 & \multirow{2}{*}{$700 \mathrm{~V}$} & $\begin{array}{l}10 \mathrm{kmb} \\
300 \mathrm{~kW}\end{array}$ & 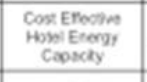 & 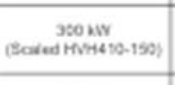 & 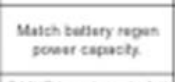 & \multirow{2}{*}{ 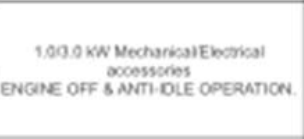 } & \\
\hline 36 & & 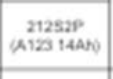 & & $\begin{array}{l}20 \mathrm{kmm} \\
402+\mathrm{kWV}\end{array}$ & 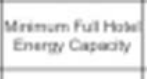 & 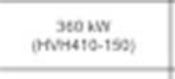 & 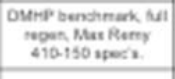 & & \\
\hline 40 & \multirow{6}{*}{ 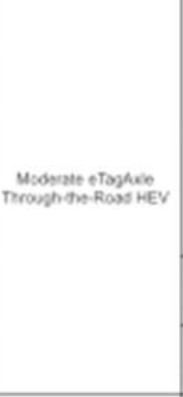 } & \multirow{4}{*}{$\begin{array}{c}10651 P \\
\text { Wizs 14ANo }\end{array}$} & \multirow{4}{*}{$950 \mathrm{~V}$} & \multirow{4}{*}{$\begin{array}{l}5 \mathrm{KNh}, \\
150 \mathrm{~kW}\end{array}$} & \multirow{4}{*}{ 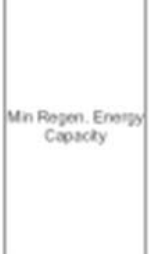 } & \multirow{4}{*}{$\begin{array}{l}130 \mathrm{nW} \\
(\text { Hก) }\end{array}$} & \multirow{4}{*}{ 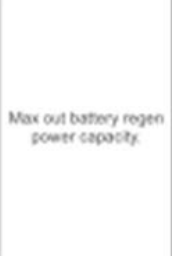 } & \multirow{6}{*}{ 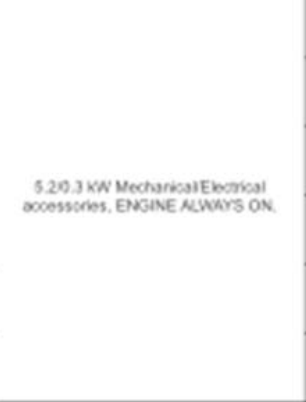 } & $5.29 \mathrm{eTO}$ Rato \\
\hline 4b & & & & & & & & & 4.11 eteg Rato \\
\hline $4 c$ & & & & & & & & & 2.17 otog Rate \\
\hline Ad & & & & & & & & & 204 otom Rate \\
\hline $4 e$ & & 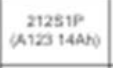 & $\operatorname{ros} \mathrm{v}$ & $\begin{array}{l}10 \mathrm{kmm} \\
300 \mathrm{~kW}\end{array}$ & 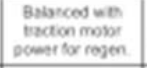 & $\begin{array}{c}350 \text { wiv } \\
\text { (Eoded HNM4 40-159) }\end{array}$ & $\begin{array}{l}\text { heremend nopon } \\
\text { capacty }\end{array}$ & & S20 thas Rath \\
\hline 41 & & 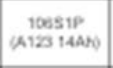 & $\operatorname{senv}$ & $\begin{array}{l}5 \times \mathrm{Nah} \\
150 \mathrm{KW}\end{array}$ & $\begin{array}{c}\text { Un fougen Emess } \\
\text { Cupacty }\end{array}$ & 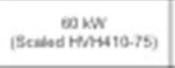 & 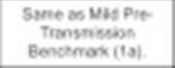 & & $5.29+T 29$ Rato \\
\hline So & 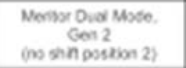 & \multirow{2}{*}{ Niz: 212528} & \multirow{3}{*}{$700 \mathrm{~V}$} & \multirow{2}{*}{$\begin{array}{l}20 \mathrm{kmb} \\
400 * \mathrm{kNV}\end{array}$} & \multirow{2}{*}{ 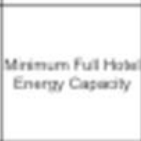 } & \multirow{3}{*}{$\begin{array}{l}360 \mathrm{WW} \\
\text { Instec } \mathrm{SFO}\end{array}$} & \multirow{3}{*}{ 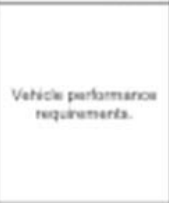 } & \multirow{3}{*}{ 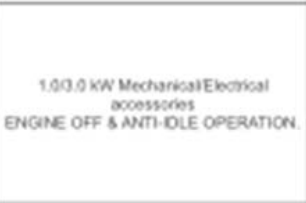 } & \\
\hline so & \multirow{2}{*}{ 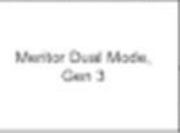 } & & & & & & & & \\
\hline so & & \begin{tabular}{|l|l|}
$21251 P$ \\
Siza $14 A N 0$
\end{tabular} & & $30 \mathrm{~km}$ & 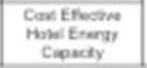 & & & & \\
\hline
\end{tabular}

\subsubsection{Alternative technology analysis assumptions/qualifications}

The following is a list of the major assumptions/qualifications for the alternative technology analysis:

- Aggressive battery power limits are used, based on forward looking values for the A123 14Ah HEV cells with beefed up DC bus which are presently under development.

- Reasonable but somewhat relaxed brake blending limits are employed in regenerative braking schemes. Assumes brake hold-off type system but acts like aggressive off-throttle regenerative braking.

- Full parallel pre-transmission cases may require heavier duty driveline and transmission to handle severe regenerative braking coast load duty.

- Energy management control schemes are subject to further optimization, especially for the dual mode.

- Base speed of motors for pre-transmission cases are relatively low at 1600-1700 rpm. However, a $1000 \mathrm{rpm}$ base speed is known to be employed on the Eaton mild parallel pre-transmission 
hybrid. This may affect motor average efficiency and regenerative capacity but may improve motor power density.

- The highway drive cycles used have more acceleration/deceleration events than the most “constant” highway cruising cycles (flat grade, constant cruise speed for hundreds of miles). They are, however, representative of a large population.

- Engine drag not explicitly considered - may improve results of parallel pre- and posttransmission cases a little (can declutch engine while regenerative braking and capture more energy).

- Efficiency and drag of mechanical drivetrain components is simply modeled.

- Accessory loading is simply modeled, and a $-1.5 \mathrm{~kW}$ "electrification bonus” is applied to electrified accessory cases.

- All models included here are "full” hybrids:

o Pre-Trans \& eAxle models have $300 \mathrm{~kW}$ peak motors.

○ DMHP has a $360 \mathrm{~kW}$ peak motor.

- Pre-Trans and DMHP have electrified accessories with associated "bonus", eAxle does not.

○ The eAxle (post-trans parallel) is not well suited to support electrified accessories (and hotel functionality) by itself.

○ Electrified case assumes constant $4.0 \mathrm{~kW}$ accessory power, non-electrified case assumes $5.5 \mathrm{~kW}$ (1.5 kW electrification bonus).

- Previous analysis based on the moderate pre-trans model indicates accessory electrification is worth approximately 3\%-7\% incremental FE improvement on urban/suburban cycles and $0.5 \%-1 \%$ on highway cycles.

- All models use a $10 \mathrm{kWh}$ battery which is “ $1 / 2$ hotel size”. The full hotel battery is twice as big at $20 \mathrm{kWh}$ :

○ The $10 \mathrm{kWh}$ is sized for peak motor regenerative power.

○ The $20 \mathrm{kWh}$ battery improves fuel economy, especially with the dual mode, but also adds cost and weight.

○ The eAxle (post-trans parallel) is not well suited to support electrified accessories (and hotel functionality) by itself.

In addition to the various powertrain and component configurations outlined in Table 2, a variety of drive cycle and overall vehicle masses were studied. This allowed a comparison of urban or line haul duty cycle influences to be better understood for each powertrain architecture, as well as mass effects. Table 3 outlines the drive cycles considered, as well as the overall vehicle mass values. Note that for the ORNL "real-world" drive cycles, a specified mass was used (in the "other" column). This mass was the actual mass of the vehicle that was used when the specific drive cycle was created. This ensures that the vehicle 
should be reasonably able to follow the drive cycle, particularly since grade is included in these cycles. There is no grade information used for the other "standard" cycles. More detailed information about of the drive cycles can be found in Appendix A. Table 4 provides more information for the array of battery packs that were simulated for this analysis. Note that each is sized such that the peak power of the traction motor is achievable, and varied capacity for engine off hoteling loads is considered.

Table 3 Drive cycles and mass considerations for alternative technology analysis

\begin{tabular}{|c|c|c|c|c|}
\hline \multirow[b]{2}{*}{ Drive Cycle } & \multirow[b]{2}{*}{ Description } & \multicolumn{3}{|c|}{ GCVW } \\
\hline & & $\begin{array}{l}\frac{\text { FULL LOAD* }}{36,287 \mathrm{~kg}} \\
(80.0 \mathrm{k} \mathrm{lb})\end{array}$ & $\begin{array}{l}\frac{\text { HALF LOAD* }}{25,990 \mathrm{~kg}} \\
(57.3 \mathrm{k} \mathrm{lb})\end{array}$ & OTHER \\
\hline CSHVR & $\begin{array}{l}\text { WVU transient (milder) City/Suburban } \\
\text { Heavy Vehicle Route }\end{array}$ & $\mathbf{X}$ & $\mathbf{X}$ & \\
\hline HD-UDDS & $\begin{array}{l}\text { EPA Heavy Duty Urban Dynamometer } \\
\text { Driving Schedule (aggressive, “Cycle D") }\end{array}$ & $\mathbf{X}$ & $\mathbf{X}$ & \\
\hline HHDDT65 & $\begin{array}{l}\text { CARB Heavy Heavy Duty Diesel Truck, 5th } \\
\text { Mode ( } 65 \text { mph cruising) }\end{array}$ & $\mathbf{X}$ & $\mathbf{X}$ & \\
\hline HDTC_NASHVILLE_KNOXVILLE & $\begin{array}{l}\text { ORNL "Real World" cycle. } 140 \text { Nashville to } \\
\text { Knoxville long haul hilly route w/grade } \\
\text { data. }\end{array}$ & & & $\begin{array}{r}35,411 \mathrm{~kg} \\
(78,066 \mathrm{lb})\end{array}$ \\
\hline HDTC_STARKVILLE_DANVILLE & $\begin{array}{l}\text { ORNL "Real World" cycle. } 165 \text { Starkville to } \\
\text { Danville long haul relatively flat route w/ } \\
\text { grade data. }\end{array}$ & & & $\begin{array}{l}33,884 \mathrm{~kg} \\
(74,700 \mathrm{lb})\end{array}$ \\
\hline
\end{tabular}

- "Empty" GCVW = 15,694 kg (34.6k lb $).$ Max payload = 20,593 kg (45.4k lb

Table 4 Matrix of battery pack configurations and sizes

\begin{tabular}{|c|c|c|l|}
\hline $\begin{array}{c}\text { Number \& Config. } \\
\text { of Cells }\end{array}$ & $\begin{array}{c}\text { Nominal } \\
\text { System } \\
\text { Voltage }\end{array}$ & $\begin{array}{c}\text { Approximate } \\
\text { System Capacity }\end{array}$ & \multicolumn{1}{|c|}{ Description } \\
\hline 106S 1P & $350 \mathrm{~V}$ & $5 \mathrm{kWh}, 150 \mathrm{~kW}$ & $\begin{array}{l}\text { Moderate HEV } \\
\text { Energy \& Power Capacity }\end{array}$ \\
\hline 212S 1P & $700 \mathrm{~V}$ & $10 \mathrm{kWh}, 300 \mathrm{~kW}$ & $\begin{array}{l}\text { Partial Hotel Energy Capacity, } \\
\text { High Power Capacity }\end{array}$ \\
\hline 212S 2P & $700 \mathrm{~V}$ & $20 \mathrm{kWh}, 400+\mathrm{kW}$ & $\begin{array}{l}\text { Full Hotel Energy Capacity, } \\
\text { Full HEV Power Capacity }\end{array}$ \\
\hline
\end{tabular}




\subsubsection{Alternative technology analysis results: overall summary}

The overall analysis results for each of the powertrain variants, compared to the conventional vehicle baseline model, are summarized in Table 5. In general, all hybrid configurations provide significantly more fuel economy improvement for urban/suburban type of operation as compared to highway types of driving. This is primarily due to the ability of the hybrid vehicles to collect wasted braking energy in the form of regenerative braking that ultimately is used by the traction motor to offset fuel use. In addition, the "full" hybrid variants offer greater regenerative braking capability, as well as the ability to shut the engine off during vehicle idle periods. One important observation is that the Meritor DMHP was shown to be equivalent, or in some cases, slightly less efficient than the "full" pre-transmission case. This certainly has cost implications when considering the complexity of the Meritor DMHP as compared to the "full" pre-transmission variant. However, it should be pointed out that the "full" pre-transmission variant is a hypothetical case scenario, and does not represent any product that is currently on the road.

Table 5 Fuel economy improvement summary (ref. conventional baseline)

\begin{tabular}{|c|c|c|c|c|c|c|c|c|c|c|c|c|}
\hline \multirow[b]{2}{*}{ Case } & \multirow[b]{2}{*}{$\begin{array}{l}\text { Hybrid- } \\
\text { ization }\end{array}$} & \multirow[b]{2}{*}{ HEV Concept } & \multirow[b]{2}{*}{ Battery } & \multirow[b]{2}{*}{ Accessories } & \multicolumn{4}{|c|}{ Urban/Suburban Drive Cycles } & \multicolumn{4}{|c|}{ Highway Drive Cycles } \\
\hline & & & & & CSHVR & $\begin{array}{l}\text { udds_ } \\
\text { truck }\end{array}$ & $\begin{array}{c}\text { CSHVR } \\
\text { (1/2 load) }\end{array}$ & $\begin{array}{c}\text { udds_ } \\
\text { truck } \\
\text { (1/2 load) }\end{array}$ & HHDDT65 & $\begin{array}{c}\text { HHDDT65 } \\
\text { (1/2 load) }\end{array}$ & $\begin{array}{c}\text { HTDC } \\
\text { NASHVILLE } \\
\text { KNOXVILLE }\end{array}$ & $\begin{array}{c}\text { HTDC } \\
\text { STARKVILLE } \\
\text { DANVILLE }\end{array}$ \\
\hline $1 \mathrm{~B}$ & Mild & Parallel Pre-Trans. & $5 \mathrm{kWh}$ & Electrical & $19.7 \%$ & $17.3 \%$ & $26.8 \%$ & $24.6 \%$ & $5.0 \%$ & $4.7 \%$ & $6.4 \%$ & $5.6 \%$ \\
\hline $1 \mathrm{~A}$ & Mild & Parallel Pre-Trans. & $5 \mathrm{kWh}$ & Mechanical & $17.5 \%$ & $14.9 \%$ & $23.3 \%$ & $20.8 \%$ & $4.0 \%$ & $4.0 \%$ & $5.6 \%$ & $5.2 \%$ \\
\hline $4 \mathrm{~F}$ & Mild & eAxle, 5.29 Ratio & $5 \mathrm{kWh}$ & Mechanical & $17.2 \%$ & $14.9 \%$ & $23.3 \%$ & $19.2 \%$ & $4.0 \%$ & $4.0 \%$ & $5.6 \%$ & $5.8 \%$ \\
\hline $2 B$ & Medium & Parallel Pre-Trans. & $5 \mathrm{kWh}$ & Electrical & $28.3 \%$ & $24.1 \%$ & $38.1 \%$ & $32.6 \%$ & $6.2 \%$ & $5.8 \%$ & $7.5 \%$ & $7.1 \%$ \\
\hline $2 A$ & Medium & Parallel Pre-Trans. & $5 \mathrm{kWh}$ & Mechanical & $24.3 \%$ & $20.5 \%$ & $31.4 \%$ & $25.4 \%$ & $5.2 \%$ & $4.7 \%$ & $6.7 \%$ & $6.5 \%$ \\
\hline $4 D$ & Medium & eAxle, 2.64 Ratio & $5 \mathrm{kWh}$ & Mechanical & $14.5 \%$ & $12.2 \%$ & $19.7 \%$ & $16.7 \%$ & $4.2 \%$ & $3.8 \%$ & $6.4 \%$ & $6.5 \%$ \\
\hline $4 \mathrm{~B}$ & Medium & eAxle, 4.11 Ratio & $5 \mathrm{kWh}$ & Mechanical & $20.6 \%$ & $13.8 \%$ & $26.5 \%$ & $21.4 \%$ & $4.7 \%$ & $4.3 \%$ & $6.4 \%$ & $6.7 \%$ \\
\hline $4 \mathrm{~A}$ & Medium & eAxle, 5.29 Ratio & $5 \mathrm{kWh}$ & Mechanical & $24.9 \%$ & $17.3 \%$ & $32.4 \%$ & $25.7 \%$ & $4.7 \%$ & $4.4 \%$ & $6.2 \%$ & $6.7 \%$ \\
\hline $4 C$ & Medium & eAxle, 7.17 Ratio & $5 \mathrm{kWh}$ & Mechanical & $28.6 \%$ & $18.6 \%$ & $37.6 \%$ & $27.2 \%$ & $4.5 \%$ & $4.3 \%$ & $5.4 \%$ & $6.2 \%$ \\
\hline $3 A$ & Full & Parallel Pre-Trans. & $10 \mathrm{kWh}$ & Electrical & $48.0 \%$ & $40.3 \%$ & $60.9 \%$ & $48.9 \%$ & $8.2 \%$ & $7.2 \%$ & $10.7 \%$ & $10.4 \%$ \\
\hline $5 C$ & Full & Dual Mode Gen 3 & $10 \mathrm{kWh}$ & Electrical & $43.4 \%$ & $31.9 \%$ & $57.5 \%$ & $39.7 \%$ & $7.4 \%$ & $6.9 \%$ & $9.9 \%$ & $9.9 \%$ \\
\hline $4 E$ & Full & eAxle, 5.29 Ratio & $10 \mathrm{kWh}$ & Mechanical & $43.4 \%$ & $30.3 \%$ & $55.0 \%$ & $38.8 \%$ & $6.2 \%$ & $5.5 \%$ & $8.8 \%$ & $9.1 \%$ \\
\hline $3 B$ & Full & Parallel Pre-Trans. & $20 \mathrm{kWh}$ & Electrical & $53.8 \%$ & $44.6 \%$ & $67.3 \%$ & $53.8 \%$ & $8.5 \%$ & $7.7 \%$ & $11.8 \%$ & $11.4 \%$ \\
\hline $5 \mathrm{~A}$ & Full & Dual Mode Gen 2a & $20 \mathrm{kWh}$ & Electrical & $68.9 \%$ & $43.0 \%$ & $74.9 \%$ & $52.0 \%$ & $8.0 \%$ & $7.5 \%$ & $11.4 \%$ & $11.4 \%$ \\
\hline $5 B$ & Full & Dual Mode Gen 3 & $20 \mathrm{kWh}$ & Electrical & $67.1 \%$ & $43.2 \%$ & $71.3 \%$ & $50.7 \%$ & $8.2 \%$ & $7.5 \%$ & $12.0 \%$ & $12.3 \%$ \\
\hline
\end{tabular}

\subsubsection{Alternative technology analysis results: “mild/moderate” hybrid baseline}

A more in depth study of the results was conducted, starting with the mild/moderate variants. Figure 23 graphically represents the simulated fuel economy for these cases. As with most hybrid comparisons, the urban drive cycles yield much less fuel economy due to increased vehicle idling. In addition, for these line haul heavy-duty trucks, the final drive ratio is chosen such that the engine operates at or near its most efficient operating region when cruising on the highway around 60-65 MPH. Therefore, these heavy-duty trucks should yield higher fuel economy for over the road drive cycles. Interestingly, the "real world" cycles suggest that the inclusion of grade substantially reduces the fuel economy of these vehicles (recall, these are the only cycles studied that include road grade). The results also suggest that these powertrain 
are reasonable indifferent to over the road drive cycles, due to the fact that each operates in a very similar manner in these conditions.

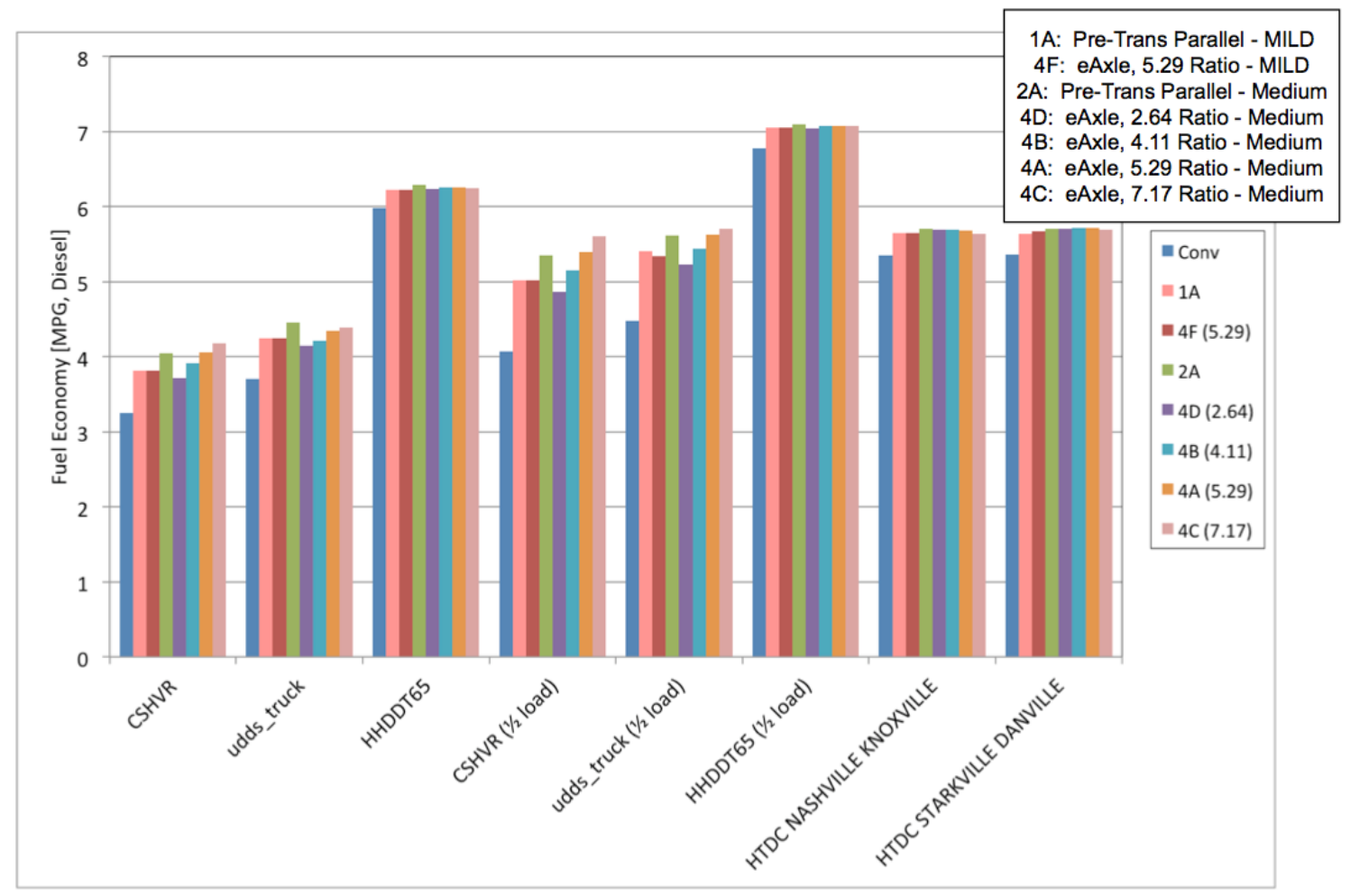

Figure 23 Simulated fuel economy comparison, mild and medium hybrids

Figure 24 represents the fuel economy improvement as compared to the baseline conventional vehicle. Here, we see that even though the simulated fuel economies for the urban cases are much lower, the improvement for these cases is substantially greater. In addition, the results show that the posttransmission (eAxle) powertrain is very sensitive to the selection of the final drive ratio, which is magnified for the urban cases. As for the highway cases for the post transmission, there appears to be a final drive ratio that correlates to an observed maximum fuel economy improvement. The post transmission case with the 7.17 final drive ration provides superior performance, in most cases, to all other variants in this class with the moderate pre-transmission variant a close second. Some general observations for the mild/medium cases are:

- Results indicate that OTR cycles are less sensitive to powertrain configuration and high voltage traction drive size.

- eAxle provides substantial opportunities for fuel economy improvement in urban driving conditions based upon final drive ratio selection.

- A small parametric study of the eAxle for gear ratio indicates 5.29:1 offers a good balance for urban and highway driving 


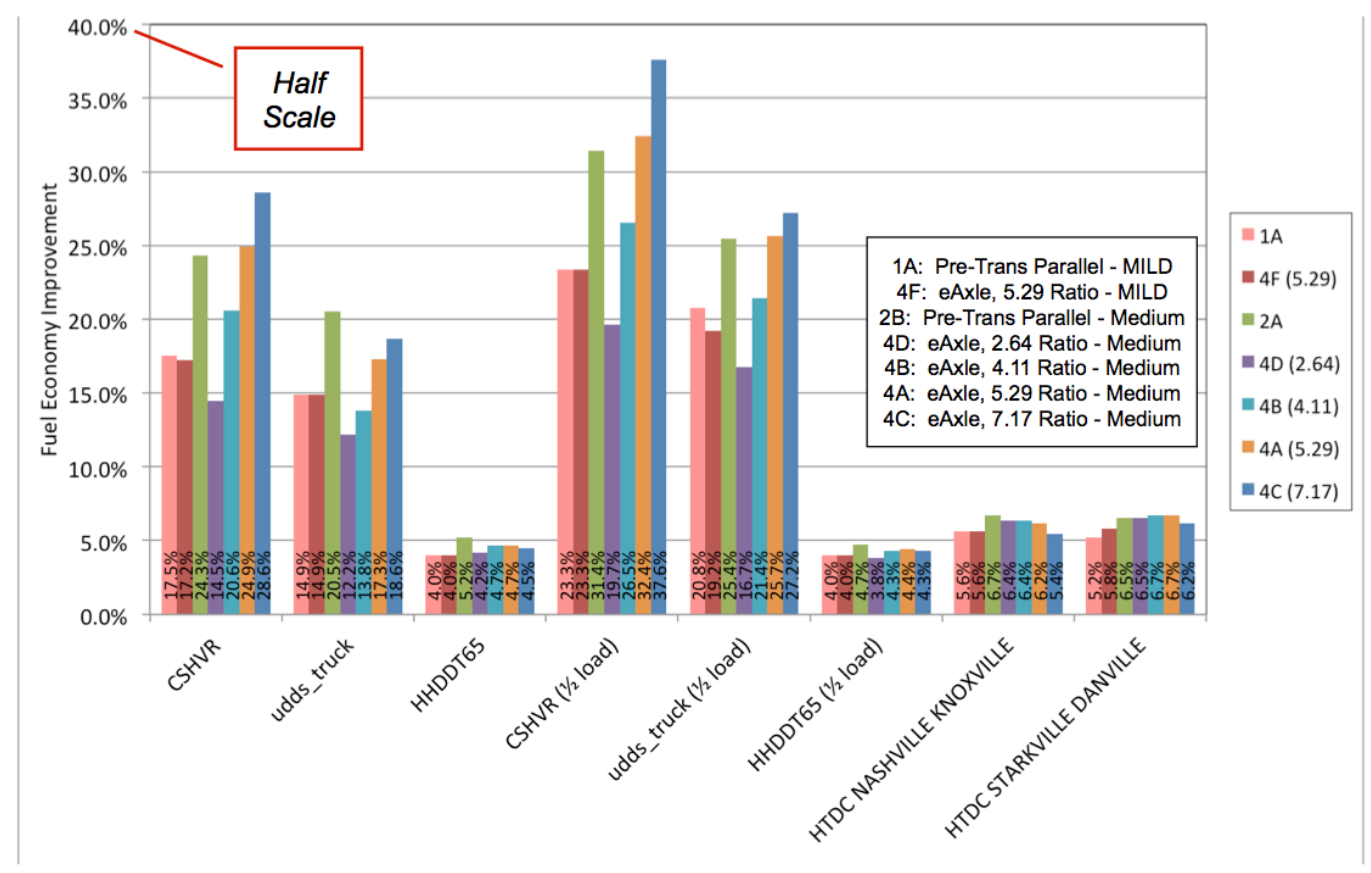

Figure 24 Simulated fuel economy improvement (ref. conventional baseline) for mild and medium hybrids

In order to gain a better understanding of the final drive ratio selection for the post-transmission (eAxle), a short parametric study was done, based upon the overall results of the alternative technology analysis. Figure 25 represents the results of this quick parametric study. For highway cycles, an optimum final drive ratio was found to be between 4.0:1 and 5.0:1 for all highway cycles considered. As for the urban cycles, an optimum final drive ratio is projected to be around 8.0:1 to 8.5:1. To verify this, the average vehicle speed for each cycle was calculated, and the optimum final drive ratio was computed based upon operating the engine at its most efficient speed ( 1350 RPM). The results agree reasonable well to the simulated fuel economy improvements observed from the study.

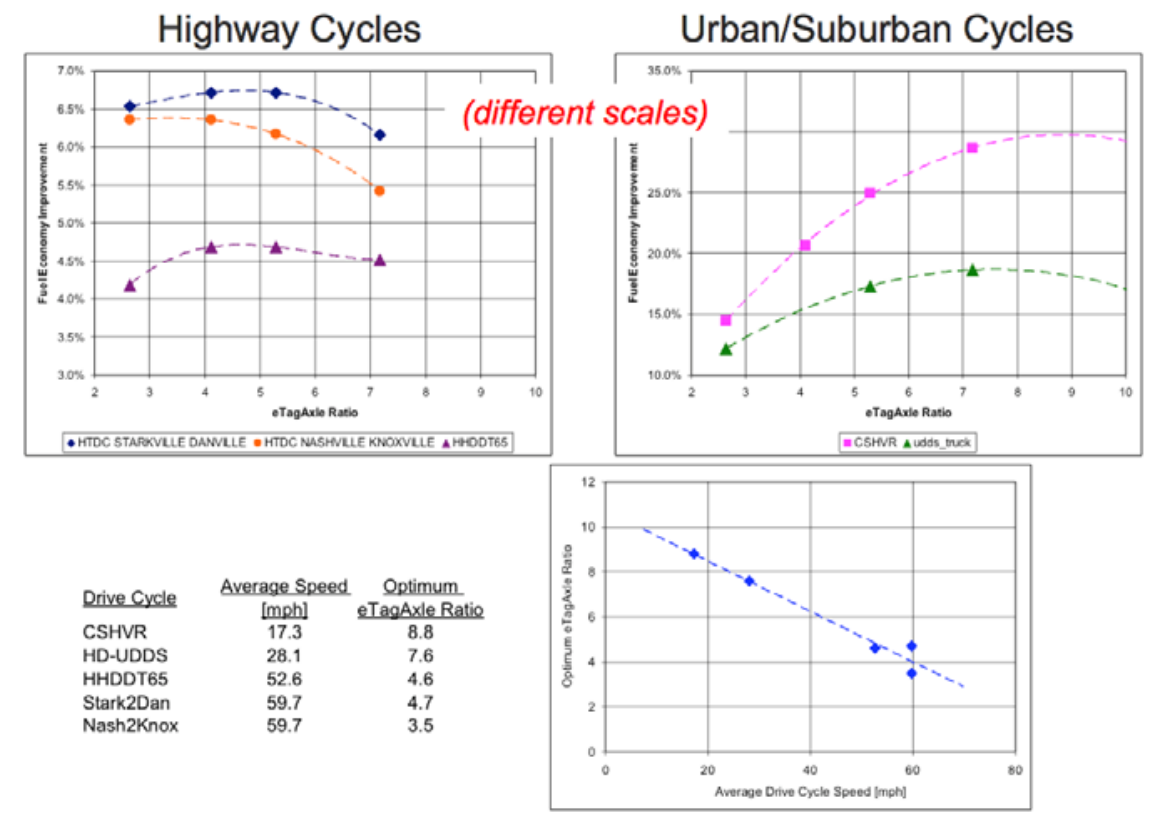

Figure 25 Parametric study results for eAxle final drive ratios 


\subsubsection{Alternative technology analysis results: “full” hybrid baseline}

The full hybrids were examined in greater detail. This includes the Meritor DMHP system along with its component variants. The "full" variants that offered the greatest potential were those with the larger battery pack. Figures 26 and 27 represents the simulated fuel economy and the simulated fuel economy improvement results for the pre-transmission and Meritor DMHP variants utilizing the larger battery, respectively. Clearly, when considering overall operation for all drive cycles, each powertrain architecture performs in a like manner.

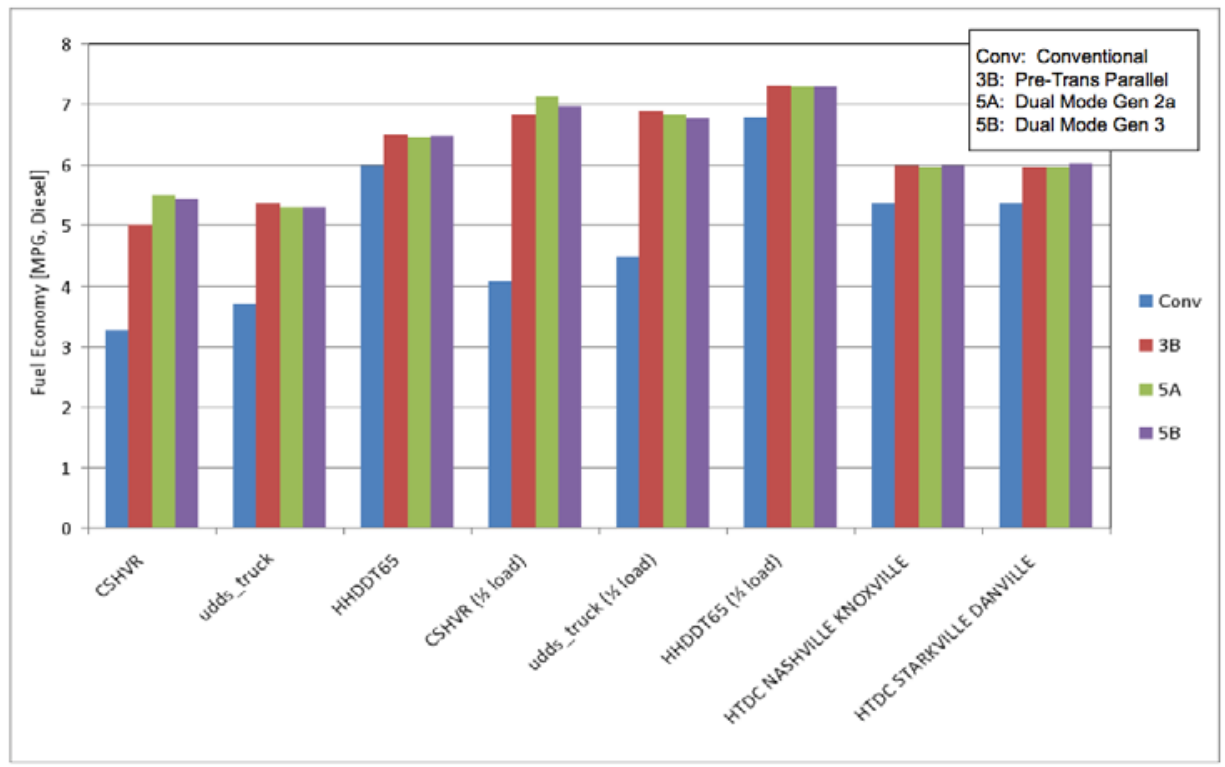

Figure 26 Fuel economy comparison, Full hybrids with larger battery

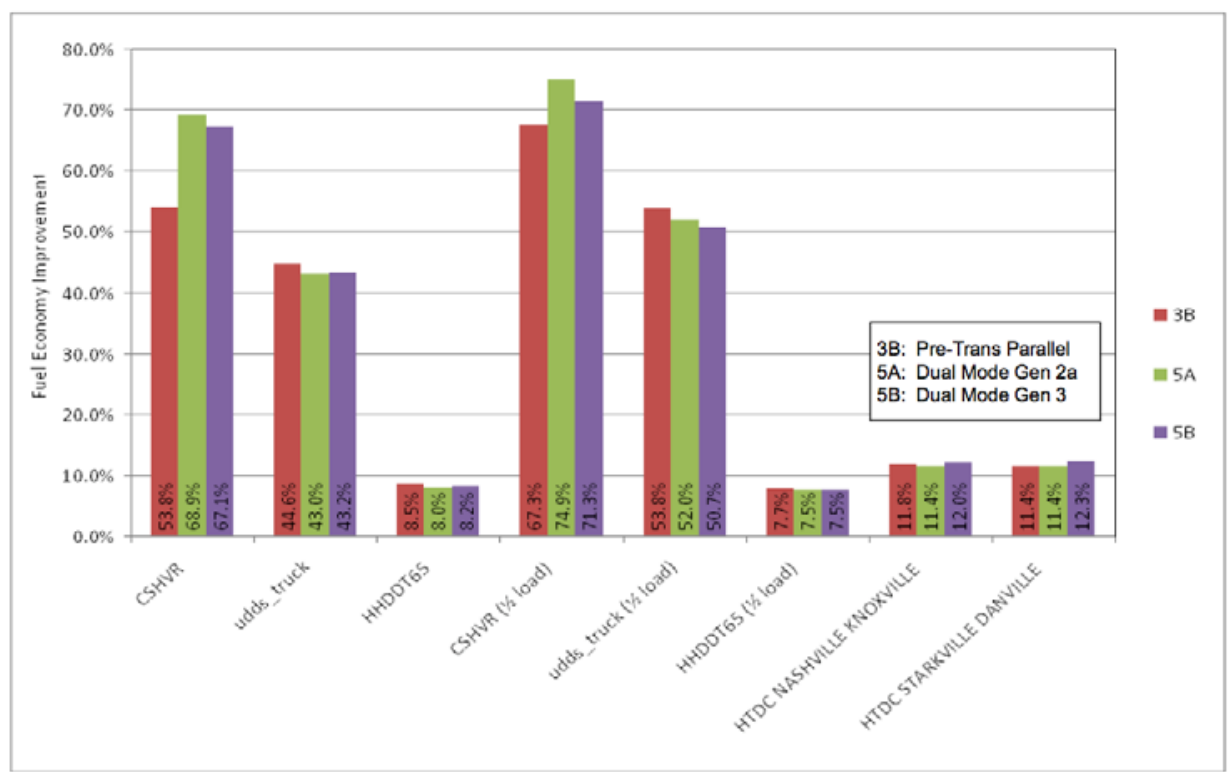

Figure 27 Fuel economy improvement, “full” hybrids baseline (with larger battery) 
However, closer scrutiny of the data yields some interesting characteristics. When determining the validity of the simulated fuel economy, the ability of the powertrain to follow the prescribed drive cycle must be addressed. Figure 28 illustrates a comparison of the actual (simulated) vehicle speed achieved by the vehicles to the desired vehicle speed. Clearly, the pre-transmission does not perform as well as the Meritor DMHP for this example, particularly at lower vehicle speeds. The Meritor DMHP provides superior performance while the pre-transmission has difficulty meeting the drive trace at these lower speeds due primarily to shifting. This leads to a misrepresentation of the predicted fuel economy for the pre-transmission case.

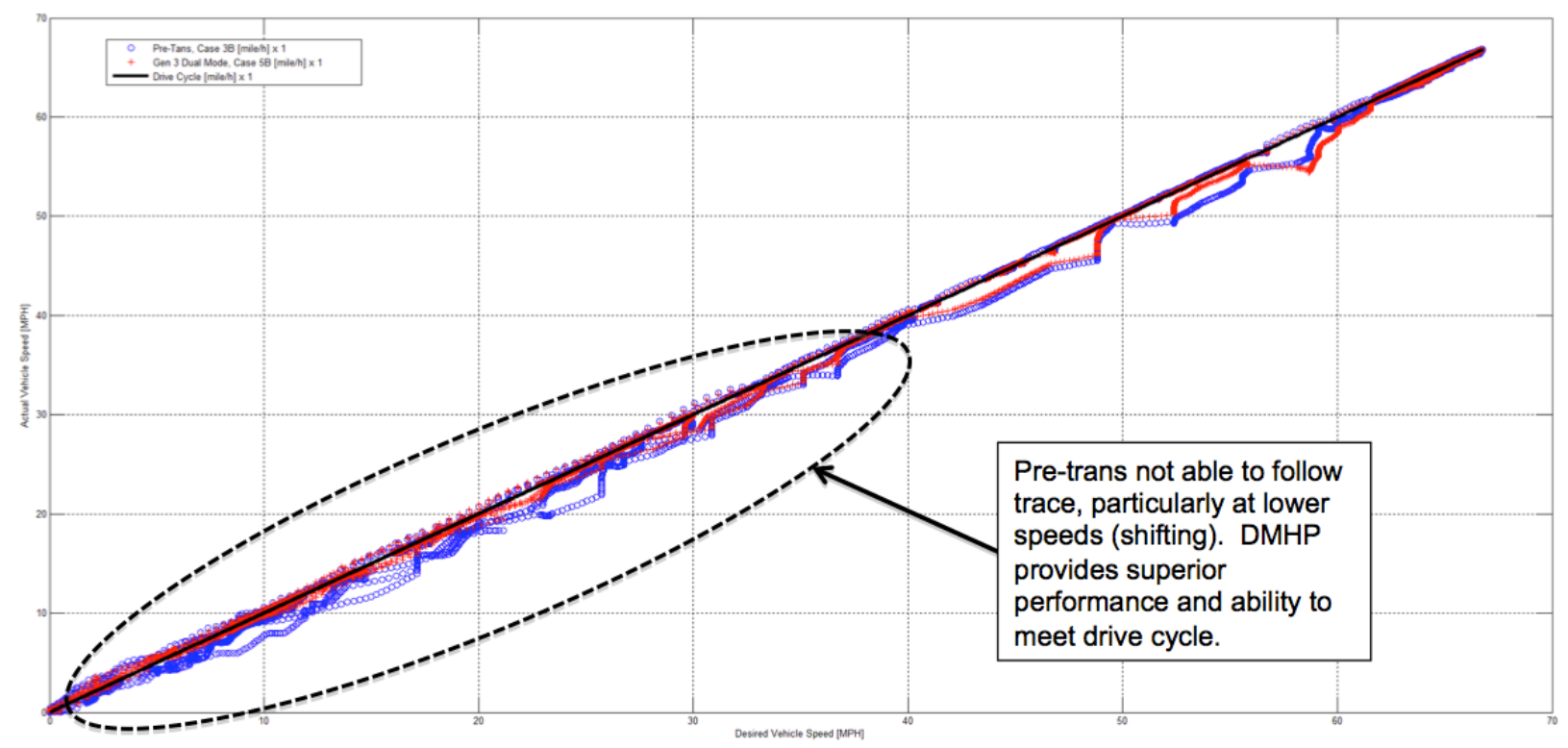

Figure 28 Comparison of drive cycle performance for full hybrids with large battery

To get a better understanding of how each powertrain operates, the actual operating envelope of the engine was examined. Figure 29 illustrates density plots for how the engine actually operated for the case of the fully loaded vehicle traversing the HHDDT65 drive cycle. Here, it becomes evident that the engine operates predominantly in its most efficient operating region for the entire drive cycle for the Meritor DMHP due to series HEV operation, while the pre-transmission case shows operation in lower efficiency regions due to shifting and vehicle/engine speed constraints.

Some general "full” hybrid observations with the larger battery are:

- Pre-trans case appears favorable over the DMHP over some drive cycles, but further investigation into the data reveals this may not be accurate.

- DMHP provides superior performance and has no difficulty following the prescribed drive cycle very closely.

- The Pre-trans case is not able to follow the drive cycle as closely, due primarily to transmission shifting. Hence, the results can be misleading since the vehicle is not travelling the same distance when compared to the DMHP.

- $\quad$ The engine loading over the (representative over the road) HHDDT65 suggests the Pre-trans does not operate as efficiently as the DMHP. 


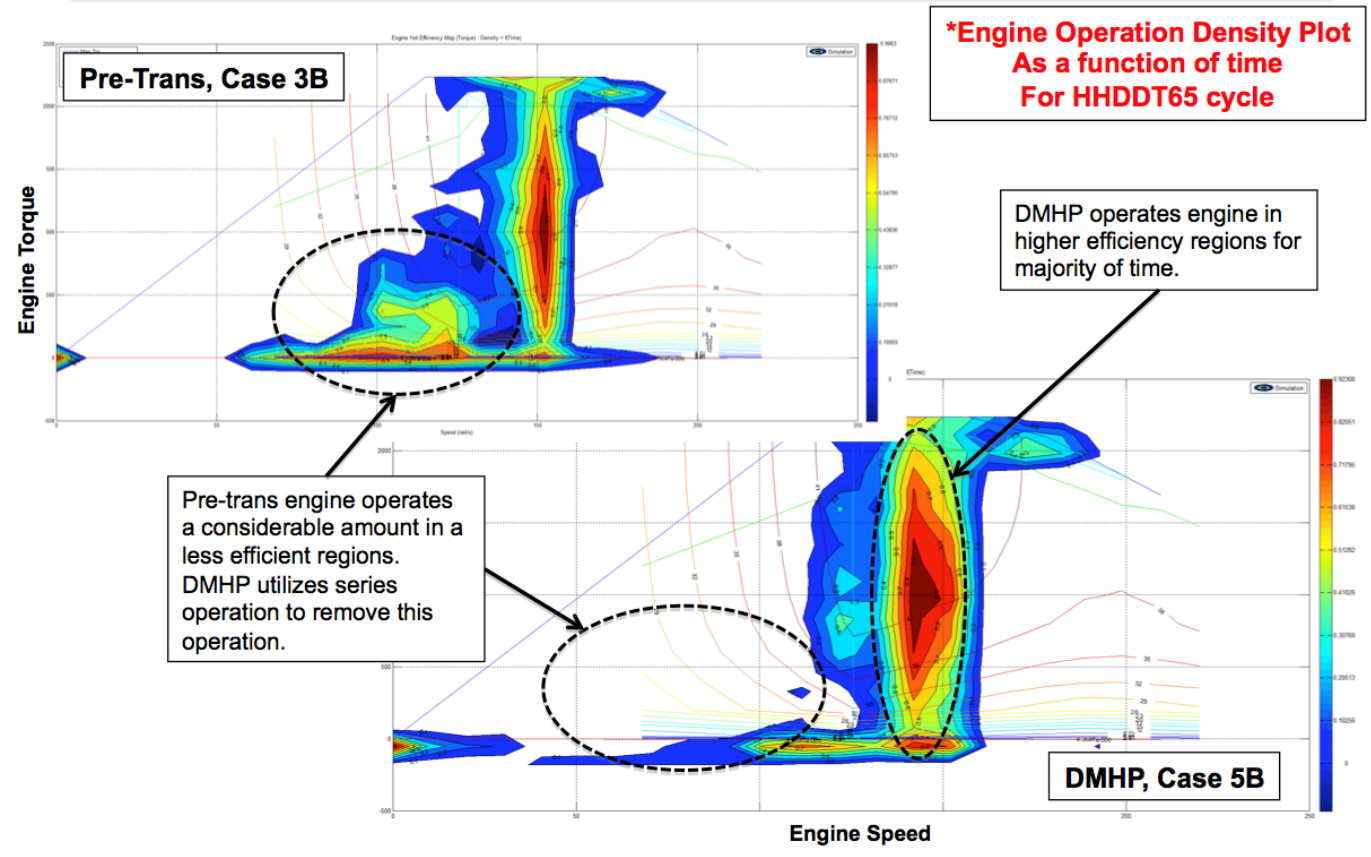

Figure 29 Engine operation comparison for full pre-transmissions parallel hybrid versus DMHP

\subsubsection{Alternative technology analysis results: effects of battery sizing}

One important aspect of the study was to understand the impact of battery sizing of overall fuel economy improvement. The physical size of the battery directly impacts the overall cost of the hybrid system, and perhaps can be the single most expensive component in the hybrid powertrain. The "full" hybrid powertrain variants were subjected to a smaller battery pack, which would, in theory, lead to a reduced cost of the system. However, this cost savings might come at the expense of system efficiency (fuel economy), as well as reduced capacity for anti-idling. Figure 30 illustrates the simulated fuel economy for the "full" hybrid powertrain variant with a reduced capacity battery pack. When compared to earlier results (Figure 27), the reduced energy storage capacity leads to a fuel efficiency reduction across the board ranging from $\sim 1.5 \%$ (for the "real-world" cycles) up to as much as $20 \%$ (urban cycles).

Figure 31 graphically depicts a comparison for the Meritor DMHP when considering the standard and reduced capacity battery options. For the urban drive cycles, there is a substantial penalty in fuel efficiency improvement of approximately $20 \%$. For the highway cycles, the variation is much smaller on the order of $\sim 0.5 \%$ for the "standard" HHDDT65 cycle to $\sim 2 \%$ for the "real-world" cycles. The additional $1.5 \%$ between the standard and "real-world" drive cycles can be attributed to compounded effects due to road grade (reduced regenerative braking capability). Figure 32 illustrates this point further by showing that the reduced energy storage capacity results in a lower charge power limitation. This effectively reduces the regenerative braking capability. During most braking events, there is a moderate to heavy loss in potential braking energy that could be captured and stored in the battery pack for future use. 


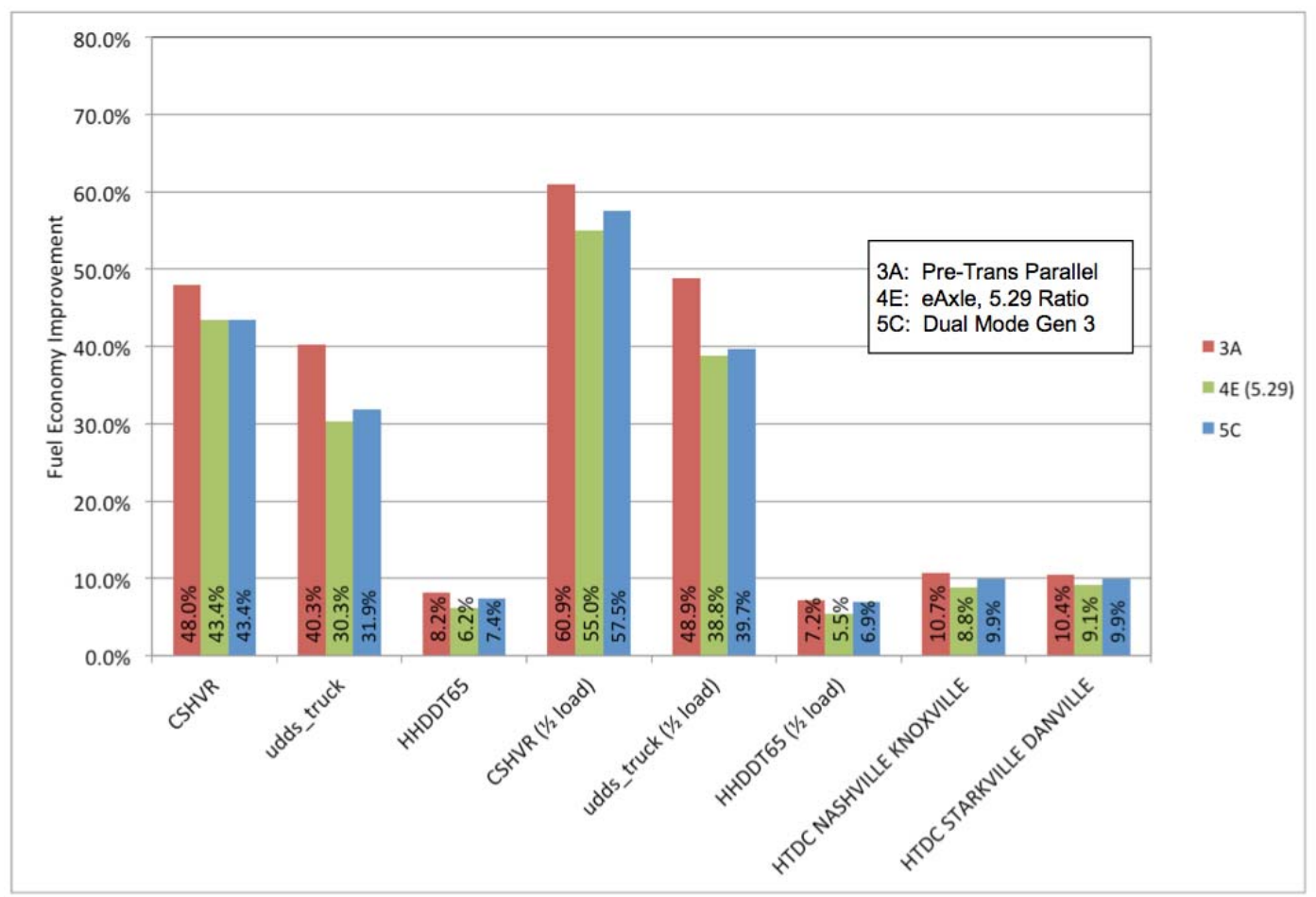

Figure 30 Simulated fuel economy improvement (ref. conventional baseline), full hybrids with small battery (700V)

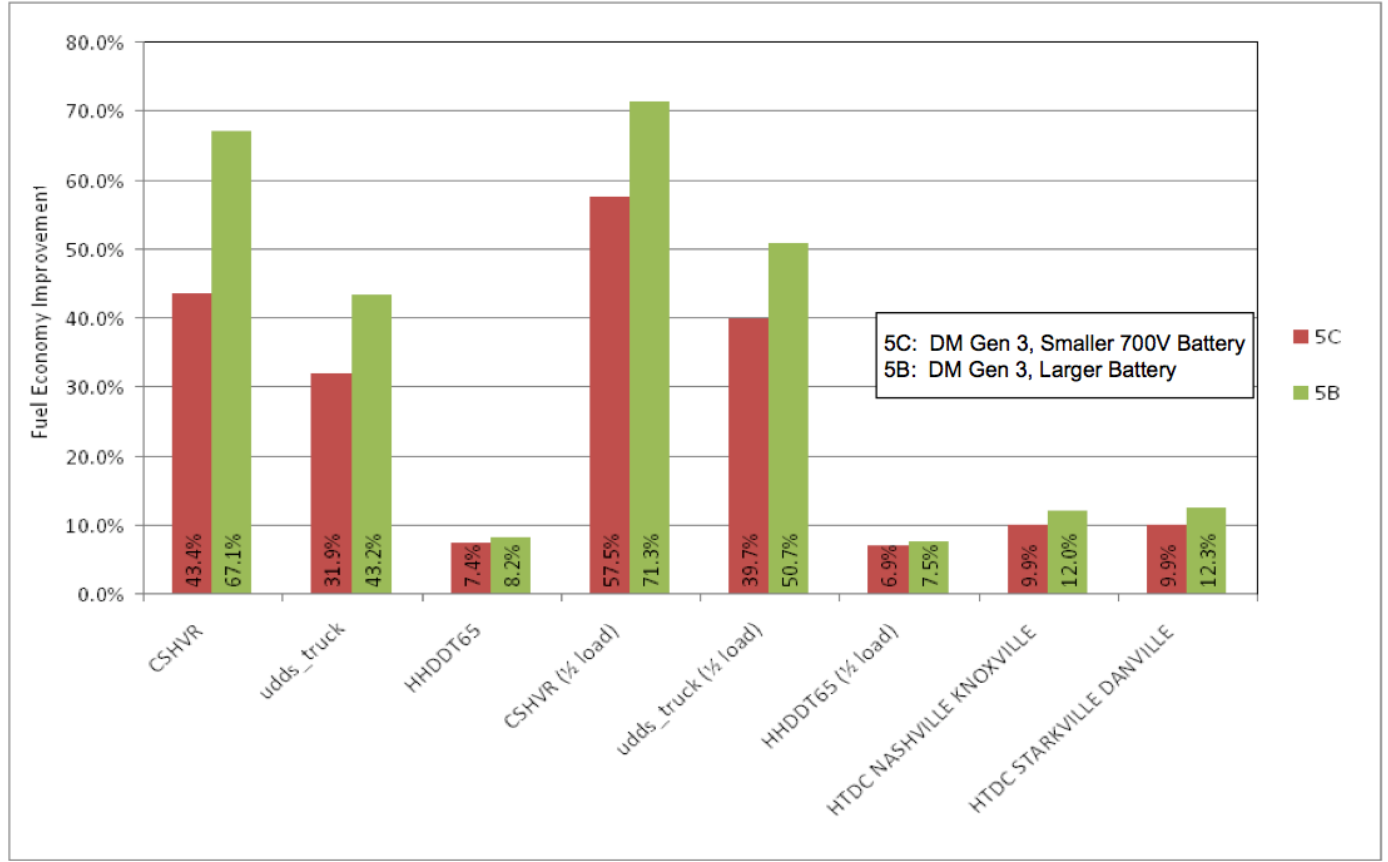

Figure 31 DMHP battery size simulated fuel economy improvement comparison 


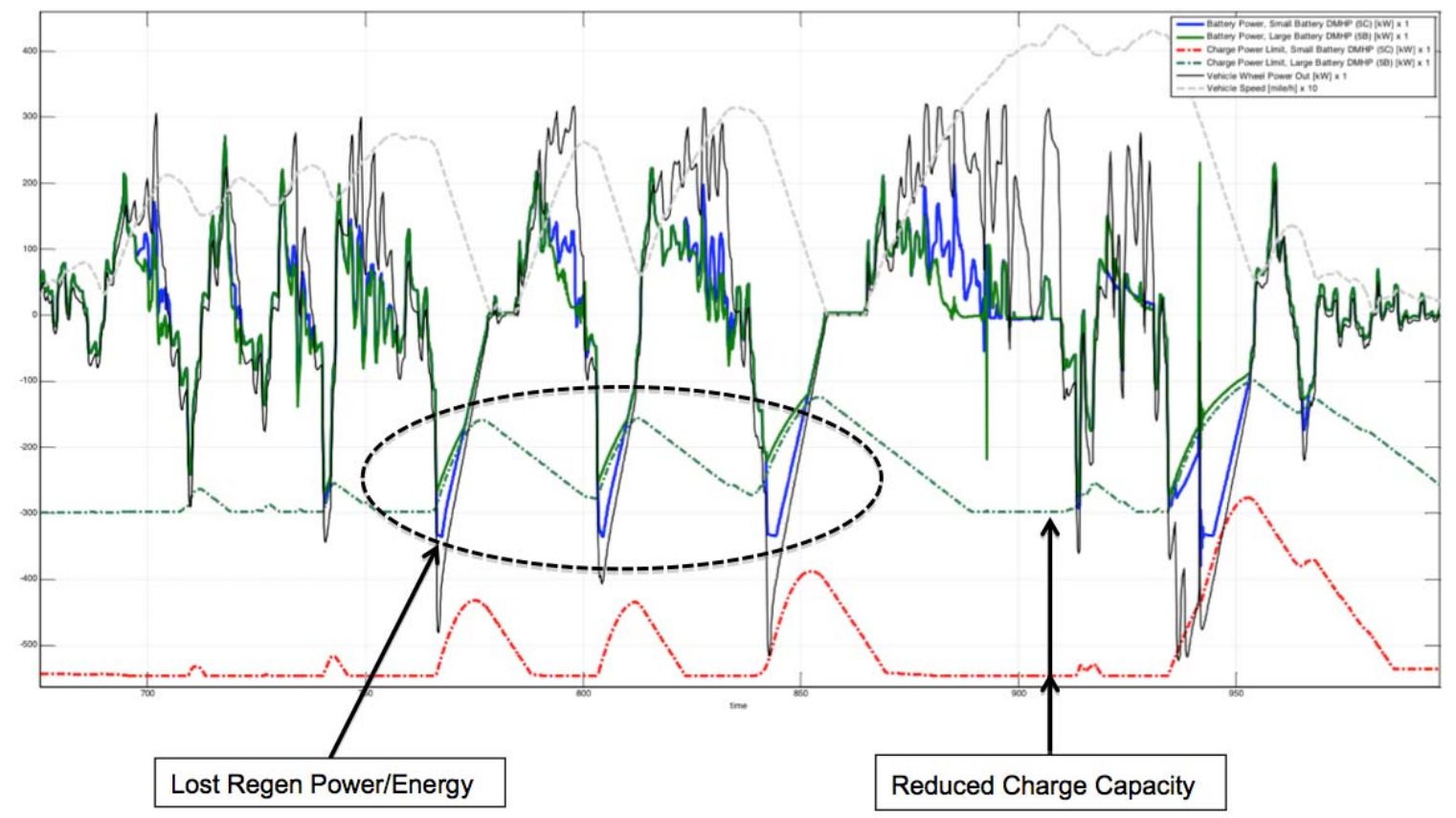

Figure 32 Battery size performance considerations for DMHP

Figure 33 presents a battery sizing comparison for the "full" pre-transmission powertrain variant. While a performance degradation is evident (maximum of $\sim 5 \%$ ), the data suggests the pre-transmission

powertrain is less sensitive to battery size than the Meritor system. As shown in Figure 34, this is not due to battery pack charge limitations, but due to traction motor torque capabilities at higher speeds. The traction motor simply cannot absorb as much torque. However, this only happens a handful of times, such that the performance degradation is minimal.

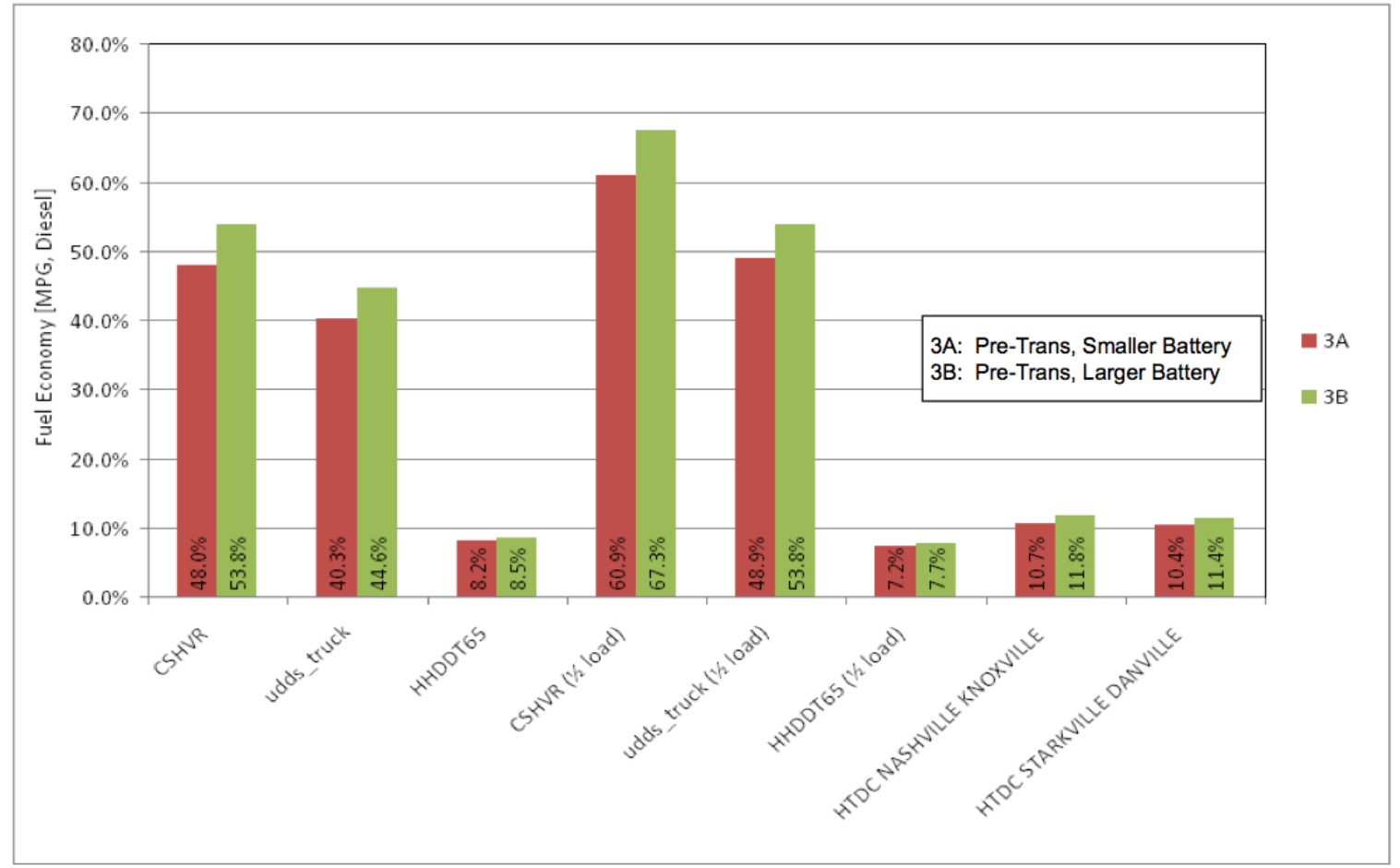

Figure 33 Fuel economy improvement comparison for pre-transmission hybrids based on battery size 


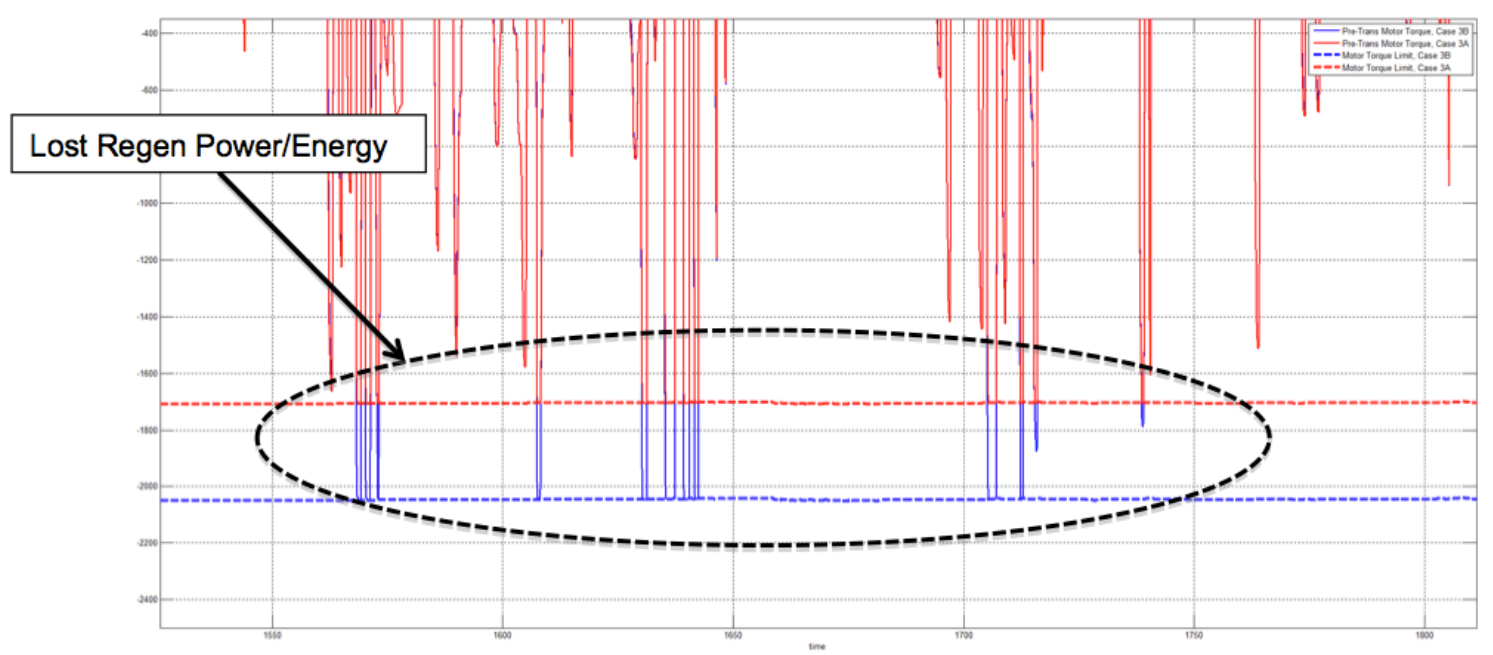

Figure 34 Effect of motor torque/speed limitations on pre-transmission hybrids

To summarize, here are some general observation related to battery sizing effects:

- DMHP battery size observations

- Effects of battery size are larger in the DMHP case. Better representation of effect of smaller ESS since electric machine constraints have no impact.

○ Regenerative braking capability in this case is a function of ESS limitation, not electric machine limitation

- Pre-transmission battery size observations

- Effects of battery size are smaller in the pre-trans case due to smaller electric motor used for smaller ESS case

- Regenerative braking capability in this case is a function of motor limitation, not ESS limitation

\subsubsection{Alternative technology analysis results: general observations}

This section presents some general findings observed during the study. Figure 35 presents the effects of anti-idling and electrified accessories for the "mild/moderate" pre-transmission powertrain variants. Antiidling plays a dominant role in fuel economy improvement for the urban drive cycles, with virtually no impact on highway cycles. Anti-idling, coupled with electrified accessories offers up to $4 \%$ fuel economy improvement. Electrified accessories afford a mild increase in fuel economy improvement (on the order of about 1\%) based upon these simulations and the assumptions of the analysis. It should be noted that these results are based upon the small, lower voltage energy storage system. The effects of anti-idling (enabled by electrified accessories) are much more substantial for the full hybrids with larger energy storage capacity. 


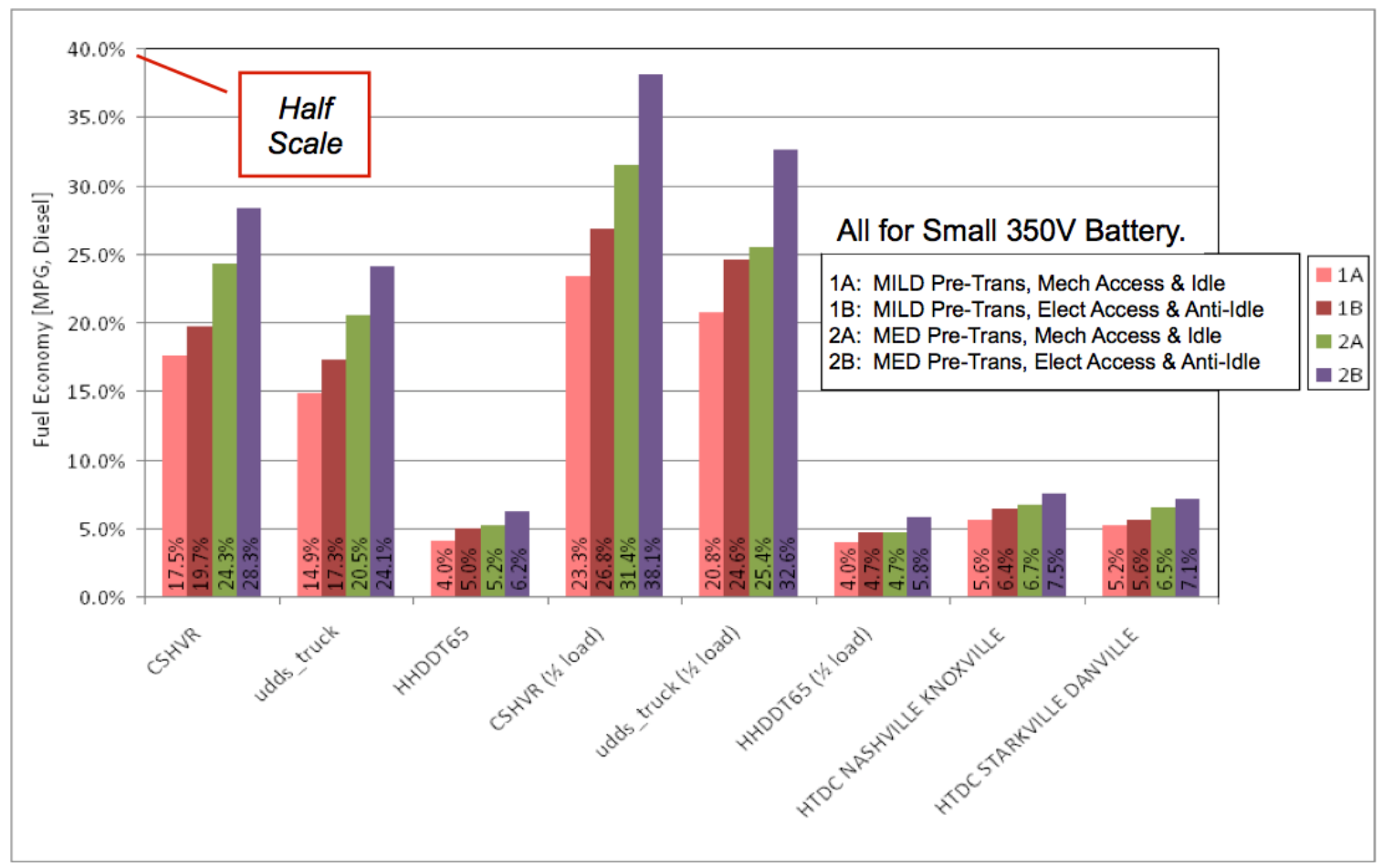

Figure 35 Fuel economy improvement considering electrical accessories and anti-idle impacts

Revisiting the energy storage system capacity comparison ("small” vs. "large”), the rate of decay of the state of charge is clearly much faster, even during idle periods where the only load on the high voltage system is from the electrified and low voltage accessories. This is shown clearly in Figure 36, comparing the Meritor DMHP with both "small” and "large" energy storage systems. In addition, the SOC fluctuates much faster during traction events (motoring and braking).

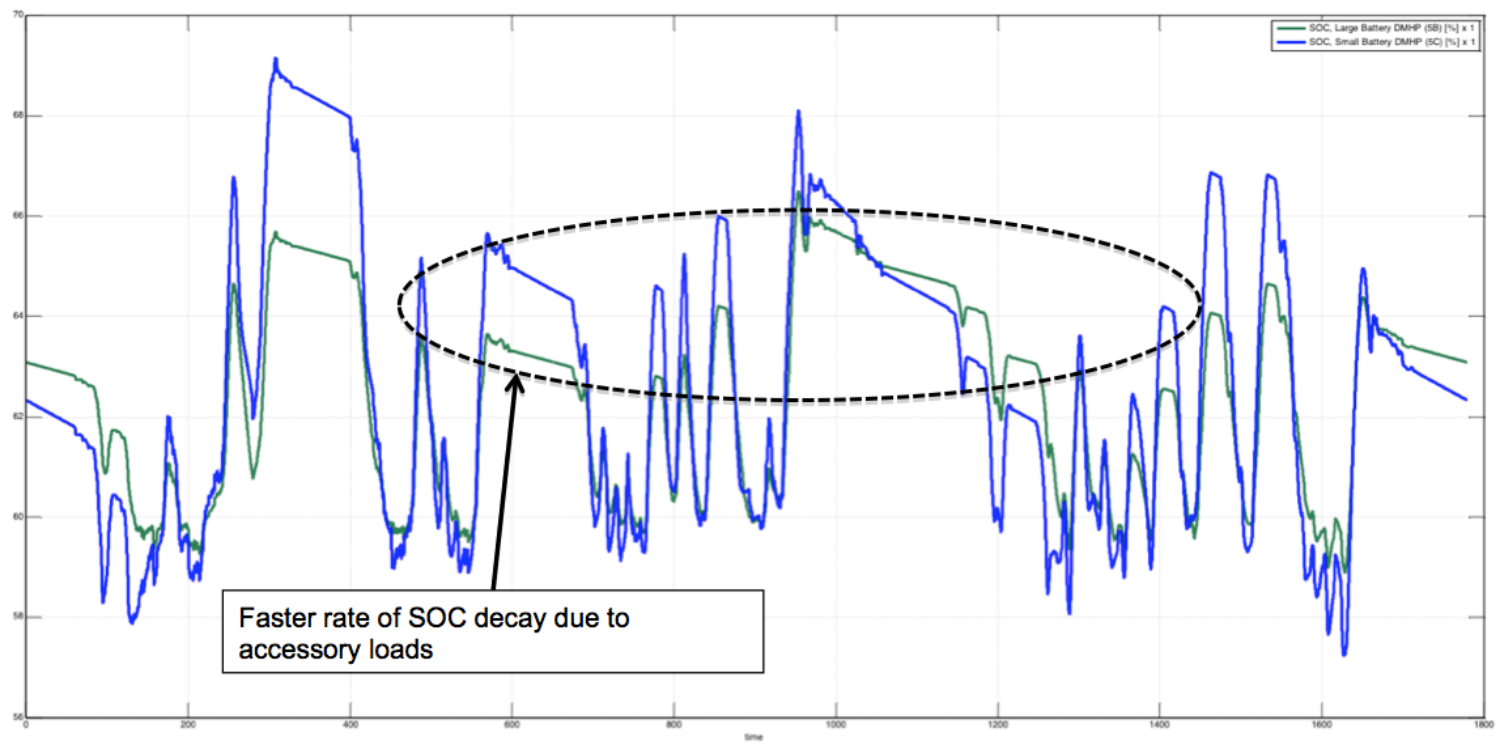

Figure 36 SOC decay rates for small and large batteries 
Another observation involved motor efficiency differences between the post-transmission and pretransmission powertrains. Figure 37 provides an excerpt of an urban drive cycle. For very low vehicle speeds, as well as idle conditions, the efficiency of the traction motor in the post-transmission parallel powertrain is substantially less than that of the pre-transmission. However, this is misleading since the motor in the post-transmission is not being used for anything (no idle charging possible with this architecture). At higher vehicle speeds, the traction motor in post-transmission becomes better, at times, than the pre-transmission variant. This is obviously a function of the selected final drive ratio as the wrong ratio (shown in red in the chart) yields much poorer performance.

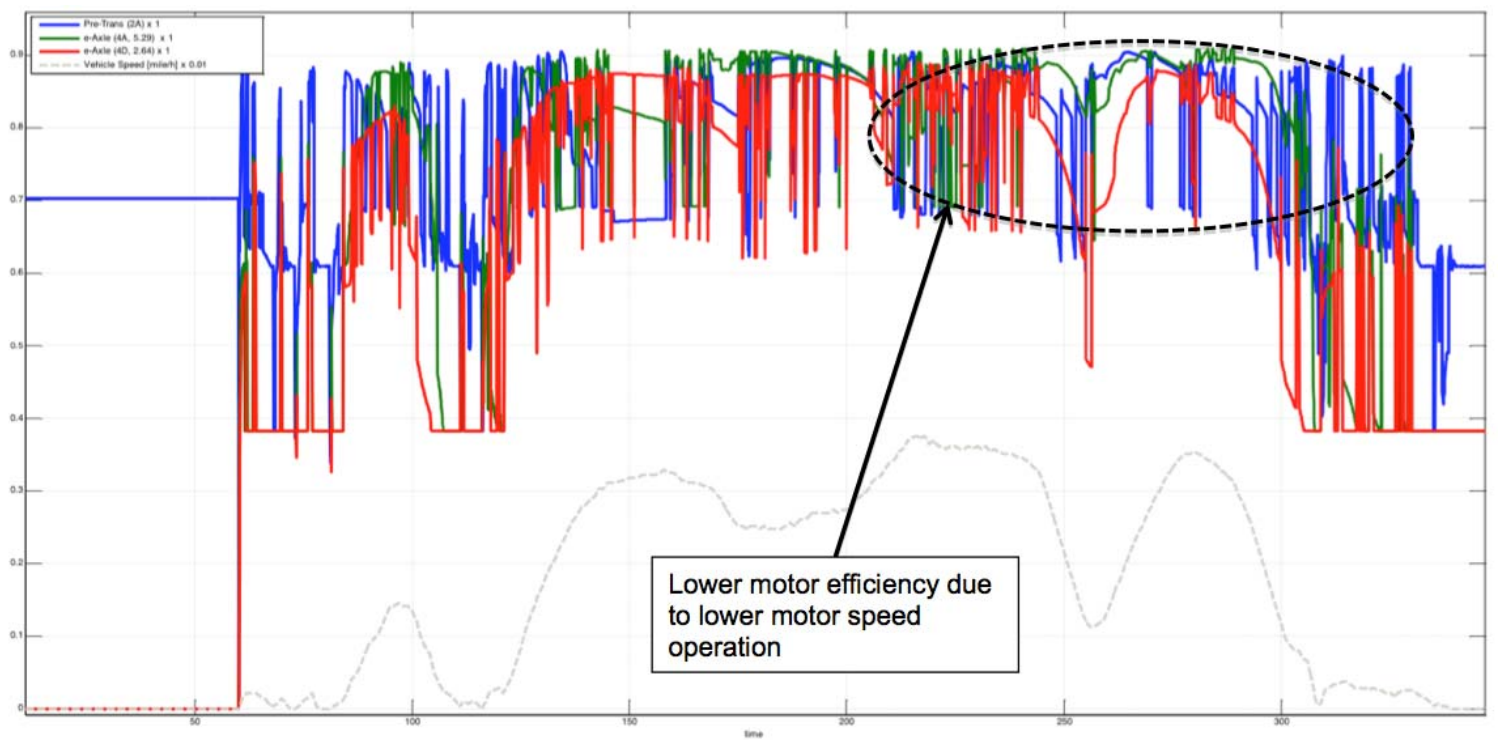

Figure 37 Pre-transmission versus post-transmission motor efficiency

From a general operator experience and performance perspective, the Meritor DMHP is quite superior. Figures 38 and 39 show excerpts of engine speed and torque, respectively, for the Meritor DMHP and the pre-transmission "full” variant. Note the lack of engine shifts and subsequent torque holes the DMHP exhibits versus the pre-transmission. This ultimately leads to, as shown in Figure 40, smooth power delivery and the ability to follow the prescribed speed trace. Due to the torque holes during each shift, the pre-transmission has difficulty adequately following the drive cycle.

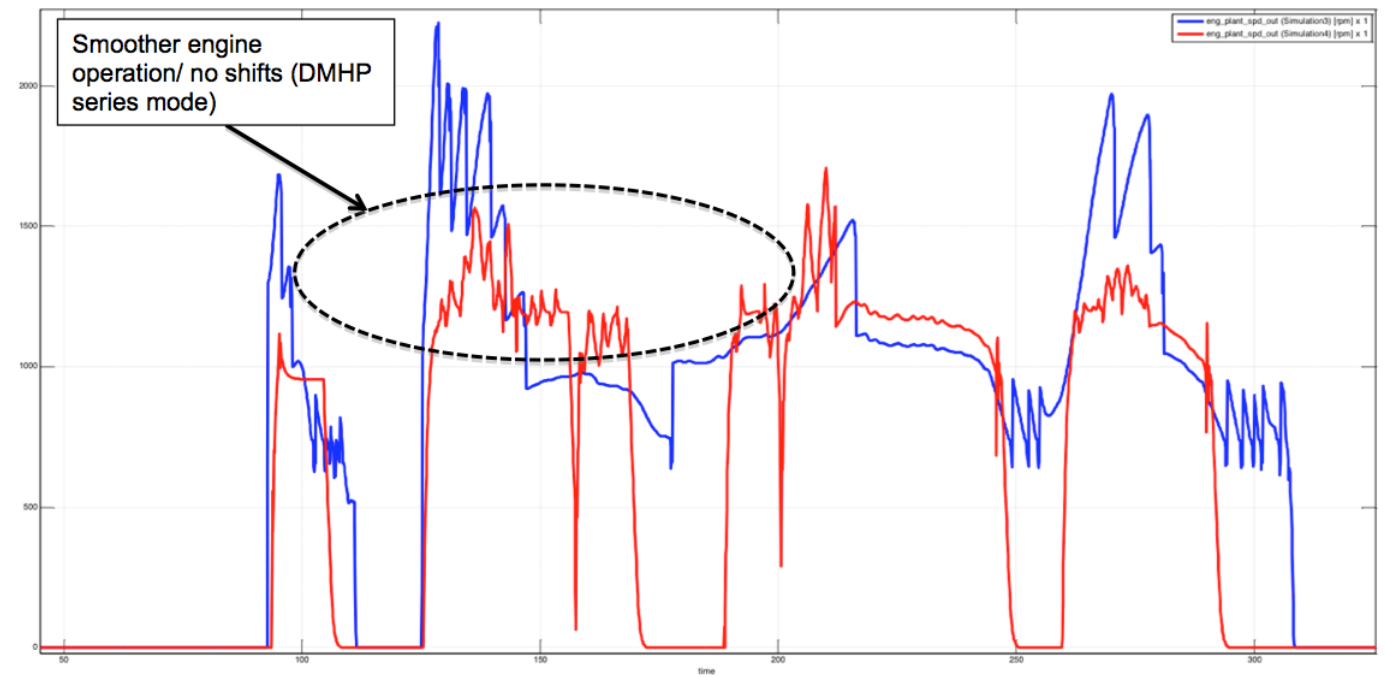

Figure 38 Pre-transmission hybrid versus DMHP engine performance considerations (speed) 


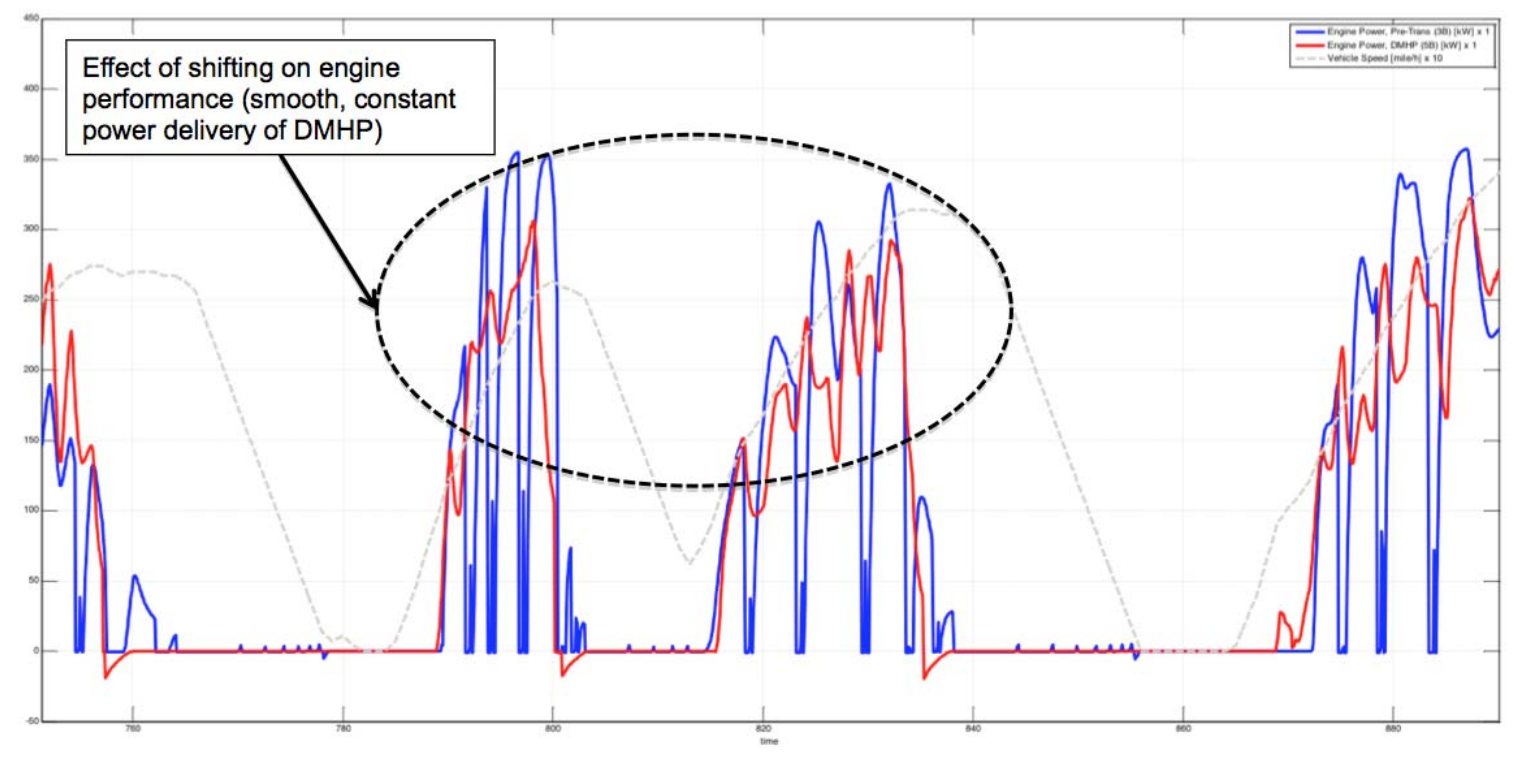

Figure 39 Pre-transmission hybrid versus DMHP engine performance considerations (torque delivery)

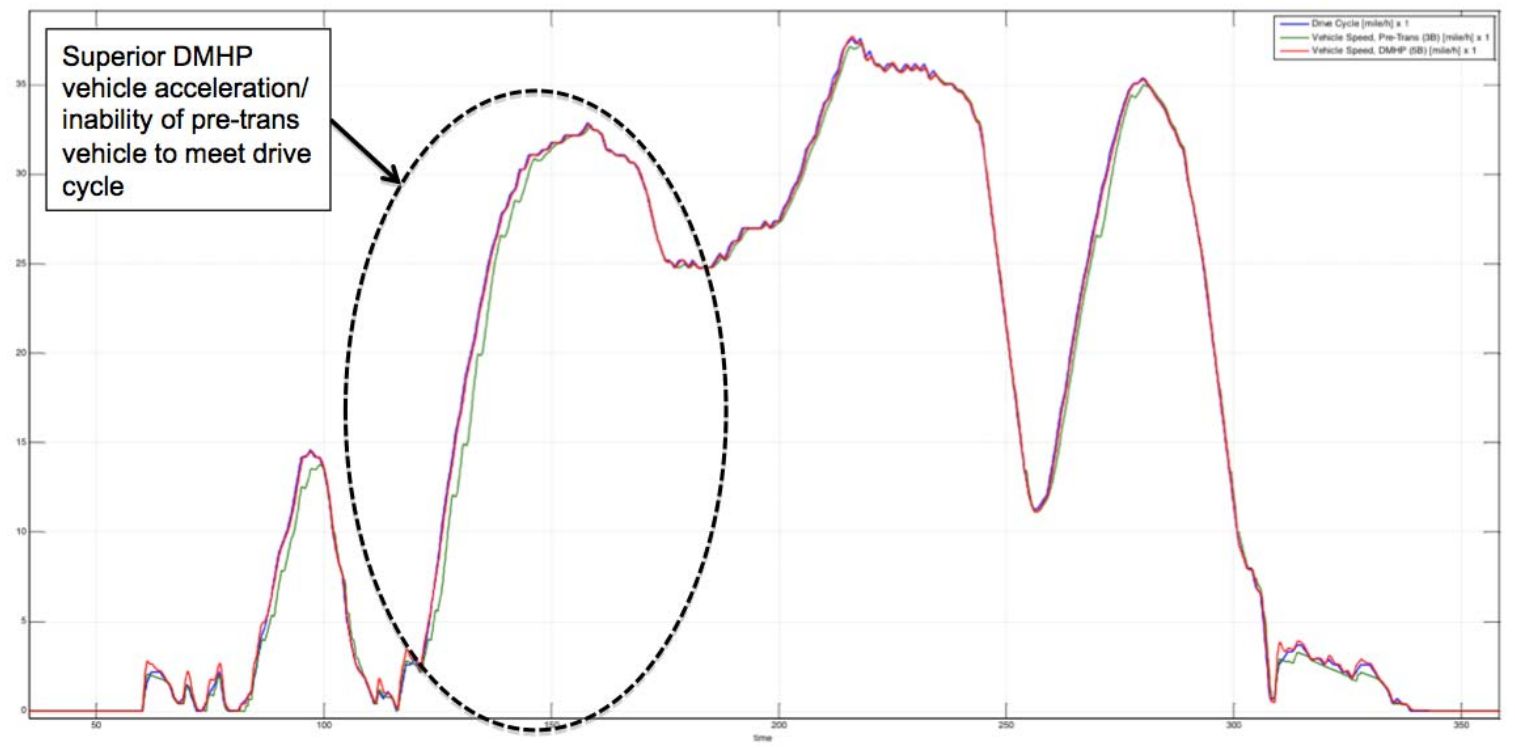

Figure 40 Pre-transmission hybrid versus DMHP vehicle performance considerations 
With respect to regenerative braking, the Meritor DMHP offers superior performance. As shown in Figure 41, the pre-transmission parallel powertrain suffers from the multitude of downshifting during decelerations. During these periods of time, no torque is transmitted from the wheels to the motor, reducing overall regenerative braking abilities for the pre-transmission. In addition, drive quality is less for the pre-transmission as can be seen from the "bumpy" speed trace near the end of each deceleration, this is a characteristic that the operator could feel.

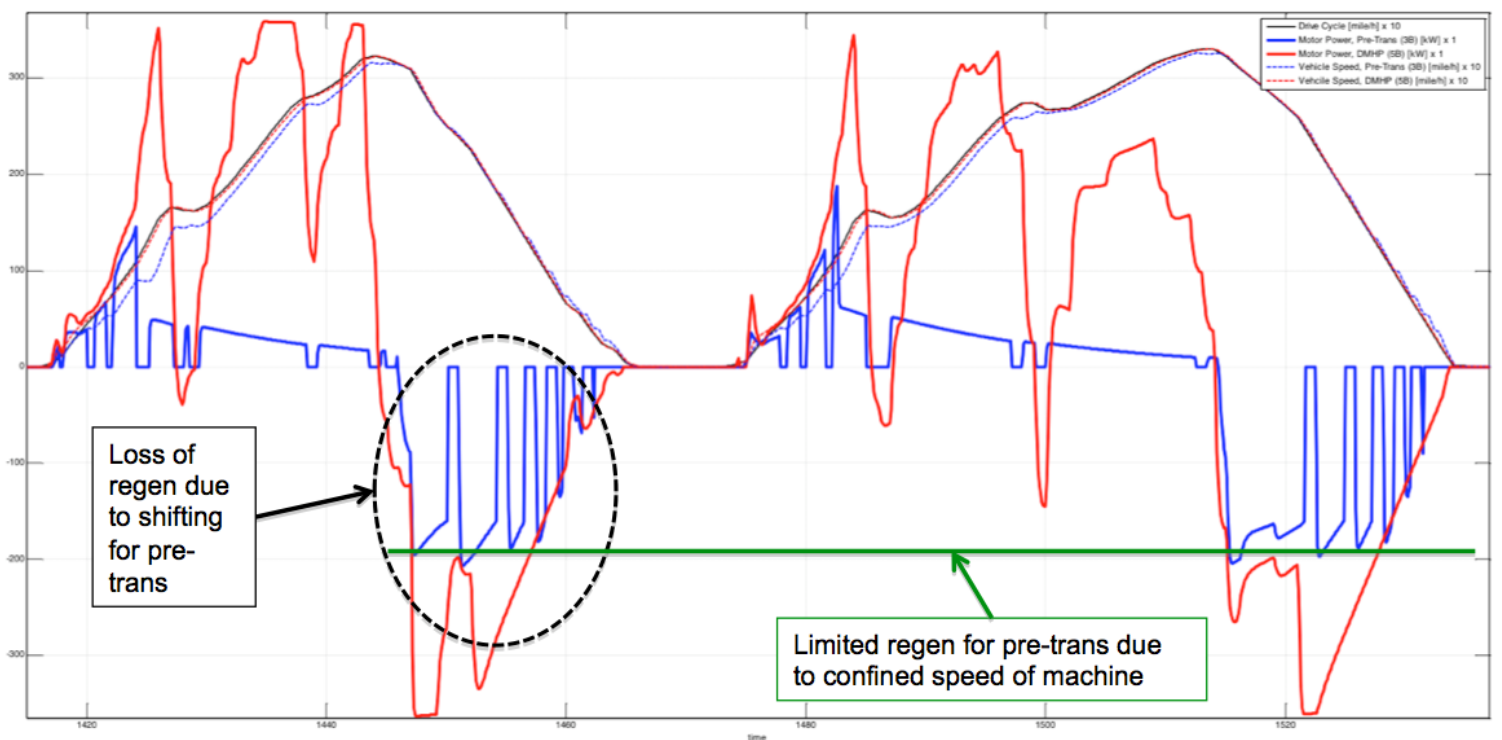

Figure 41 Pre-transmission hybrid versus DMHP regenerative braking performance considerations

\subsubsection{Alternative technology analysis results: summary}

The following list summarizes the key points for the alternative technology analysis performed as part of this CRADA:

- The moderate eAxle and parallel pre-transmission give similar FE improvements.

- The full dual mode and parallel pre-transmission HEV's give similar average FE improvements across drive cycles.

- The DMHP is more sensitive to battery size than the full parallel pre-transmission.

- The parallel pre-transmission regenerative braking is motor torque limited based on speed.

- The DMHP regenerative braking is battery limited at a higher power but has more battery throughput and energy conversion losses due to series mode - improvement potential.

- Electrified accessories and anti-idle offer FE benefits, but not so much as to be clearly compelling, especially for highway drive cycles (subject to current accessory assumptions).

- The optimum eAxle ratio is linearly correlated with the average drive cycle speed, and is in the middle of the typical axle ratio range for the highway drive cycles and motors analyzed. 


\subsection{EXPERIMENTAL RESULTS}

\subsubsection{Test facility: ORNL Vehicle Systems Integration (VSI) Laboratory}

The ORNL VSI laboratory is a powertrain testing facility that is uniquely capable of analyzing light-duty to full heavy-duty Class 8 powertrains. The VSI Lab is co-located with three transportation-centric research centers at ORNL to satisfy virtually any research request or project requirement. The Fuels, Engines and Emissions Research Center (FEERC) at ORNL offers advanced analytical chemistry expertise and unique emissions measurement capabilities, as well as extensive expertise in high efficiency combustion, alternative fuels, and advanced lubricants. Engine evaluations can be conducted with or without the emissions aftertreatment system, and sampling of both the engine-out and aftertreatment-out emissions are possible. The VSI Lab is equipped with a transient emissions measurement system capable of measuring $\mathrm{CO}_{2}, \mathrm{NO}_{\mathrm{X}}, \mathrm{CO}$, and $\mathrm{HC}$ emissions, and extensive particulate matter characterizations can be performed.

For in-depth power electronics and electric machine componentry analysis and evaluation, the VSI Lab can tap into the Power Electronics and Electric Machinery Research Center (PEEMRC). PEEMRC is home to the Power Electronics and Electric Machines (PEEM) Laboratory, which is recognized as the U.S. Department of Energy's (DOE) lead lab for power electronics and electric motor development. PEEM offers a broad spectrum of state-of-the-art measurement equipment along with a rapid prototyping mechanical fabrication shop. Characterization of high power traction drive systems is critical to understanding overall vehicle system efficiency. The VSI Lab features power analysis tools to fully characterize the high-voltage power electronics and electric machine drive system.

Proper evaluation of advanced technology powertrains requires understanding of real-world operating conditions, such as duty cycle. The VSI Lab draws upon ORNL's Center for Transportation Analysis that provides access and use of ORNL's Medium Truck Duty Cycle (MTDC) and Heavy Truck Duty Cycle (HTDC) databases for developing real-world drive cycles, including grade.

The VSI Powertrain Test Cell was utlizied exclusively for this project. The following list summarizes the spcifications for this tst cell:

- Twin AVL 500 kW AC transient dynamometers each capable of absorbing $3,000 \mathrm{~N} \cdot \mathrm{m}$ of continuous torque and can provide $2,700 \mathrm{~N} \cdot \mathrm{m}$ of motoring torque

- Accelerations/decelerations of up to $3,500 \mathrm{rpm} / \mathrm{sec}$, allowing precise following of engine speed variations during engine cranking or gear shifting

- Up to $20,000 \mathrm{~N} \cdot \mathrm{m}$ of torque absorption when dynamometers are linked through summing gearbox for powertrain

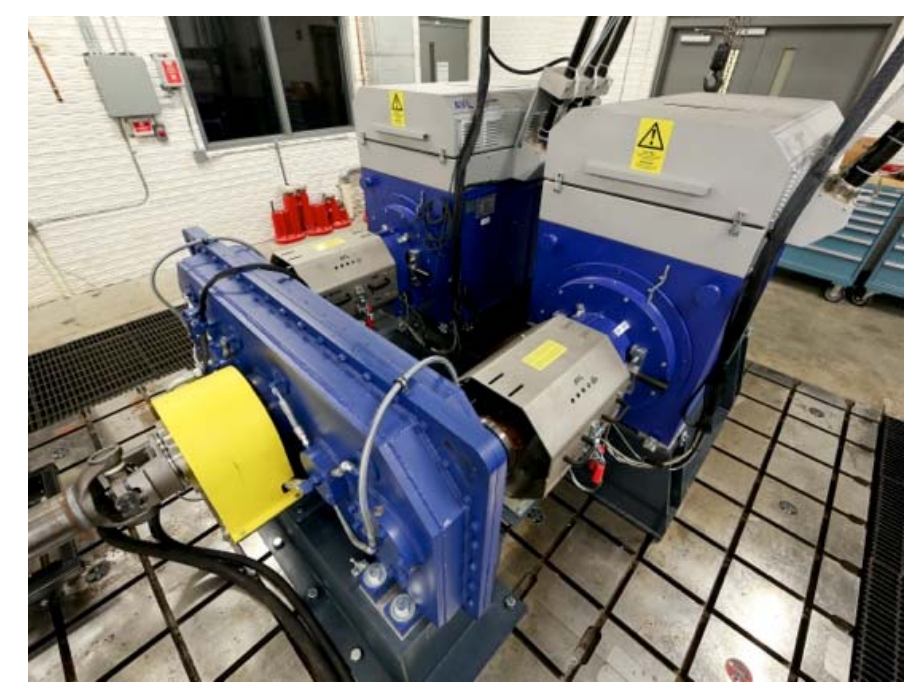

- An AVL $400 \mathrm{~kW}$ energy storage system emulation with flexibility to simulate different energy storage systems as part of " $X$ "-in-the-loop evaluations or when batteries are still in development

- A dSPACE hardware-in-the-loop (HIL) real-time platform for vehicle system emulation 
The VSI Powertrain Test Cell was configured for two (2) distinct types of testing for this project. The first configuration was to utilize the test engine only (including complete aftertreatment) in an engine-inthe-loop approach. The second configuration adds the Meritor Hybrid Drive Unit (HDU) to the engine in a powertrain-in-the-loop approach. The rest of the vehicle was emulated through the use of the previously established model developed during the Analytical Phase of this project. Figure 42 graphically depicts the "X-in-the loop" approach or the ORNL VSI laboratory. The real-time virtual environment consists of a user interface that connects the vehicle model that is targeted to a real-time computing platform. This custom developed system commands the actuators (in this case the battery emulator and powertrain dynamometers), which are connected to the unit under test.

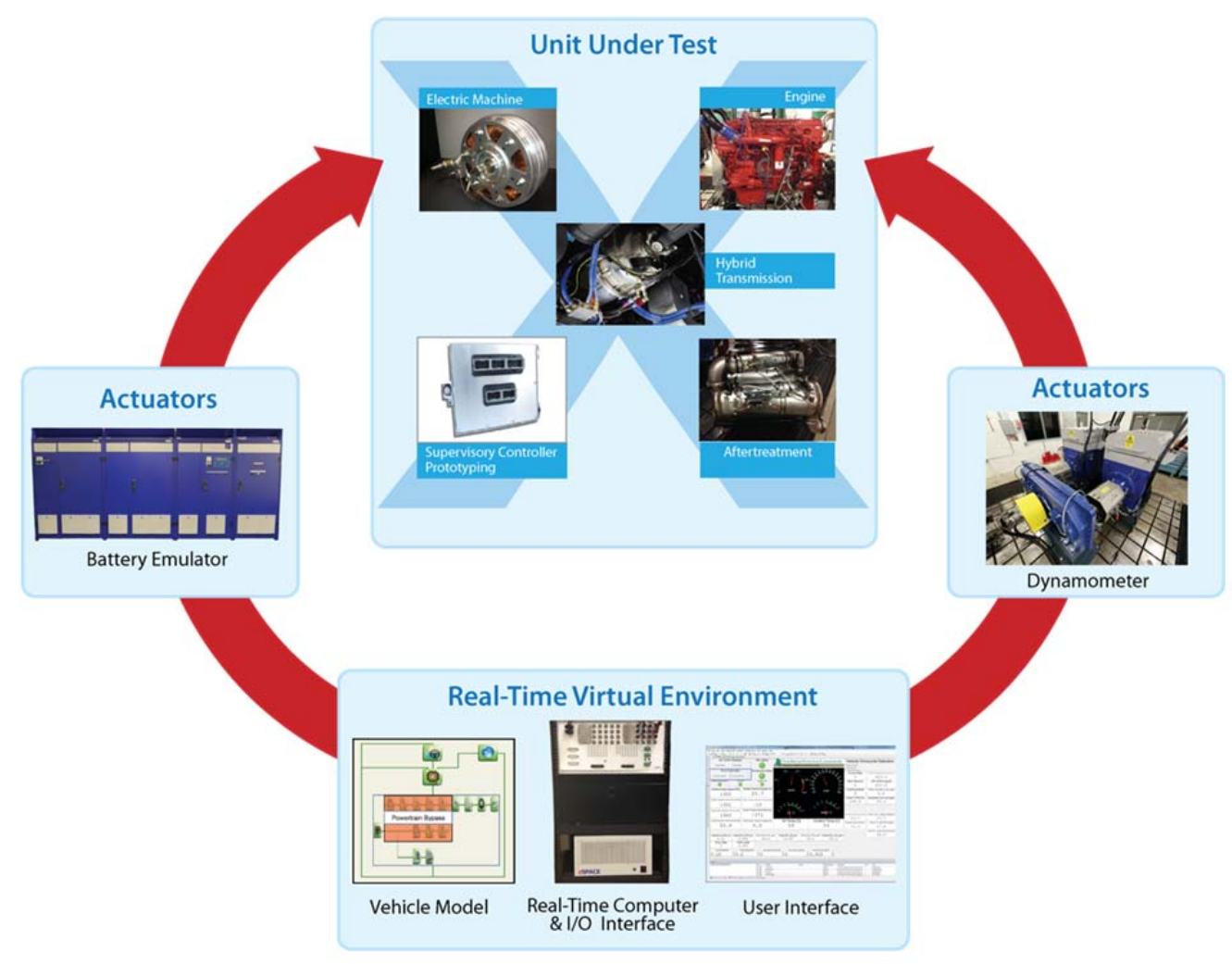

Figure 42 Hardware-in-the-loop representation of the ORNL VSI Laboratory

\subsubsection{Experimental results}

The experimental phase of this project was shortened considerably due to mechanical issues with prototype HDU supplied by Meritor for this project. Consequently, only a small amount of data was collected during this phase of the project.

\subsubsection{Engine-in-the-loop experimental results}

A Cummins ISX 450 15-liter diesel engine was procured and used as the basis for the powertrain for all experiments in this project. A full exhaust after-treatment system was also procured to complete the setup. Figure 43 shows the complete engine-in-the-loop installation at the ORNL VSI laboratory. Here, only the engine is actually tested. The rest of the powertrain and vehicle are simulated utilizing the same simulation models developed during the Analytical Phase of the project. 


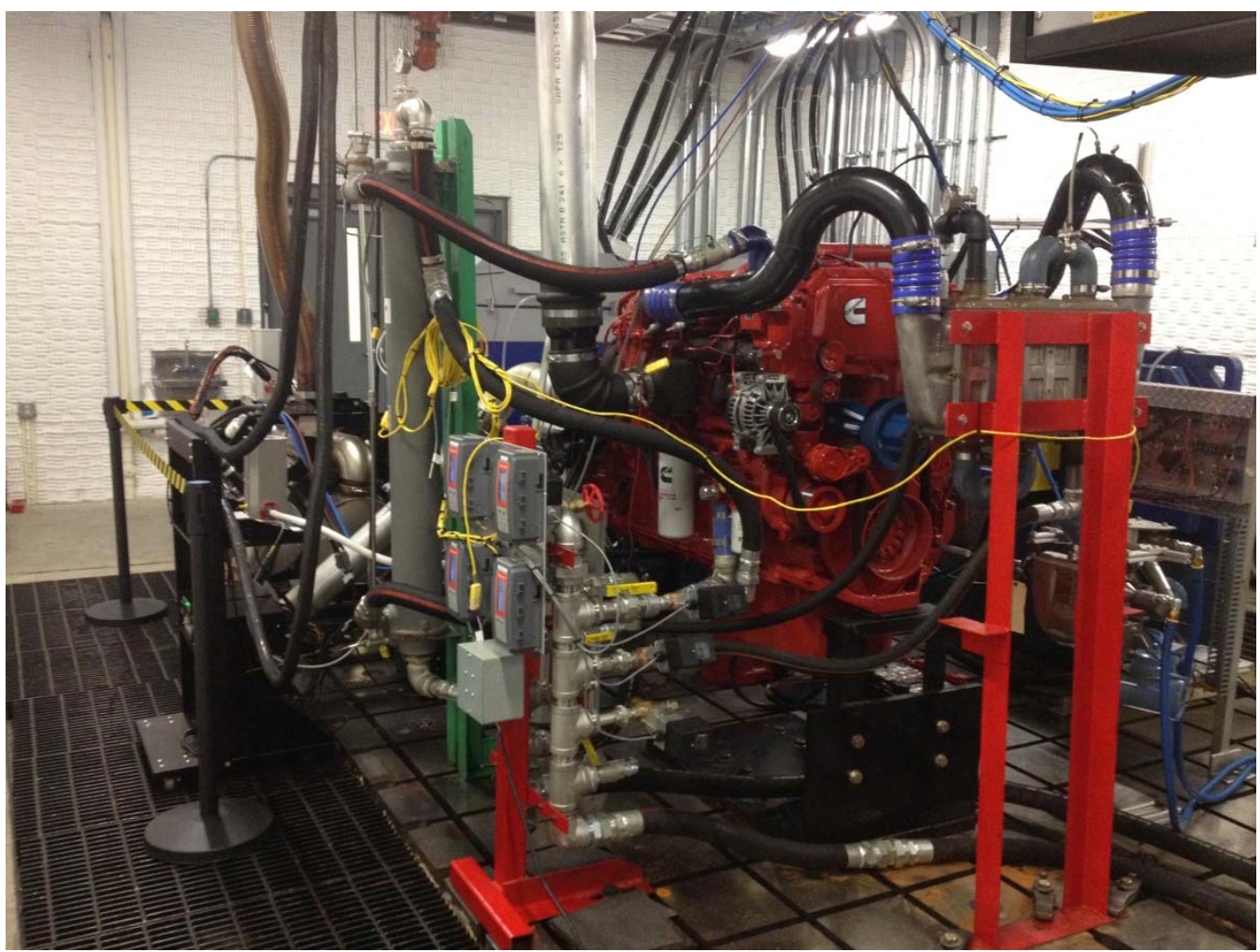

Figure 43 Engine-in-the-loop installation in the ORNL VSI Laboratory

The engine-in-the-loop configuration was exercised for the conventional and Meritor DMHP powertrain architectures for the same exact (simulated) vehicle. Figure 44 outlines the overall fuel economy improvement results for the three (3) standard cycles tested during the engine-in-the-loop experimental phase. As predicted from the Analytical Phase, the Meritor DMHP performed exceptionally well for the urban drive cycle applications. However, the expected results for the HHDDT65 drive cycle (simulated regional line haul) fell short, with improvements of approximately 1.5\% compared to predicted values of $\sim 6 \%$. This is mainly contributed to differences in the engine fuel map used during the Analytical Phase compared to the actual engine fueling behavior of the engine, and the associated intricacies of how the engine actually operates from a transient sense (dynamic and thermal considerations). Time was not available to do more optimization of the hybrid control strategy to determine whether more significant improvements could be realized.

For all cases, the standard driver model from the modeling package that was used during the Analytical Phase was also used during the Experimental Phase. This is important due to the fact that heavy-duty models, due to their weight/inertia, are very sensitive to the tuning of simulation driver models. One set of experiments was performed that explored the sensitivity of the driver model on a fully loaded powertrain model. As shown in Figure 44, the green bar illustrates "relaxing" the tuning parameters for the driver model such that the vehicle is still capable of following the speed trace, but is not as aggressive as the baseline driver. Here, a marked improvement in the fuel economy is noted, based solely on the driver behavior. A future investigation would involve utilizing a distance based duty cycle and driver model that would give better insight into the fuel economy potential of the Meritor DMHP. 


\section{Fuel Economy Results: Conventional vs DMHP}

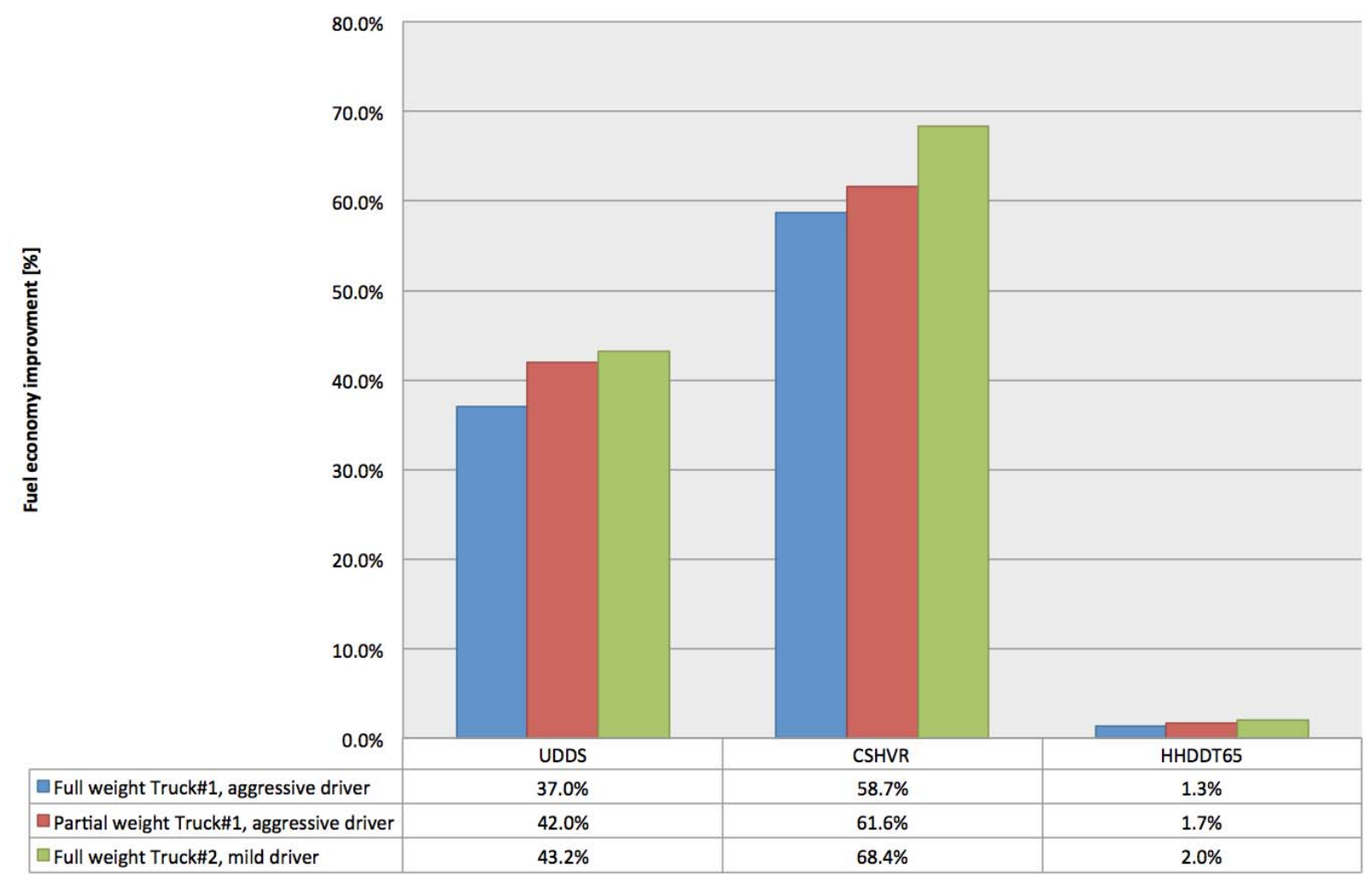

Figure 44 Engine-in-the-loop experimental fuel economy improvement test results

Since the virtual vehicle model is the only difference between the two (2) configurations of the engine-inthe-loop phase, a deeper analysis was conducted to understand the engine fuel use behavior of each powertrain variant. Figure 45 show the instantaneous fuel rates for both the conventional and Meritor DMHP cases during the HHDDT65 drive cycle. It is clear that the fuel use is very consistent for both powertrains during the cruise portion of the drive cycle (center portion). However, there is marked difference when considering the lower speed portions at the beginning and the end.

Figure 46 represents a magnified potion of the first 400 seconds of the same HHDDT65 experiment. For the first 100 seconds, the Meritor DMHP exhibits no fuel use during all electric operation. From around 100 seconds until approximately 210 seconds, the Meritor is operating as a series HEV. Notable during this portion, the minimum fuel rate suggests that the engine is requested to load (charge) at a higher than idle rate. This represents an opportunity for improvement in the supervisory control strategy. Around the 300-second mark, the Meritor DMHP fuel use is significantly higher than that of the conventional. This is due to the supervisory controller requesting additional engine power to charge the battery pack after the extended acceleration up to the cruise speed.

Figure 47 illustrates the last 400 seconds of the HHDDT65 drive cycle. Here, we see similar results to that of the first 400 seconds of the experiment. However, a significant difference rests in the deceleration portion of the drive cycle from cruising speed down to zero. The engine is still being fueled, even during a braking event while in parallel mode. The explanation for fuel flow during these regenerative braking events is that the supervisory controller generates engine torque requests of zero. The ECU understands the zero torque request literally as zero torque, not as fuel cut-off. As a consequence, the ECU fuels the engine to generate zero torque, which equates to approximately $3-6 \%$ engine load, or $3-6 \mathrm{~kg} / \mathrm{hr}$ fuel flow. Certainly the control strategy could be improved to reduce fuel consumption further for the DMHP. 


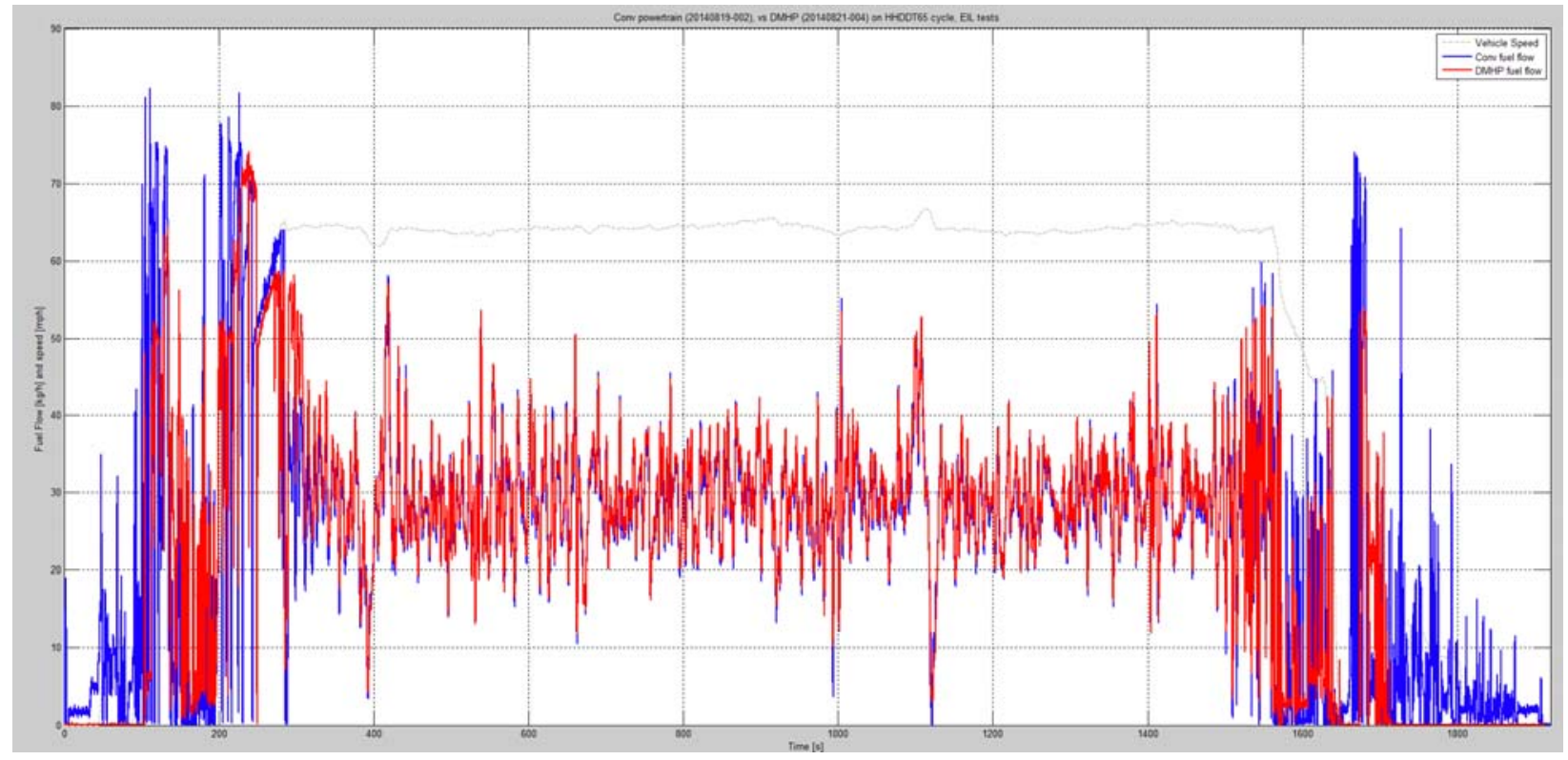

Figure 45 Engine-in-the-loop fuel use comparison for the conventional and Meritor DMHP powertrains

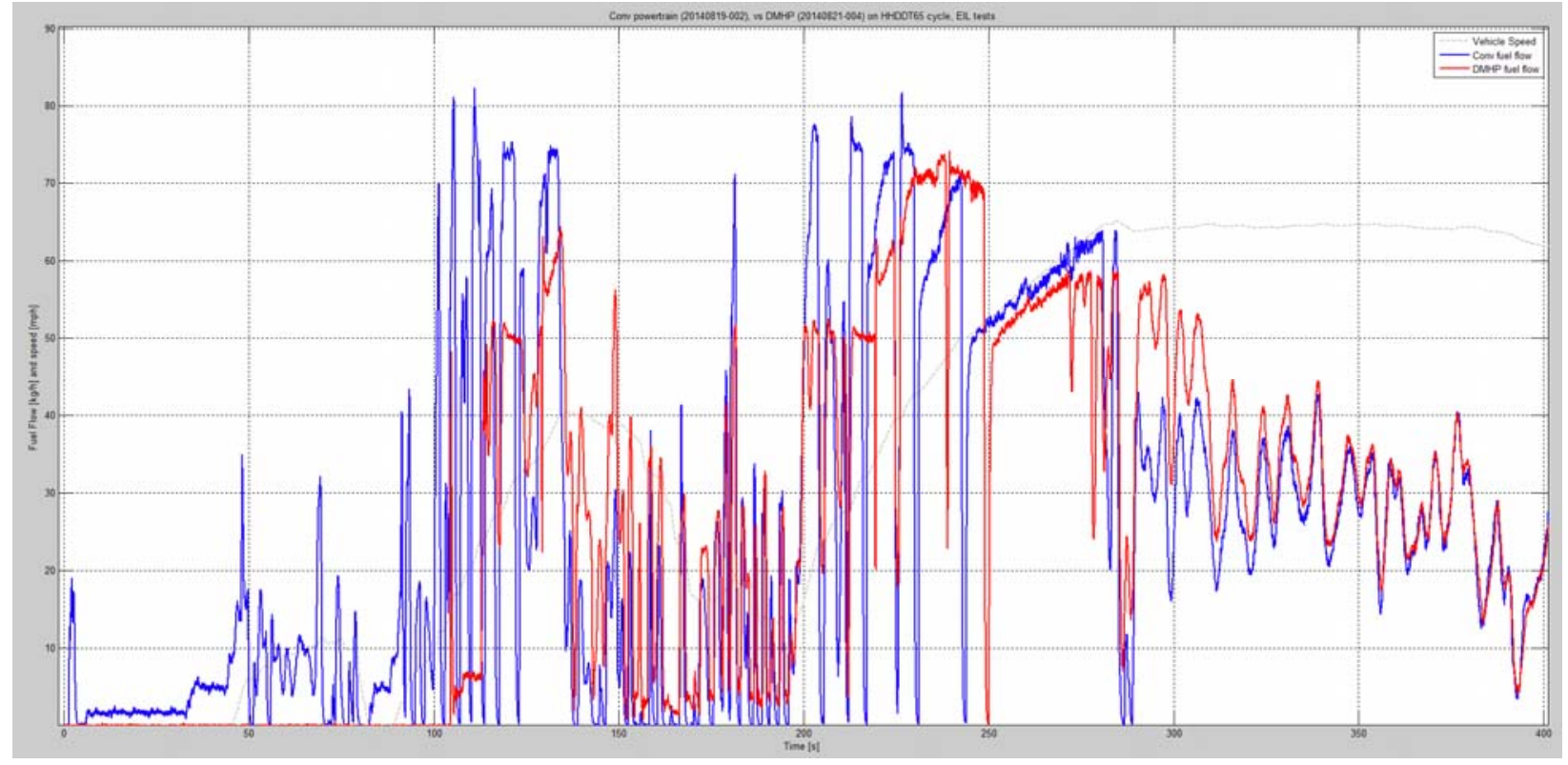

Figure 46 First 400 seconds of the HHDDT65 drive cycle for engine-in-the-loop testing 


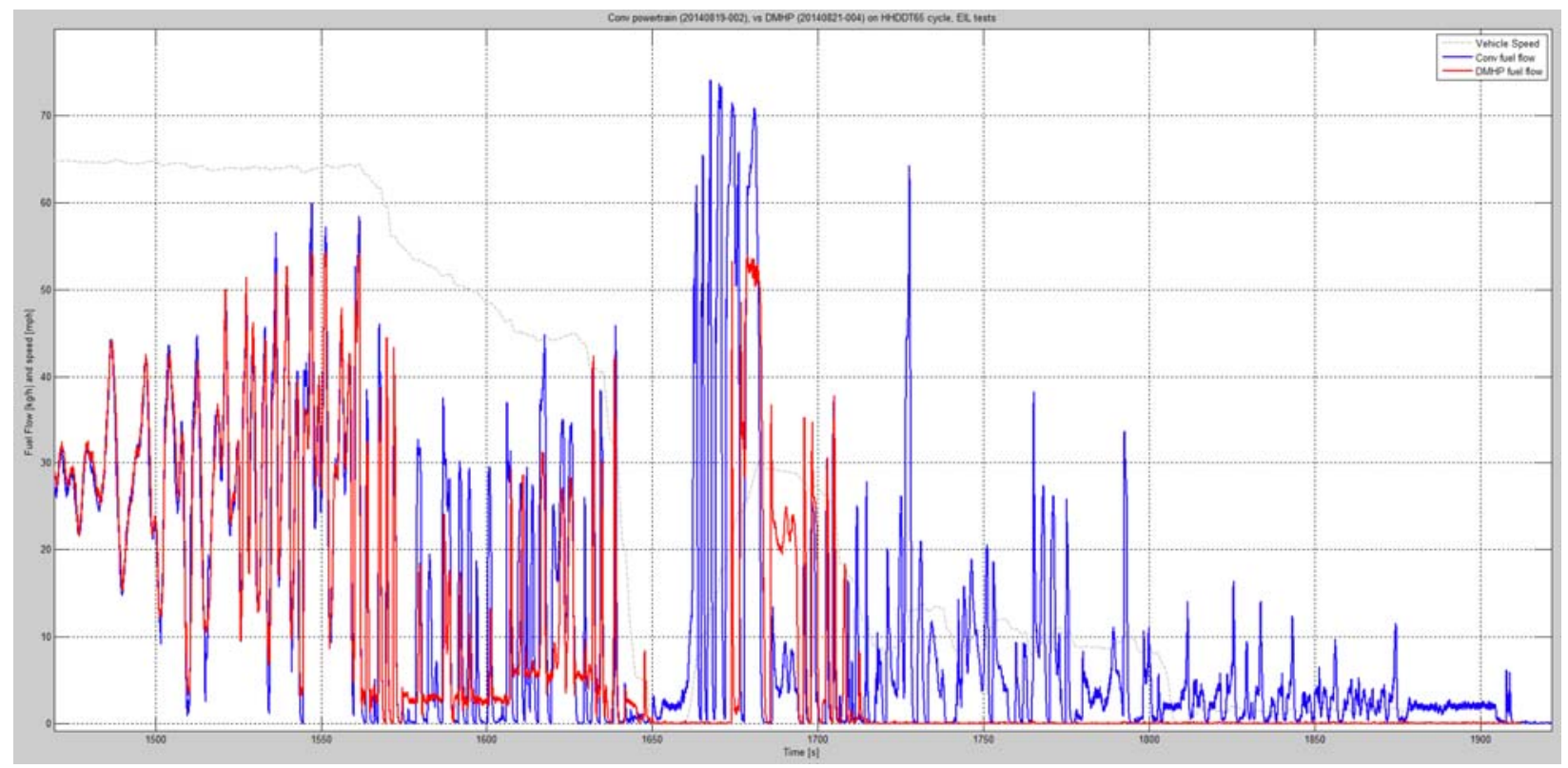

Figure 47 Last 400 seconds of the HHDDT65 drive cycle for engine-in-the-loop testing

\subsubsection{Powertrain-in-the-loop results}

Meritor developed, built, and delivered the HDU to ORNL to be mated to the same Cummins ISX 450 engine as in the engine-in-the-loop test phase. Figure 48 shows a close-up of the actual unit under test. The generator can be seen to the right mated directly to the engine, with the traction motor in the middle, and two-speed range box on the right side mated to transmission output shaft/u-joint. These electric machines are based upon switched-reluctance technology, with a Meritor-developed dual inverter assembly (mounted underneath the HDU). Figure 49 shows a full view of the complete powertrain installation for the Meritor DMHP in the ORNL VSI laboratory. An RC filter was supplied by Meritor to "condition" the high voltage leads coming from the ORNL VSI Battery Emulator into the dual inverter system of the HDU to avoid any potential line resonance issues due to the length of the supply cables and lack of actual energy storage system.

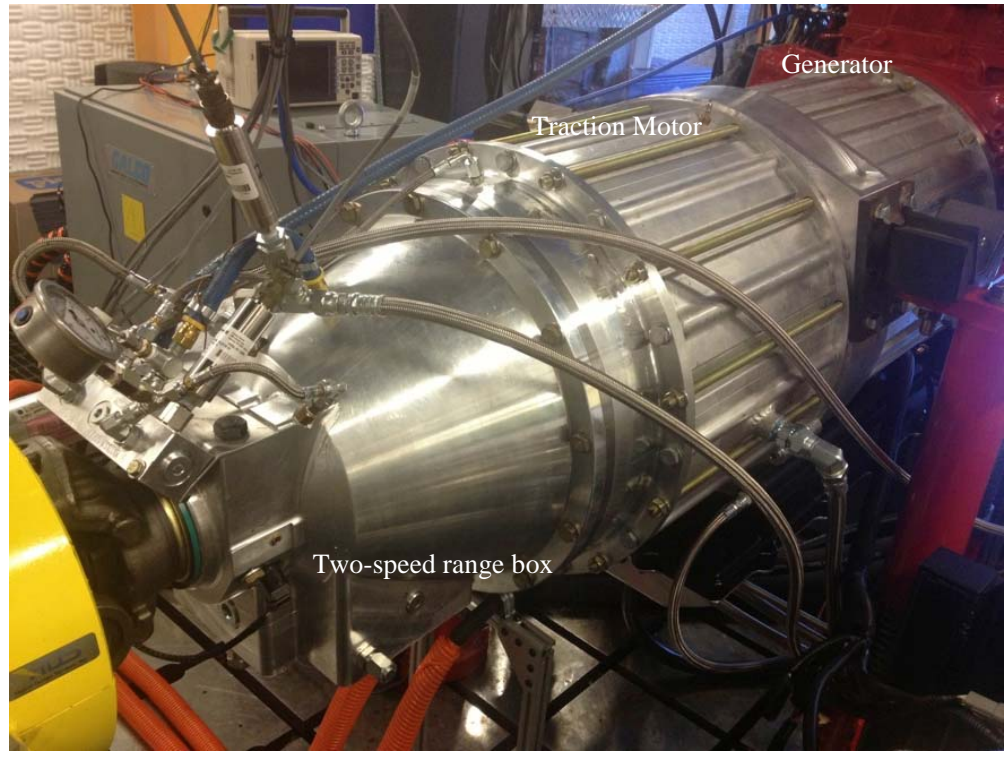

Figure 48 Prototype Meritor Hybrid Drive Unit installed in the ORNL VSI laboratory 


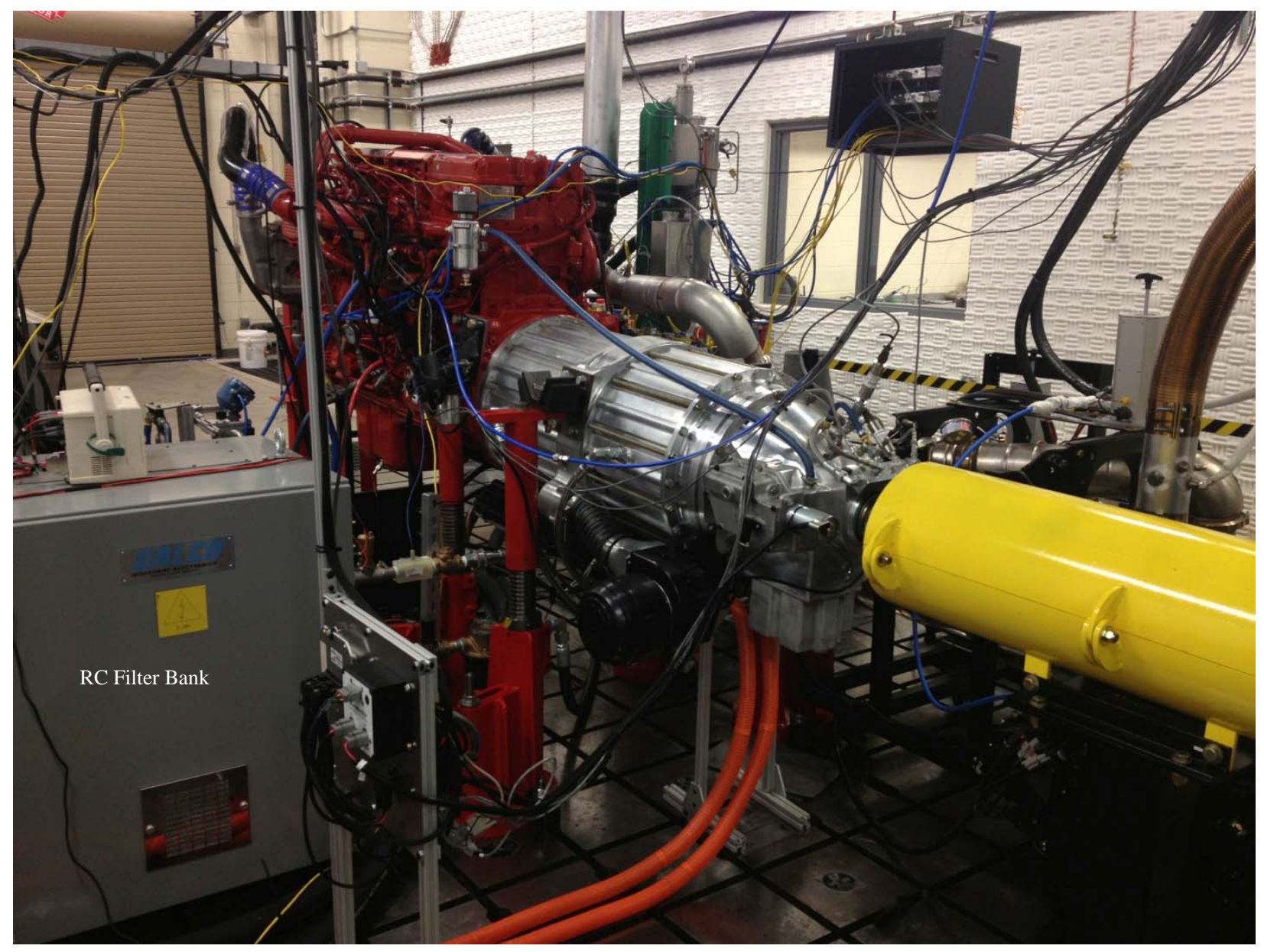

Figure 49 Full installation of the Meritor HDU with test engine in ORNL VSI Laboratory

Figure 50 represents a summary of the fuel economy improvement for the limited powertrain-in-the-loop testing that was completed during this CRADA. Due to speed limitations of the ORNL VSI powertrain dynamometer, the final drive ratio of the vehicle was limited to 3.36:1. This limitation skewed the results of the fuel economy tests for the Meritor DMHP such that at highway cruise speeds, the engine operated at speeds much lower than optimal (1100 RPM versus 1350 RPM). For the highway cycles, this had a negative effect and thus reduced the fuel economy improvement significantly, as shown in Figure 50. There is opportunity for increased fuel economy improvement through utilization of the correctly sized final drive ratio.

In addition, the powertrain-in-the-loop tests suffered the same issues as the engine-in-the-loop tests regarding a commanded engine torque of zero. The ECU understands the zero torque request literally as zero torque, not as fuel cut-off. As a consequence, the ECU fuels the engine to generate zero torque, which equates to approximately 3-6\% engine load, or 3-6kg/hr fuel flow. Certainly the control strategy could be improved to reduce fuel consumption further for the DMHP.

The red bar in Figure 50 illustrates "relaxing” the tuning parameters for the driver model such that the vehicle is still capable of following the speed trace, but is not as aggressive as the baseline driver. Here, a marked improvement in the fuel economy is noted, based solely on the driver behavior. A future investigation would involve utilizing a distance based duty cycle and driver model that would give better insight into the fuel economy potential of the Meritor DMHP. 


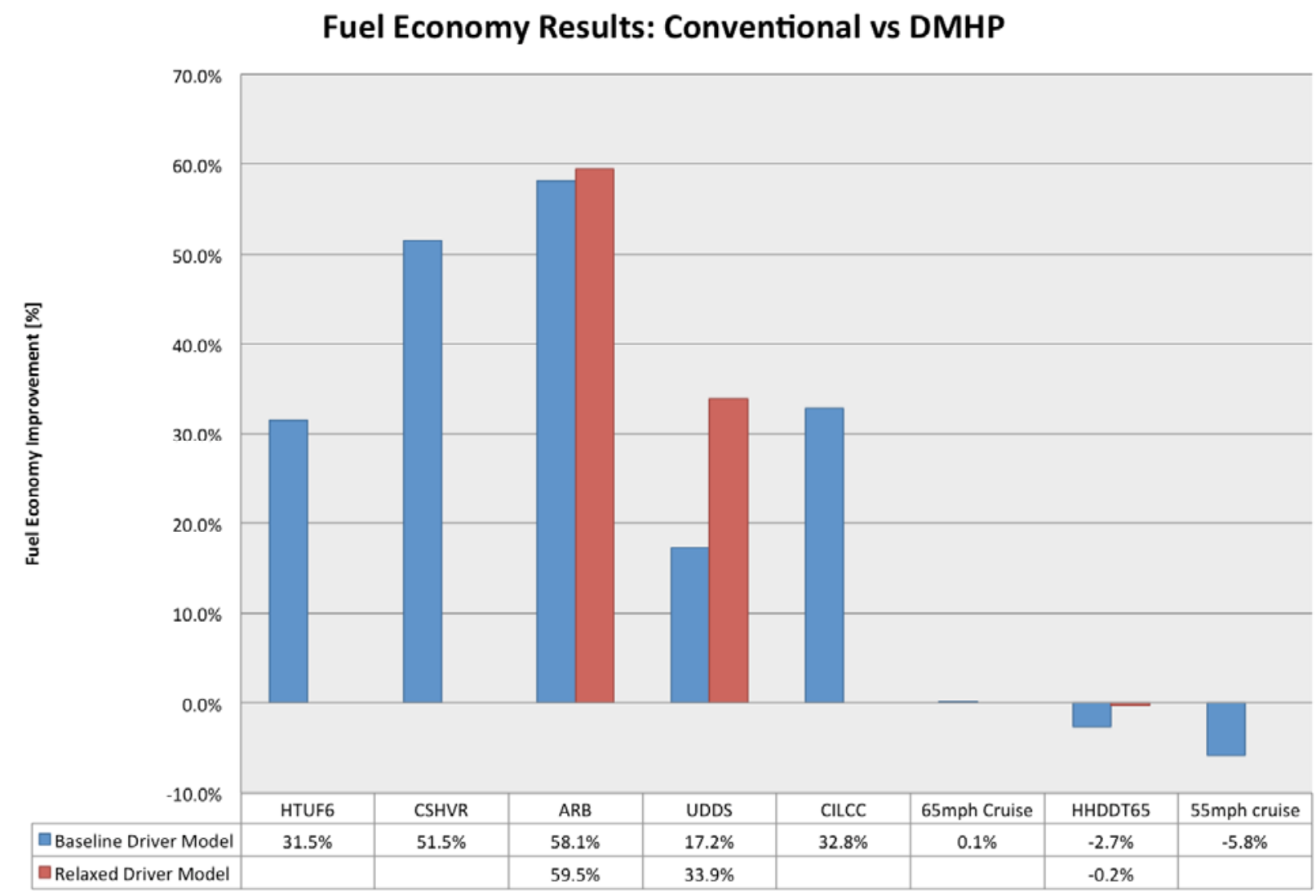

Figure 50 Powertrain-in-the-loop fuel economy improvement experimental results summary

One final observation that explains the reduction in fuel economy improvements for the Meritor DMHP over the conventional is graphically represented in Figure 51. Here, a portion of an urban drive cycle is shown for the operation of the traction motor. During parallel-low mode operation, the traction motor is commanded to loosely follow the vehicle speed. Ideally, the traction motor should be completely decoupled from the driveline to conserve SOC. However, the Transmission Control Unit (TCU) is commanding the traction motor, not the VSCM. This strategy was employed by Meritor for NVH reasons to keep the traction motor in a "ready" speed to re-engage into series HEV operation. This is another area that could be explored in future work to further reduce the load on the ESS, and increase overall fuel economy. It is worth mentioning. However, that the expected gain would be minimal since the DMHP operates in this mode for only short periods of time, and only briefly for highway styles of driving. 


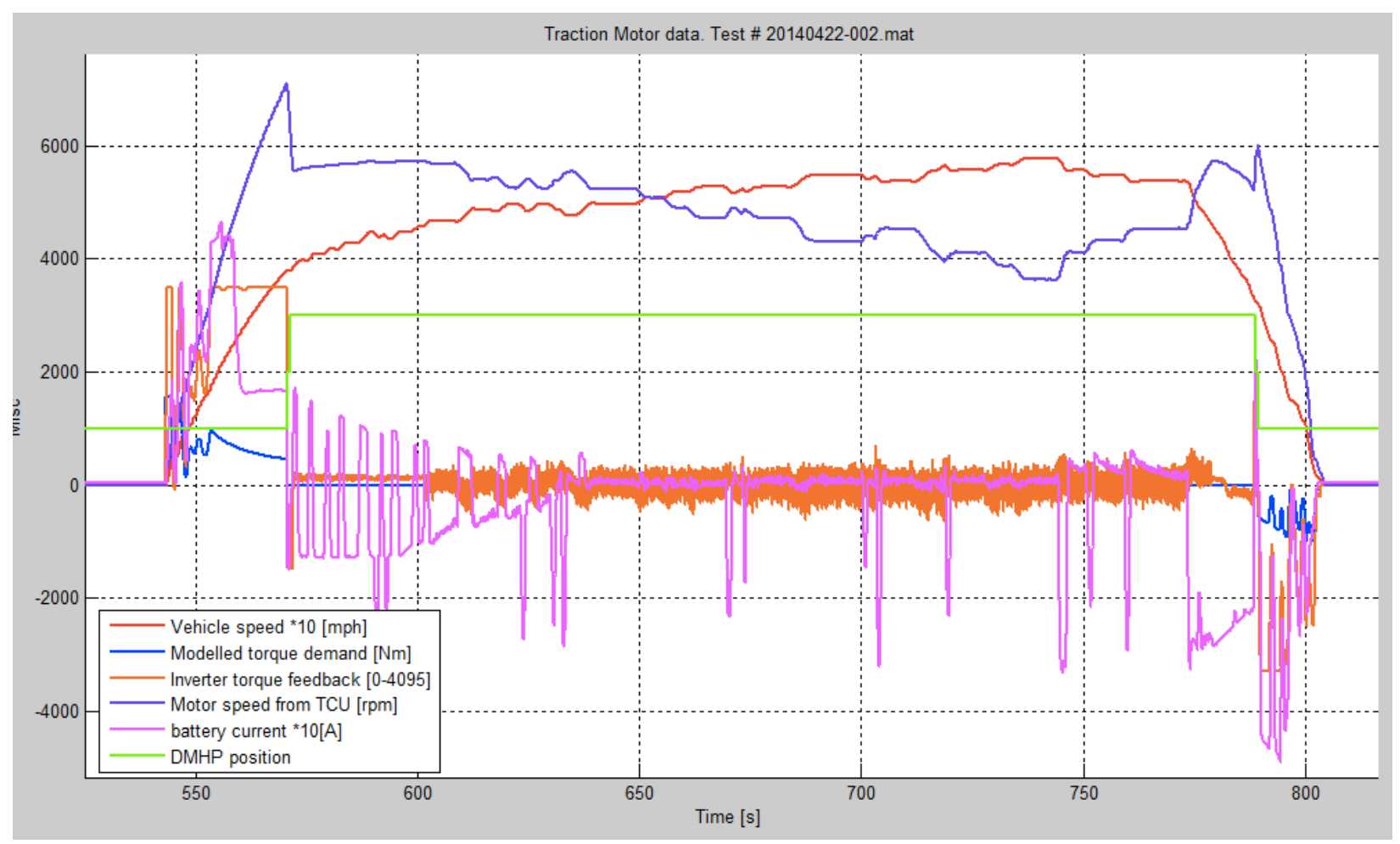

Figure 51 Traction motor operation for Meritor HDU during parallel low mode 
APPENDIX 


\section{APPENDIX A. DRIVE CYCLES}
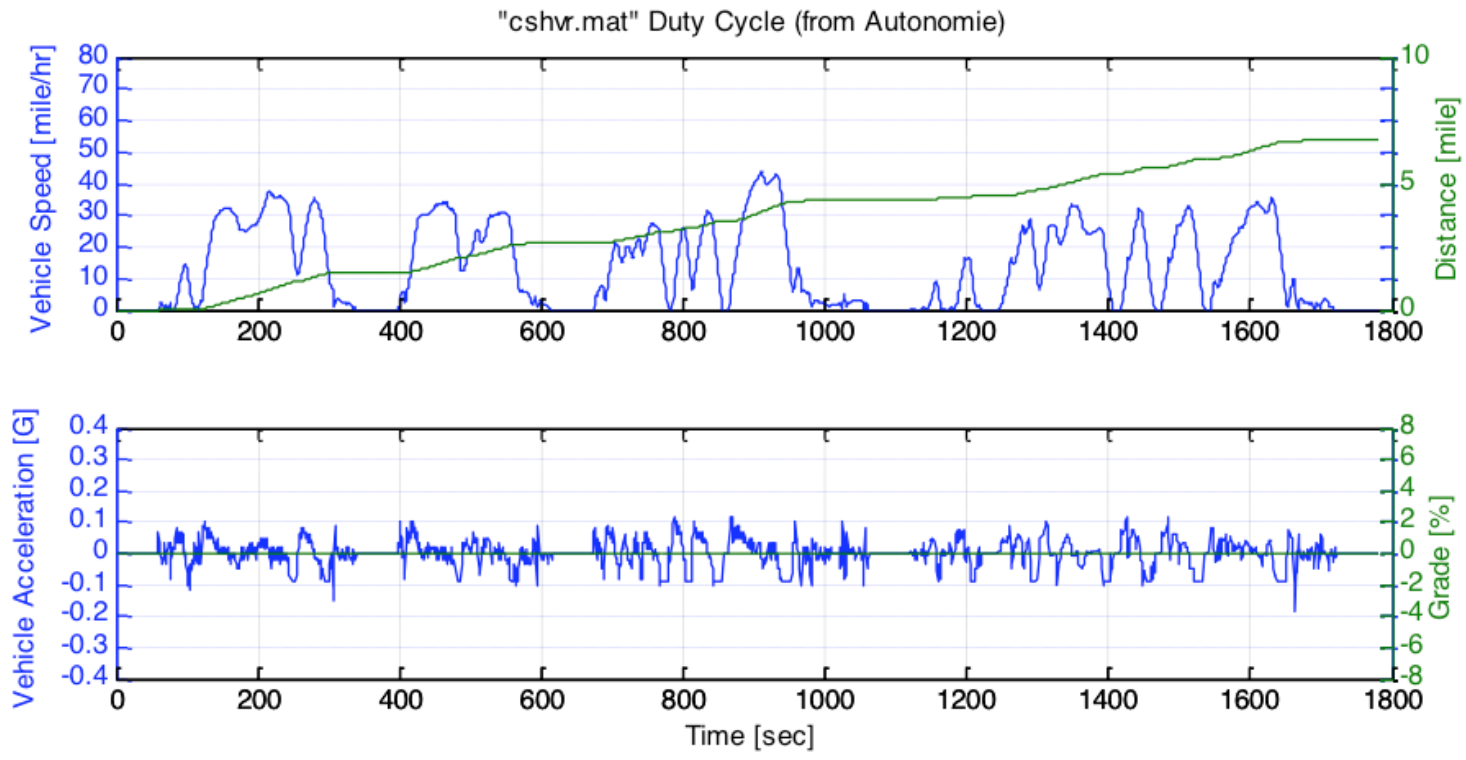

\begin{tabular}{|l|l|}
\hline Time, Total $=1780 \mathrm{sec}$ & Accel, Max $=0.119 \mathrm{G}$ \\
Time, Idle $=385 \mathrm{sec}$ & Accel, Avg* $=0.0397 \mathrm{G}$ \\
Distance, Total $=6.72 \mathrm{mile}$ & Decel, Max $=-0.182 \mathrm{G}$ \\
Starts, Total $=18$ & Decel, Avg* $=-0.0471 \mathrm{G}$ \\
Starts/Distance $=2.68 \mathrm{starts} / \mathrm{mile}$ & Grade, Max $=0 \%$ \\
Distance/Start $=0.373 \mathrm{mile} / \mathrm{start}$ & Grade, Avg* $=0 \%$ \\
Speed, Max $=43.8 \mathrm{mile} / \mathrm{hr}$ & Grade, Min $=0 \%$ \\
Speed, Avg* $=17.3 \mathrm{mile} / \mathrm{hr}$ & Idle time not used in averages.
\end{tabular}

Figure 52 CSHVR drive cycle (standard) 
"HHDDT65.mat" Duty Cycle (from Autonomie)
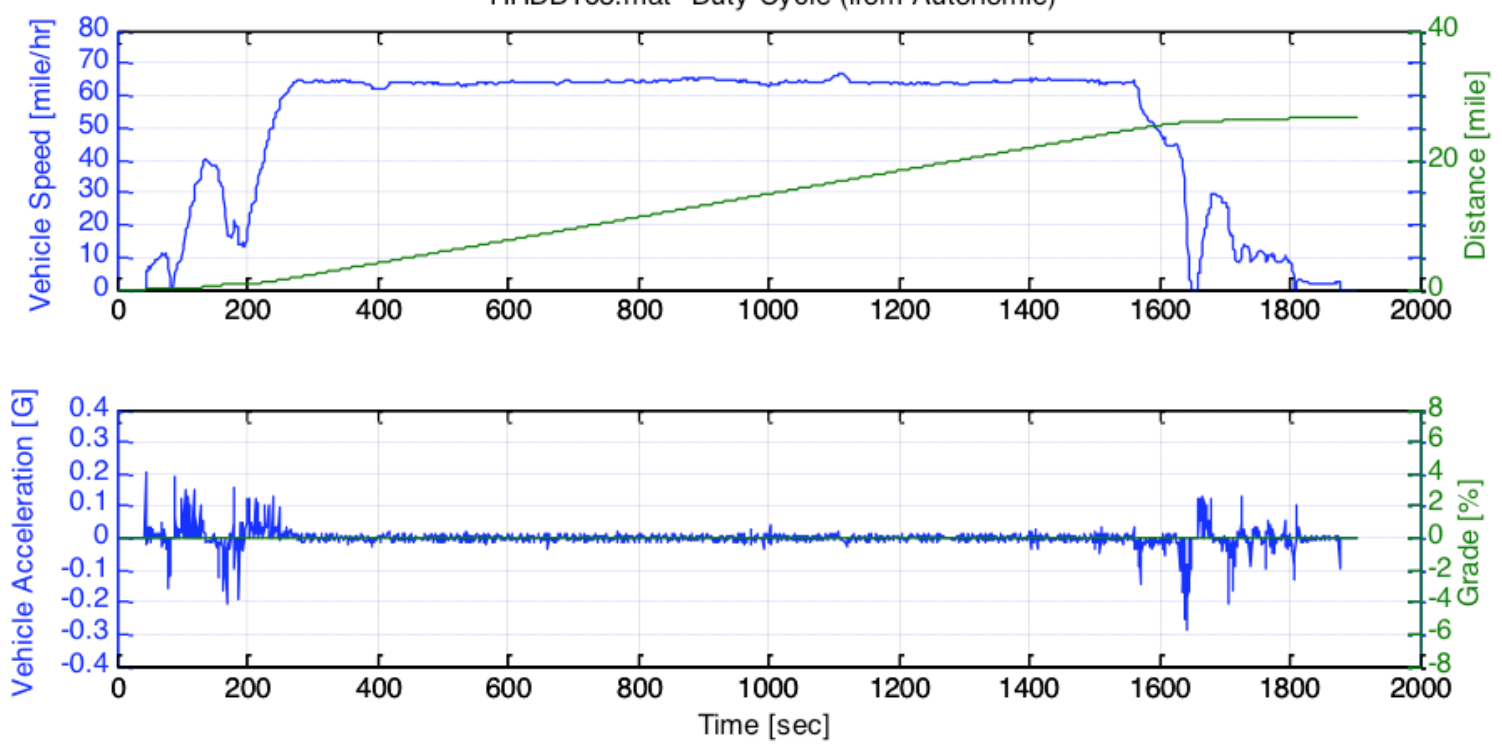

\begin{tabular}{|l|l|}
\hline Time, Total $=1904 \mathrm{sec}$ & Accel, Max $=0.209 \mathrm{G}$ \\
Time, Idle $=90 \mathrm{sec}$ & Accel, Avg* $=0.0184 \mathrm{G}$ \\
Distance, Total $=26.5 \mathrm{mile}$ & Decel, Max $=-0.287 \mathrm{G}$ \\
Starts, Total $=4$ & Decel, Avg* $=-0.0194 \mathrm{G}$ \\
Starts $/$ Distance $=0.151$ starts/mile & Grade, Max $=0 \%$ \\
Distance $/$ Start $=6.62 \mathrm{mile} / \mathrm{start}$ & Grade, Avg* $=0 \%$ \\
Speed, Max $=66.8 \mathrm{mile} / \mathrm{hr}$ & Grade, Min $=0 \%$ \\
Speed, Avg* $=52.6 \mathrm{mile} / \mathrm{hr}$ & $*$ Idle time not used in averages. \\
\hline
\end{tabular}

Figure 54 HHDDT65 drive cycle (standard) 
"ORNL_HTDC_NASHVILLE_KNOXVILLE.mat" Duty Cycle (from Autonomie_1210)
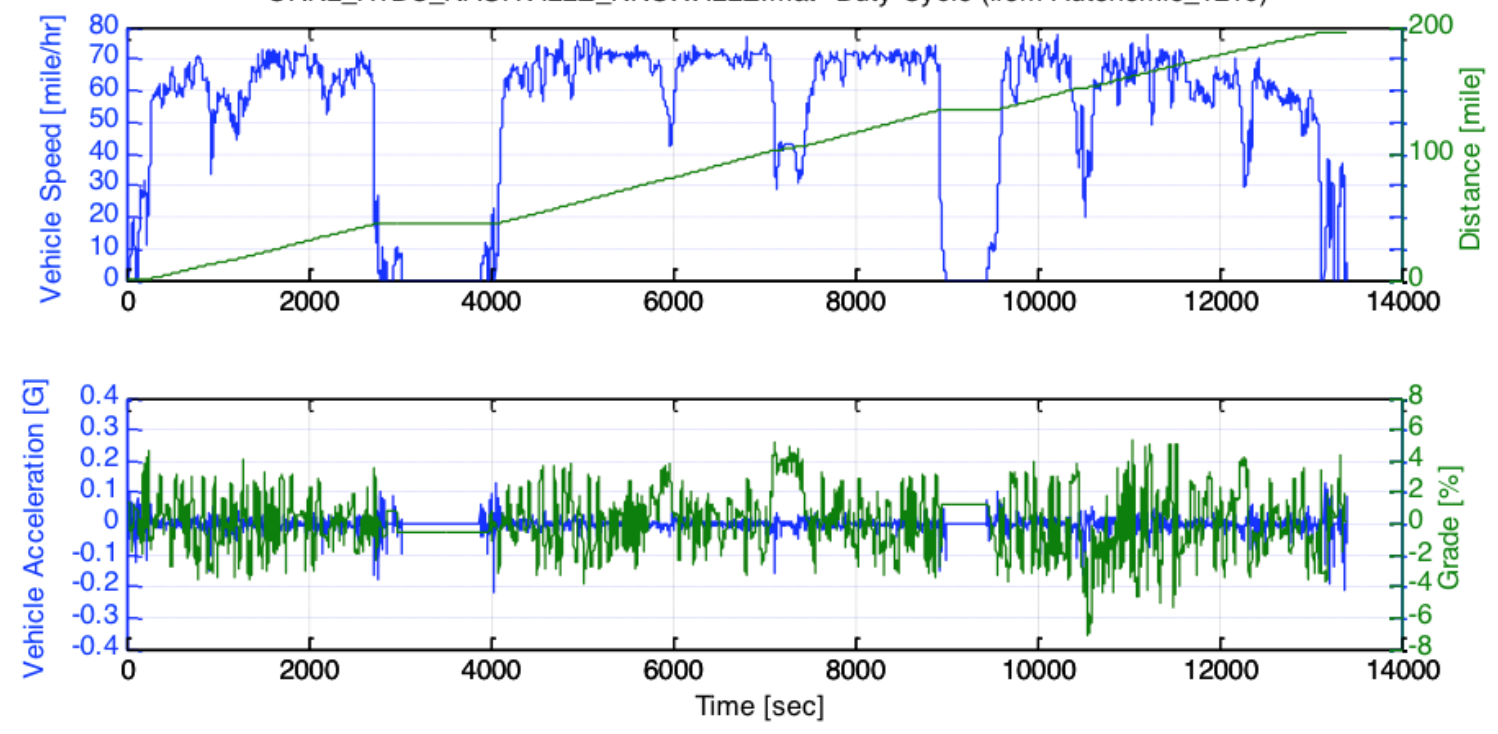

\begin{tabular}{|l|l|}
\hline Time, Total $=13407 \mathrm{sec}$ & Accel, Max $=0.133 \mathrm{G}$ \\
Time, Idle $=1.56 \mathrm{e}+003 \mathrm{sec}$ & Accel, Avg* $=0.0129 \mathrm{G}$ \\
Distance, Total $=197 \mathrm{mile}$ & Decel, Max $=-0.222 \mathrm{G}$ \\
Starts, Total $=14$ & Decel, Avg* $=-0.0137 \mathrm{G}$ \\
Starts/Distance $=0.0712 \mathrm{starts} / \mathrm{mile}$ & Grade, Max $=5.31 \%$ \\
Distance $/$ Start $=14 \mathrm{mile} / \mathrm{start}$ & Grade, Avg* $=0.111 \%$ \\
Speed, Max $=77.7 \mathrm{mile} / \mathrm{hr}$ & Grade, Min $=-7.08 \%$ \\
Speed, Avg* $=59.7 \mathrm{mile} / \mathrm{hr}$ & * Idle time not used in averages. \\
\hline
\end{tabular}

Figure 55 Nashville, TN to Knoxville, TN via I-40 drive cycle (ORNL HTDC) 
"ORNL_HTDC_STARKVILLE_DANVILLE.mat" Duty Cycle (from Autonomie)
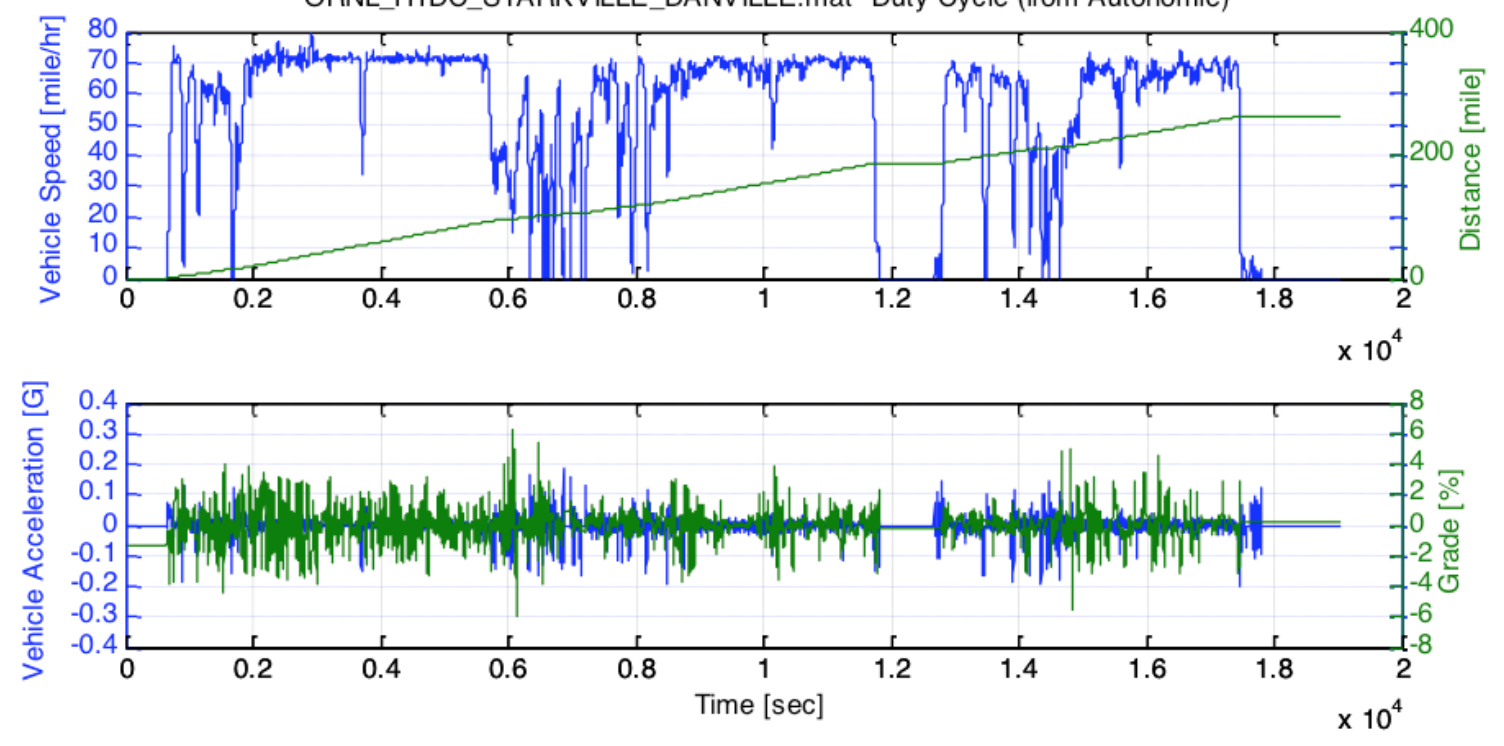

\begin{tabular}{|c|c|}
\hline $\begin{array}{l}\text { Time, Total }=19057 \mathrm{sec} \\
\text { Time, Idle }=3.2 \mathrm{e}+003 \mathrm{sec} \\
\text { Distance, Total }=263 \mathrm{mile} \\
\text { Starts, Total }=33 \\
\text { Starts } / \text { Distance }=0.126 \mathrm{starts} / \mathrm{mile} \\
\text { Distance } / \text { Start }=7.97 \mathrm{mile} / \mathrm{start} \\
\text { Speed, Max }=79.7 \mathrm{mile} / \mathrm{hr} \\
\text { Speed, Avg* }=59.7 \mathrm{mile} / \mathrm{hr}\end{array}$ & $\begin{aligned} \text { Accel, } \operatorname{Max}=0.184 \mathrm{G} \\
\text { Accel, } \operatorname{Avg}^{\star}=0.0148 \mathrm{G} \\
\text { Decel, } \operatorname{Max}=-0.202 \mathrm{G} \\
\text { Decel, } \mathrm{Avg}^{\star}=-0.0173 \mathrm{G} \\
\text { Grade, } \operatorname{Max}=6.19 \% \\
\text { Grade, } \operatorname{Avg}^{\star}=0.0236 \% \\
\text { Grade, Min }=-5.91 \% \\
\star \text { Idletime not used in averages }\end{aligned}$ \\
\hline
\end{tabular}

Figure 56 Clarksville, TN to Danville, IN duty cycle (ORNL HTDC) 